\title{
Anti-Obesity Therapy: from Rainbow Pills to Polyagonists
}

\author{
T. D. Müller, C. Clemmensen, B. Finan, R. D. DiMarchi, and M. H. Tschöp
}

Institute for Diabetes and Obesity, Helmholtz Diabetes Center, Helmholtz Zentrum München, German Research Center for Environmental Health, Neuherberg, Germany (T.D.M., C.C., M.H.T.); German Center for Diabetes Research, Neuherberg, Germany (T.D.M., C.C., M.H.T.); Department of Chemistry, Indiana University, Bloomington, Indiana (B.F., R.D.D.); and Division of Metabolic Diseases, Technische Universität München, Munich, Germany (M.H.T.)

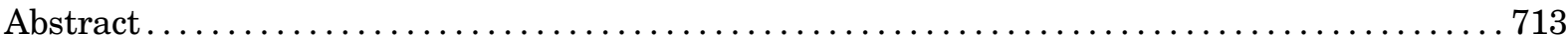

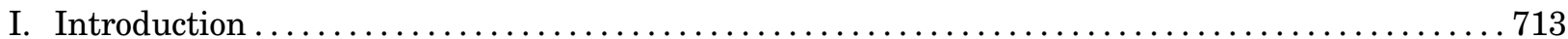

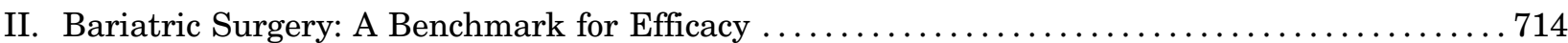

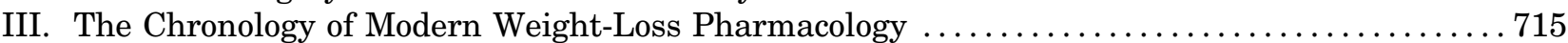

A. Thyroid Hormones ............................................. 716

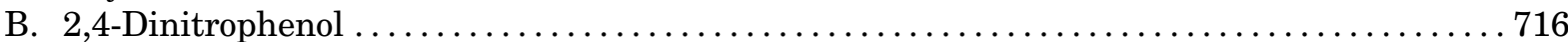

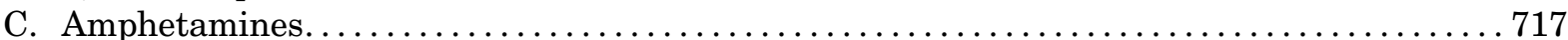

1. Methamphetamine ............................................... 717

2. Amphetamine Congeners ......................................... 718

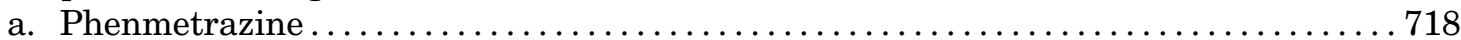

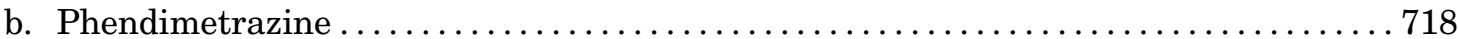

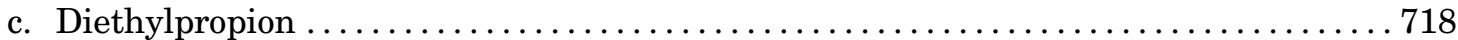

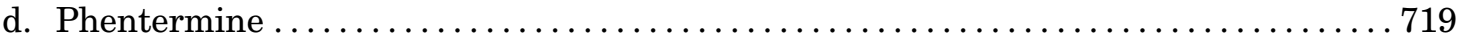

D. The Rainbow Pills ................................................. 719

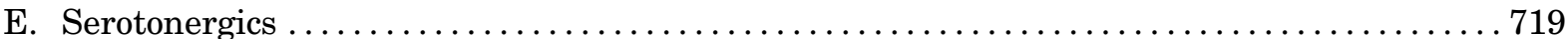

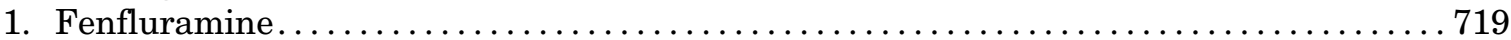

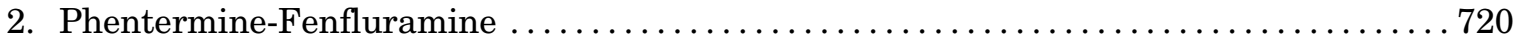

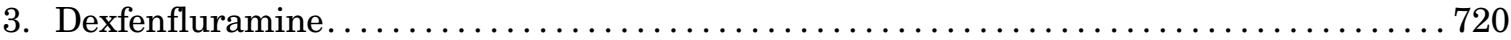

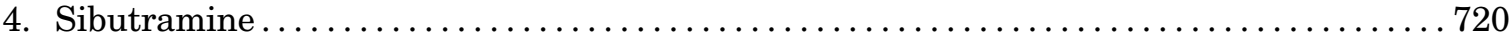

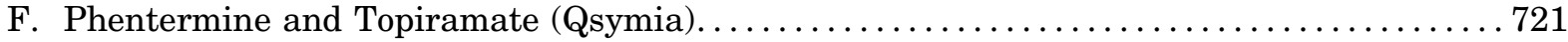

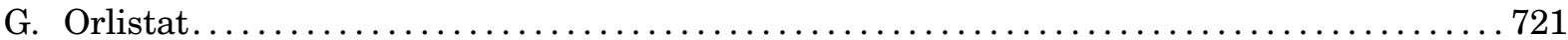

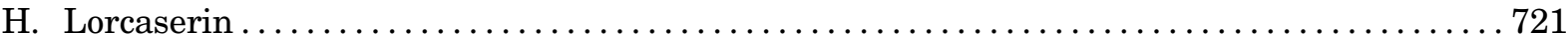

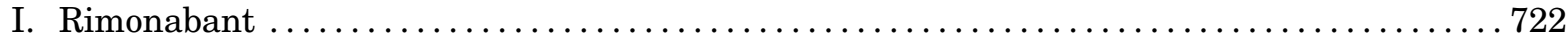

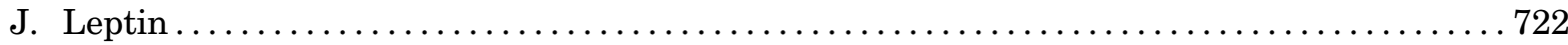

IV. From Glucagon-Like Peptide 1 Monoagonism to Multimode Incretin-Based Pharmacology . . . 723

A. Optimized Glucagon-Like Peptide 1 Monoagonists ........................... 723

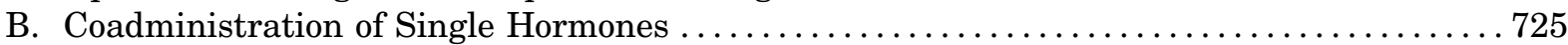

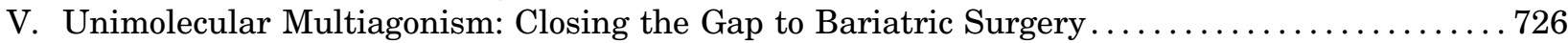

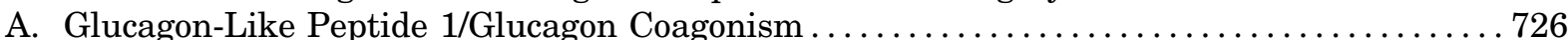

B. Glucagon-Like Peptide 1/Amylin Coagonism . . . . . . . . . . . . . . . . . . . . . . . . . . . 729

Address correspondence to: T. D. Müller, Institute for Diabetes and Obesity, Helmholtz Diabetes Center, Helmholtz Zentrum München, Parkring 13, 85748 Garching, Germany. E-mail: timo.mueller@helmholtz-muenchen.de; or M. H. Tschöp, Institute for Diabetes and Obesity, Helmholtz Diabetes Center, Helmholtz Zentrum München, Parkring 13, 85748 Garching, Germany. E-mail: matthias.tschoep@helmholtzmuenchen.de

This work was supported in part by Alexander von Humboldt Foundation, Helmholtz Alliance ICEMED and Helmholtz Initiative on Personalized Medicine iMed by Helmholtz Association, and Helmholtz cross-program topic "Metabolic Dysfunction" (to M.H.T.). This work was further supported by German Research Foundation Grants DFG-TS226/1-1 and DFG-TS226/3-1, European Research Council ERC AdG HypoFlam 695054, and German Center for Diabetes Research (DZD e.V.)

T.D.M. and C.C. have nothing to disclose. B.F. and R.D.D. are current employees of Novo Nordisk. R.D.D. is a cofounder of Marcadia, a company that pioneered the discovery of glucagon mixed agonists. It was acquired by Roche and later Novo Nordisk. M.H.T. is a scientific advisor for Novo Nordisk and Erx Biotech.

https://doi.org/10.1124/pr.117.014803. 
C. Glucagon-Like Peptide 1/Glucose-Dependent Insulinotropic Polypeptide Coagonism . . . . . 729

D. Glucagon-Like Peptide 1/Glucagon/Glucose-Dependent Insulinotropic Polypeptide

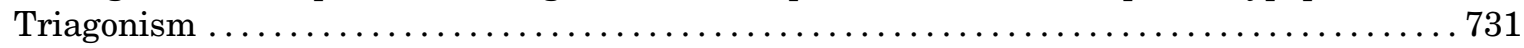

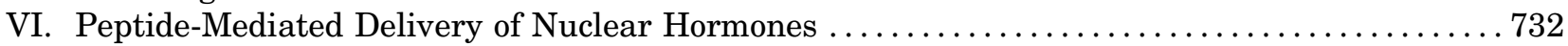

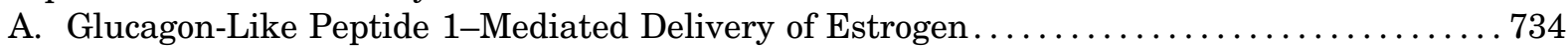

B. Glucagon-Mediated Delivery of Thyroid Hormone Tri-iodothyronine . . . . . . . . . . . 735

C. Glucagon-Like Peptide 1-Mediated Delivery of Dexamethasone .................... 736

VII. Outlook ............................................................ 737

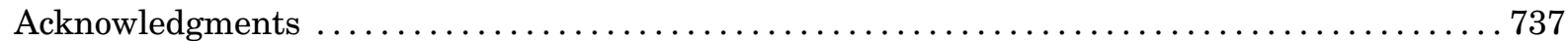

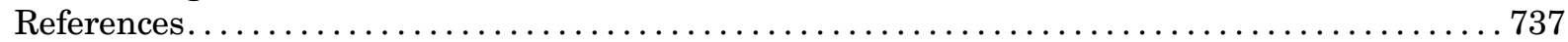

\begin{abstract}
With their ever-growing prevalence, obesity and diabetes represent major health threats of our society. Based on estimations by the World Health Organization, approximately 300 million people will be obese in 2035. In 2015 alone there were more than 1.6 million fatalities attributable to hyperglycemia and diabetes. In addition, treatment of these diseases places an enormous burden on our health care system. As a result, the development of pharmacotherapies to tackle this lifethreatening pandemic is of utmost importance. Since the beginning of the 19th century, a variety of drugs have been evaluated for their ability to decrease body weight and/or to improve deranged glycemic control. The list of evaluated drugs includes, among many others, sheep-derived thyroid extracts, mitochondrial uncouplers, amphetamines, serotonergics, lipase inhibitors, and a variety of hormones produced and secreted by the gastrointestinal tract or adipose tissue. Unfortunately,
\end{abstract}

when used as a single hormone therapy, most of these drugs are underwhelming in their efficacy or safety, and placebo-subtracted weight loss attributed to such therapy is typically not more than $10 \%$. In 2009, the generation of a single molecule with agonism at the receptors for glucagon and the glucagon-like peptide 1 broke new ground in obesity pharmacology. This molecule combined the beneficial anorectic and glycemic effects of glucagon-like peptide 1 with the thermogenic effect of glucagon into a single molecule with enhanced potency and sustained action. Several other unimolecular dual agonists have subsequently been developed, and, based on their preclinical success, these molecules illuminate the path to a new and more fruitful era in obesity pharmacology. In this review, we focus on the historical pharmacological approaches to treat obesity and glucose intolerance and describe how the knowledge obtained by these studies led to the discovery of unimolecular polypharmacology.

\section{Introduction}

The escalating prevalence of diabetes and obesity represents an incessant and escalating burden to modern societies. Obesity is characterized by an excess of body fat resulting from a chronic surplus in energy intake over energy expenditure. In the progression of obesity, the lipid deposition in adipose tissue can exceed the storage capacity of adipocytes, resulting in elevated circulating concentrations and inappropriate accumulation in multiple tissues, most notably liver and skeletal muscle. Fat deposits in such ectopic tissues are unhealthy and can initiate tissue inflammation, endoplasmic reticulum (ER) stress, and endothelial dysfunction, accelerating the development of obesityassociated pathologies, such as insulin resistance and type 2 diabetes (T2D) (Hotamisligil et al., 1993, 1996; Ozcan et al., 2004). In line with this proposed model of lipotoxicity, ectopic accumulation of reactive lipid species such as diacylglycerol, free fatty acids, free cholesterol, and ceramides have all been demonstrated to impair systems metabolism through local tissue inflammation and induction of ER stress (Unger, 2002; Virtue and Vidal-Puig, 2008; Symons and Abel, 2013; Contreras et al., 2014).

Of the numerous comorbidities linked to obesity, the most common are T2D; a variety of cardiovascular complications such as hypertension, coronary artery disease, and stroke; and certain types of cancer (Guo and Garvey, 2016). Notably, obesity and T2D represent top preventable causes of premature death and disability (Mathers and Loncar, 2006; Bauer et al., 2014), and the World Health Organization estimates that annually approximately 1.5 million deaths are directly attributable to diabetes (WHO, 2016). In the United States alone, about a quarter of a million adults prematurely die every year due to the consequences of excess body weight (Allison et al., 1999). The global burden that obesity and diabetes places upon our health care systems demands the development of effective, safe, and sustainable treatment options to combat this sizable and growing public dilemma.

ABBREVIATIONS: 5HT, serotonin; AgRP, agouti-related peptide; Aib, aminoisobuturic acid; CB1R, type I cannabinoid receptor; CEX, Cterminal extension; CNS, central nervous system; DIO, diet-induced obese; dn, dominant-negative; DNP, 2,4-dinitrophenol; DPP-IV, dipeptidylpeptidase IV; E2, estradiol; ER, endoplasmic reticulum; FDA, Food and Drug Administration; FGF21, fibroblast growth factor 21; GcgR, glucagon receptor; GIP, glucose-dependent insulinotropic polypeptide; GIPR, GIP receptor; GLP-1, glucagon-like peptide 1; GLP-1R, GLP-1 receptor; HFD, high-fat diet; LDL, low-density lipoprotein; NPY, neuropeptide Y; OXM, oxyntomodulin; PEG, polyethylene glycol; phen-fen, phentermine-fenfluramine; POMC, proopiomelanocortin; PYY, peptide YY; RYGB, Roux-en-Y gastric bypass; T2D, type 2 diabetes; T3, tri-iodothyronine; TR, thyroid receptor; TRb, $\beta$ receptor; VSG, vertical sleeve gastrectomy. 
In 1938, the United States passed the Food, Drug, and Cosmetic Act, upon which manufacturers were compelled to document drug safety to the Food and Drug Administration (FDA) to acquire approval for marketing and distribution. In 1962, through congressional approval of the Kefauver-Harris amendment, the FDA was authorized to review drug efficacy, and as such rendered the agency the final arbiter of the risks and benefits supporting drug approval and distribution in the United States (Colman, 2005). The drug approval process directed by the FDA or the European Medicines Agency has continually evolved and is currently separated into several distinct clinical phases. Phase I is typically performed in healthy volunteers with a specific focus on tolerability, pharmacokinetics, and acute measures of safety. Phase II progresses to assess drug efficacy and safety in the first cohorts of carefully selected and wellcharacterized patients. The phase III clinical studies aim to confirm sustained efficacy and longer-term safety, in large-scale multicenter patient trials. Once a drug is registered yet subsequent to commercialization, phase IV studies are often employed to further assess effects in even larger-scale, chronic studies. From start to finish, the governmental regulatory agencies assess and monitor the risk-benefit of drug candidates and registered medicines, with authority to restrict or remove them in clinical use.

Although regulatory oversight is well defined, the historical performance as it pertains to drugs controlling body weight has been populated with notable challenges (Colman, 2005). Many weight-lowering pharmacotherapies that were initially approved for treatment of obesity were subsequently withdrawn as safety concerns emerged to dominate the pharmacological benefits (Astrup, 2010; Adan, 2013). Whereas unfavorable balance in safety relative to efficacy determined the fate of several highly promising pharmacotherapies, weight loss induced by bariatric surgery has proven remarkably effective and sustainable. The improvement of metabolic control following a surgical intervention cannot be singularly justified by the physical limitation in gastrointestinal uptake of food, and notably glucose metabolism is typically improved much before a meaningful decrease in body weight is observed (Pories et al., 1995; Peterli et al., 2009; Bayham et al., 2012). Because the improvement in metabolism following surgical intervention relies on endocrine factors, it provides optimism for the discovery of medicinal options to counteract excess body weight in comparable magnitude to invasive surgery, but only time will tell whether this is a "mission impossible."

Although historical weight-loss drugs failed to meet expectations (Fig. 1), there has been important progress in recent years in the emergence of novel therapeutics. In particular, peptide-based agonism at the glucagon-like peptide 1 (GLP-1) receptor (GLP-1R) has demonstrated meaningful reduction in body weight and serves as a central ingredient to which additional pharmacology of other key metabolic hormones has been integrated to single molecular entities. Several purposefully designed, unimolecular multiagonists have recently been reported, with the first occurring in 2009 (Day et al., 2009). Nearly every pharmaceutical company active in cardiometabolic diseases is pursuing some aspect of this conceptual approach (Brandt et al., 2018). In this review, we present the achievements and the disappointments in modern weight-loss pharmacology and discuss the emergence of these unimolecular multiagonists as a promising path to a new era.

\section{Bariatric Surgery: A Benchmark for Efficacy}

As of today, bariatric surgery remains the most effective way to sizably lower body weight. Among the commonly used procedures are Roux-en-Y gastric bypass (RYGB), vertical sleeve gastrectomy (VSG), or adjustable gastric banding. The continued refinement through the last decade in surgical techniques and improvement in laparoscopic procedures has resulted in enhanced recovery, fewer adverse outcomes, and hospitalization routinely required for typically no more than 1 to 2 days (Robinson, 2009).

Bariatric surgery is rapidly gaining in popularity, and large-scale follow-up studies dependent on the surgical procedure, demonstrating sustained weight loss of 13\%-27\%, with follow-up for as much as 15 years (Sjöström et al., 2007). The body weight loss following RYGB is beneficially accompanied by a decrease in subsequent mortality (Sjöström et al., 2007) and often the complete remission of insulin resistance and T2D (Pories et al., 1995; Carlsson et al., 2012). This last observation has led the American Diabetes Association to recommend bariatric surgery in certain circumstances also for the treatment of T2D (Chakradhar, 2016; Rubino et al., 2016).

Rapid improvement in glycemic control after RYGB or VSG is observed within a few days following surgery, and notably prior to clinically relevant weight loss (Pories et al., 1995; Peterli et al., 2009; Bayham et al., 2012). About 8 weeks after the surgery, approximately $80 \%$ of patients are able to discontinue diabetes medication (Bayham et al., 2012), with improved insulin sensitivity demonstrated within the first postoperative week (Isbell et al., 2010; Umeda et al., 2011; Jørgensen et al., 2012; Faria et al., 2013). Some case reports show a decrease in fasting blood glucose of more than $40 \%$ by the end of the first postoperative day, with resolution of T2D and discontinuation of exogenous insulin treatment after just 6 days (Pories et al., 1995).

The molecular mechanisms underlying the sustained improvement in body weight and glucose metabolism following bariatric surgical interventions are not completely understood and are subject of intense scientific investigation. Despite some contention 


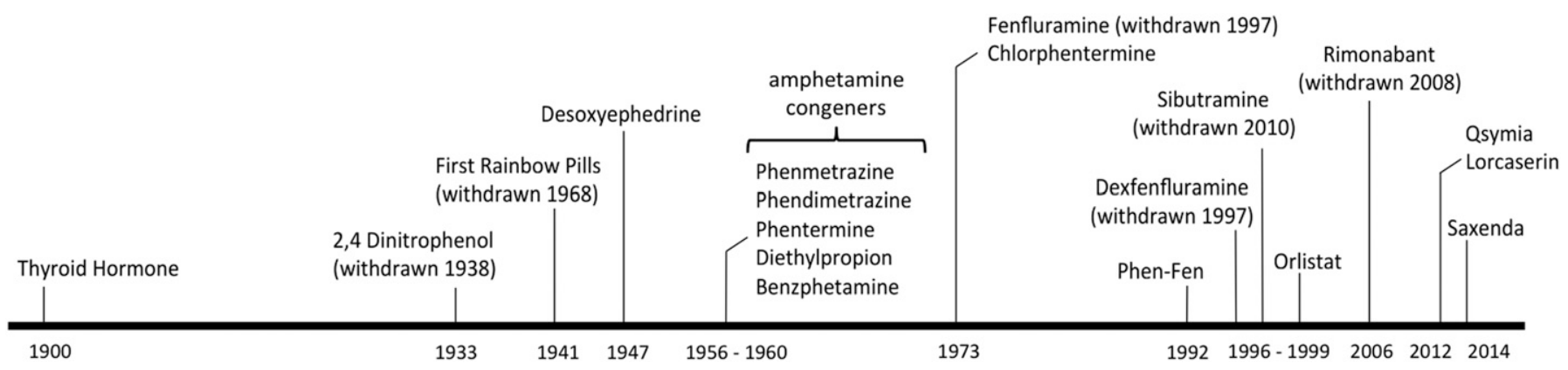

Fig. 1. Time line of pharmacotherapies used to treat obesity from 1900 until today.

(Werling et al., 2013, 2015), changes in energy expenditure or the rate by which nutrients are taken up from the intestine do not explain the initial efficacy or the sustained weight reduction (Olbers et al., 2006; Odstrcil et al., 2010; Carswell et al., 2014; Münzberg et al., 2015; Schmidt et al., 2016). Chronic changes in food consumption are typically reported after bariatric surgery and are considered a causal factor in sustained weight loss (Brolin et al., 1994; Sjöström et al., 2004; Laurenius et al., 2012; Münzberg et al., 2015). Molecular mechanisms that support reduction in food intake seem, however, not to rely on physical limitations of the gastrointestinal tract (Ryan et al., 2014), but instead pertain to changes in food preference, taste perception, and alterations in the food reward system (Scruggs et al., 1994; Burge et al., 1995; Miras and le Roux, 2010; Shin and Berthoud, 2011; Mathes and Spector, 2012; Laurenius et al., 2013).

Endocrine changes in gastrointestinal hormone secretion following RYGB or VSG include enhanced postprandial secretion of GLP-1 (le Roux et al., 2006; Korner et al., 2007; Isbell et al., 2010; Jacobsen et al., 2012; BojsenMoller et al., 2014; Svane et al., 2016) and peptide YY (PYY) (le Roux et al., 2006; Svane et al., 2016), whereas circulating levels of glucose-dependent insulinotropic polypeptide (GIP) and ghrelin are typically diminished (Cummings et al., 2002; Korner et al., 2007). The observation that RYGB and VSG lead increased postprandial GLP-1 secretion has widely resulted in the hypothesis that enhanced GLP-1 action contributes to reduced food intake, weight loss, and improved glucose metabolism typically observed after these surgical procedures. However, VSG also improves body weight and glycemic control in mice deficient for the GLP-1 receptor, and surprisingly with equal efficiency when compared with wild-type controls (Wilson-Perez et al., 2013). These data suggest that enhanced GLP-1 action alone cannot explain the metabolic benefits of this surgery. Consistent with this notion, singular inhibition of either GLP-1 or PYY alone does not affect food intake in humans following RYGB (Svane et al., 2016). However, as shown in the same study, when GLP-1 and PYY signaling are both collectively blocked, food consumption is increased by $\sim 20 \%$. Consequently, it has been proposed repeatedly that GLP-1, when acting in concert with other gastrointestinal peptides, might play a role in the sustained weight loss associated with bariatric surgery (Svane et al., 2016). Notably, also signaling via the farnesoid$\mathrm{X}$-activated receptor seems to play an important role in the metabolic benefits achieved by bariatric surgery because the efficacy of VSG to decrease body weight is strikingly reduced in mice lacking farnesoid-X-activated receptor (Ryan et al., 2014).

In summary, whereas the molecular mechanisms underlying the improvement in energy and glucose metabolism by bariatric surgery are not fully understood, surgery is the only currently available intervention that achieves sustained weight loss and correction of T2D. However, with the appreciable sustained efficacy, it should be noted that a surgical approach to disease management is highly invasive, irreversible in most instances, and not without risk (Marcotte and Chand, 2016). In most countries, bariatric surgery is accessible to only a small fraction of patients who are extremely obese. In this regard, the National Institutes of Health recommends bariatric surgery for obesity at a body mass index $>40 \mathrm{~kg} / \mathrm{m}^{2}$ or at a body mass index $>35 \mathrm{~kg} / \mathrm{m}^{2}$ in association with other significant comorbidities requiring an immediate weight reduction (Robinson, 2009). Consequently, it remains an important option for extreme forms of obesity, but surgery seems impractical as a general strategy to tackle the global "diabesity" pandemic. Accordingly, pharmacological options to similarly address excess body weight and improve glycemic control are urgently required.

\section{The Chronology of Modern Weight-Loss Pharmacology}

Modern weight-loss pharmacology begins near the end of the 19th century, where growing industrialization and change in lifestyle propelled a persistently increasing demand for drugs to control body weight (Fig. 1). Eager to satisfy a generation that was yearning for a pill to melt away fat mass within a (few) blink(s) of an eye, a variety of weight-lowering drugs were evaluated during the first half of the 20th century (Rodgers et al., 2012; Adan, 2013). Reflective of the complex 
nature of systemic energy regulation, the mode of action underlying these drugs ranged from central modulation of hunger and satiety, to limiting intestinal nutrient transport, and to direct manipulation of energy expenditure. Viewed retrospectively, certain of these pharmacological approaches could easily be characterized as careless and unmindful. Additionally, some of the people using them were equally so in their quest for supplemental beauty.

\section{A. Thyroid Hormones}

The thyroid gland has been known for centuries for its ability to increase metabolic rate. There are clinical reports that date from the 1890s on the weight-lowering effect of sheep-derived thyroid extracts (McCone, 1897). Apart from decreasing body weight and body fat mass via stimulation of energy expenditure, thyroid hormone also improves hepatic lipid metabolism. It can decrease lowdensity lipoprotein (LDL) cholesterol via enhanced reverse cholesterol transport and clearance of LDL via the liver (Baxter and Webb, 2009). Unfortunately, excess thyroid hormone action also leads to muscle and bone catabolism, as well as to cardiac arrhythmia, tachycardia, and heart failure, which severely limits its use to control body weight (von Olshausen et al., 1989; Woeber, 1992; Galloe et al., 1993). Nevertheless, at the end of the 19th century, physicians already experimented with thyroid extracts to lower body weight and occasionally prescribed strychnine or digitalis leaf to attenuate thyroid hormone's adverse cardiovascular effects (Cohen et al., 2012). Regrettably, in some cases, excessive thyroid hormone supplementation proved a terminal treatment and served to accentuate that "all that glitters, is not gold" (Bhasin et al., 1981).

The biologically active form of thyroid hormone is tri-iodothyronine (T3), which promotes its pharmacology through two specific nuclear thyroid receptor (TR) isofroms, TR $\alpha$ and TR $\beta$. Notably, T3 stimulation of heart rate is substantially impaired in mice lacking $\mathrm{TR} \alpha$, whereas the ability of T3 to lower cholesterol is fully preserved in these mice (Grover et al., 2003). Relative to wild-type controls, T3 stimulation of metabolic rate is only blunted by about $50 \%$ in mice lacking $\mathrm{TR} \alpha$. Treatment of rats and nonhuman primates with the TR $\beta$-selective agonist KB-141 further increased metabolic rate and decreased cholesterol and body weight, without affecting heart rate (Grover et al., 2003). Collectively, these data suggest that T3 regulates cholesterol metabolism via signaling through TR $\beta$, whereas the cardiovascular effects of T3 are mediated via $\mathrm{TR} \alpha$, and $\mathrm{T} 3$ regulation of metabolic rate is mediated via both $\mathrm{TR} \alpha$ and $\mathrm{TR} \beta$ (Grover et al., 2003).

Administration of T3 increases metabolic rate in a variety of species, including mice (Oh and Kaplan, 1994; Jekabsons et al., 1999; Grover et al., 2003, 2005), rats (Whaley et al., 1959), and humans (Barbe et al., 2001; Johannsen et al., 2012). Notably, T3 also enhances oxygen consumption in excised rat tissues such as the liver, kidney, heart, and skeletal muscle (Whaley et al., 1959), indicating that $\mathrm{T} 3$ stimulation of metabolic rate is mediated through direct tissue action. The molecular mechanism underlying T3 modulation of metabolic rate includes uncoupling of oxidative phosphorylation from mitochondrial ATP synthesis in skeletal muscle and other peripheral tissues (Hess and Martius, 1951; Lardy and Feldott, 1951; Lebon et al., 2001), regulation of lipogenesis (Freake et al., 1989), activation of $\mathrm{Na}^{+} / \mathrm{K}^{+}$ATPase (IzmailBeigi and Edelman, 1970), enhanced mitochondrial biogenesis (Gustafsson et al., 1965), and stimulation of futile cycling (Newsholme and Crabtree, 1976; Shulman et al., 1985). In line with the proposed role of T3 to regulate energy metabolism via mitochondrial uncoupling in skeletal muscle, mRNA levels of uncoupling protein 3 are decreased threefold in skeletal muscle of hypothyroid rats and are increased sixfold in hyperthyroid rats relative to euthyroidic controls (Gong et al., 1997). Administration of T3 further increases expression of uncoupling protein 3 in skeletal muscle of various species, including mice (Jekabsons et al., 1999; Jucker et al., 2000), rats (Larkin et al., 1997; Masaki et al., 2000), and humans (Barbe et al., 2001). Although these and numerous other studies convincingly show that $\mathrm{T} 3$ affects metabolic rate via action in peripheral tissues, more recent studies suggest that $\mathrm{T} 3$ also affects energy metabolism via central nervous system (CNS)-dependent mechanisms that include hypothalamic regulation of $5^{\prime}$ adenosine monophosphate-activated protein kinase (Lopez et al., 2010; Martinez-Sanchez et al., 2017) and sympathetic nervous system-mediated regulation of brown adipose tissue (Alvarez-Crespo et al., 2016). However, no effect on energy expenditure or body weight was reported in another study in which T3 was chronically administered into either the paraventricular hypothalamus or the ventromedial hypothalamus of rats (Zhang et al., 2016).

In summary, case reports on the use of thyroid hormones to control excess body weight date back to the end of the 19th century (McCone, 1897). Due to its ability to lower body weight and to improve lipid metabolism, thyroid hormone also became one of the major active constituents of the famous rainbow pills, which are discussed later in this review (see The Rainbow Pills). However, the pharmacological potential of T3 is restricted by adverse effects, predominantly cardiovascular in nature. Nevertheless, the hepatic action of T3 to improve lipid metabolism renders T3 a validated candidate for more advanced pharmacological approaches. Consistent with this perspective, and as discussed later in this review, a novel strategy entails the recruitment of a peptide hormone to preferentially deliver T3 to the liver (Finan et al., 2016a).

\section{B. 2,4-Dinitrophenol}

During the First World War, a number of French munitions workers died after being accidentally exposed 
to large amounts of 2,4-dinitrophenol (DNP), a substance that was used in the manufacture of explosives (Perkins, 1919). DNP was also commonly used as a dye, for wood preservation, photographic development, and as an herbicide (Harper et al., 2001; Grundlingh et al., 2011). An overdose of DNP results in overheating, fever, and eventually death (Perkins, 1919; Tainter et al., 1934). In the decade following 1910 , more than 35 cases of fatal DNP intoxication were recorded (Horner, 1941; Grundlingh et al., 2011).

In 1933, Maurice Tainter from Stanford University published the first clinical report on the weightlowering properties of DNP (Tainter et al., 1933). DNP was administered in a daily dose between 3 and $5 \mathrm{mg} / \mathrm{kg}$, and the reported weight loss was in the range of $1.5 \mathrm{~kg}$ per week. The pharmacological effect resided in the ability of DNP to increase metabolic rate via enhanced mitochondrial uncoupling, thus favoring heat production over ATP synthesis (Cutting et al., 1933; Tainter et al., 1933, 1935). When used in a dose of $300 \mathrm{mg} / \mathrm{d}$, weight loss induced by DNP seemed to be well tolerated and associated with an increase in metabolic rate of $\sim 50 \%$ (Tainter et al., 1933, 1934; Dunlop, 1934). In subsequent clinical studies, metabolic rate was shown to increase in average by $11 \%$ per $100 \mathrm{mg}$ DNP (Dunlop, 1934; Tainter, 1935; Harper et al., 2001). In anesthetized dogs, DNP dose-dependently increased oxygen consumption by as much as 12 -fold above baseline (Hall et al., 1933). Although the weight-lowering effect of DNP is impressive, the margin between $\mathrm{ED}_{50}$ and $\mathrm{LD}_{50}$ is razor-thin. In line with this notion, acute administration of $20-50 \mathrm{mg} / \mathrm{kg}$ DNP can be lethal in humans (Macnab and Fielden, 1998; Hsiao et al., 2005), and its extended half-life that ranges from 46 hours in mice (Robert and Hagardorn, 1985) to 54-88 hours in humans (Zhao et al., 2015) further complicates its use. Repeated daily administration of DNP leads to accumulation, and with it the risk for fatal intoxication is increased. In line with this notion, early clinical studies showed that metabolic rate gradually increases with daily administration of $3-5 \mathrm{mg} / \mathrm{kg} \mathrm{DNP}$, and plateaued at $\sim 40 \%$ above baseline after a few weeks of treatment (Cutting et al., 1933; Harper et al., 2001). Following its introduction as a weight loss pharmacotherapy in 1933, the interest in DNP was tremendous. In 1934 alone, Stanford Clinics supplied over 1,200,000 DNP capsules to physicians, or directly to patients with physician prescriptions (Tainter et al., 1934). Stanford scientists estimated that within this 1 year, more than 100,000 people in the United States were treated with DNP.

The classic adverse effects of DNP include hyperthermia, tachycardia, diaphoresis, tachypnea, nausea, and vomiting (Grundlingh et al., 2011). Nevertheless, commercialization of DNP boomed until reports of adverse liver, heart, and muscle effects (MacBryde and Taussig, 1935) prompted the FDA in 1935 to state that "treatment of a mild chronic condition such as obesity with a toxic agent capable of inducing serious injury and death appears unjustified" (Colman, 2007). The FDA, however, did not suspend DNP until 1938, when reports accumulated that linked the administration of DNP, even when administered in physiologic doses and under physician supervision, to the development of cataracts (Horner et al., 1935; Horner, 1936; Colman, 2007). Until the removal from commercial distribution in 1938, it is estimated that more than 2500 Americans were blinded as a result of DNP-induced cataracts (Horner, 1936; Colman, 2007).

The use of DNP did not completely disappear despite termination in 1938 (Fig. 1). In 1981, a United States physician restarted commercializing DNP in self-made diet pills (Mitcal), which he distributed as intracellular hyperthermia therapy in his private weight-loss clinic (Kurt et al., 1986; Grundlingh et al., 2011). In 1982, the FDA received notice from patients using Mitcal, and in a subsequent lawsuit it was estimated that approximately 14,000 people had been treated, with one reported fatality. After being fined in 1986 for drug law violations, this physician continued prescribing DNP for various clinical applications until 2008 when he was sentenced for trading DNP as an intracellular hyperthermia cancer therapy (Grundlingh et al., 2011). Despite this dubious history, DNP remains a common illegal drug substance employed by bodybuilders and others who are either careless or misguided in risking their health to melt away fat.

\section{Amphetamines}

1. Methamphetamine. In the 1940s, amphetamines gained rapid popularity given their appetite-suppressing effect, and the FDA approved the use of methamphetamine desoxyephedrine (tradenames Hydrin and Desoxyn) for the treatment of obesity in 1947 (Colman, 2005) (Fig. 1). The appetite suppression of methamphetamine (well recognized by its street name crystal meth) resides in its ability to stimulate the synthesis and release of catecholamines, especially dopamine, from CNS nerve terminals. This leads to an increase in metabolic rate and stimulation of anorectic hypothalamic neurocircuits and other brain areas. In the hypothalamus, monoaminergic neurons project from the arcuate nucleus to the median eminence, and amphetamine stimulation of monoamine release inhibits food intake via stimulation of proopiomelanocortin (POMC) neuronal activity, whereas neurons expressing neuropeptide Y (NPY)/agouti-related peptide (AgRP) are inhibited (Heisler et al., 2002, 2006; Kuo, 2005, 2006; Garfield and Heisler, 2009; Kuo et al., 2009, 2012; Roepke et al., 2012; Chu et al., 2014; Jones and Bloom, 2015).

The interest in using amphetamines for the purpose of controlling excess body weight was propelled by case reports showing that thrice daily administration of $2 \mathrm{mg}$ desoxyephedrine could decrease body weight by as 
much as $24.5 \mathrm{~kg}$, and seemingly without major adverse effects (Ray, 1947). Nonetheless given their action on the central reward system, amphetamines possess a certain risk for addiction (Schuster and Thompson, 1969; Balster and Schuster, 1973; Yokel and Pickens, 1973; Gotestam and Andersson, 1975). The use of desoxyephedrine for body weight lowering was not the intended initial purpose, which was treatment of narcolepsy, depression, postencephalitic Parkinson syndrome, alcoholism, cerebral arteriosclerosis, and hay fever (Colman, 2005). The addictive and abuse potential of desoxyephedrine hampered its pharmacological use to treat obesity and inspired pharmaceutical companies to develop chemically-related analogs that were intended to retain the anorectic effect, but with far less safety concerns. Up until 1960, several amphetamine congeners, such as phenmetrazine, phendimetrazine, diethylpropion, phentermine, and benzphetamine, were registered by the FDA for use as an adjunct to lifestyle change in the treatment of obesity (Colman, 2005) (Fig. 1).

2. Amphetamine Congeners. Like other amphetamines, the congeners act as sympathomimetics to stimulate the release of monoamines, especially dopamine and/or norepinephrine from CNS nerve terminals. The purportedly reduced addictive potential of the congeners remained in question (Wilson et al., 1971; Gotestam and Andersson, 1975), and the FDA, after the Kefauver-Harris amendments became effective in 1962, more closely scrutinized the risk and benefits. A large meta-analysis comprising more than 200 clinical studies and more than 10,000 individuals concluded that the congeners, although statistically significant in lowering body weight, are only marginally more effective relative to treatment with placebo (Colman, 2005). Of note, the FDA at that point in history defined the efficacy of a drug as "statistically different (superior) to placebo," unfortunately neglecting whether the observed difference was of clinical relevance. Consequently, despite showing only limited efficacy, the congeners remained approved drugs for the treatment of obesity. Because a certain addictive potential could not be ruled out (Gotestam and Andersson, 1975), the FDA henceforth restricted their use to only short-term (a few weeks) treatment (Colman, 2005). The limited efficacy paired with restrictions for use largely dampened the pharmacological interest in amphetamine congeners as monotherapy for body weight management. However, some congeners still remain approved in combination to lifestyle modifications for the shortterm treatment of obesity and are, as later reviewed, used in adjunct to other weight loss drugs.

a. Phenmetrazine. Phenmetrazine was approved by the FDA for the treatment of obesity in 1956 and was commercialized under the trade name Preludin (Boehringer-Ingelheim, Ingelheim, Germany) (Colman, 2005). Preludin has sympathomimetic properties similar to that of ephedrine and amphetamine and thus inhibits food intake by stimulating the release of norepinephrine and dopamine from CNS nerve terminals (Ressler, 1957; Szenas and Pattee, 1957; Leith and Beck, 1958; Rothman and Baumann, 2006). Preludin was commonly administered thrice daily in an amount of $25 \mathrm{mg}$, and, when given in adjunct to a calorierestricted diet, placebo-subtracted weight loss induced by preludin is typically about $\sim 0.5 \mathrm{~kg} / \mathrm{wk}$ with significant improvement of blood glucose after 4-6 weeks of treatment (Robillard, 1957; Leith and Beck, 1958; Briggs et al., 1960; Baggio et al., 2004). Adverse effects associated with phenmetrazine include tachycardia, heart arrhythmias, hypertension, convulsions, restlessness, agitation, vomiting, and diarrhea (Clarke, 2007). Due to its action on the brain reward system, phenmetrazine still carries an abusive potential (Bethell, 1957) and when chronically used can lead to delusions and paranoia (Clarke, 2007). There is at least one reported case of fatal phenmetrazine poisoning (Norheim, 1973). Due to its euphoric effect, phenmetrazine enjoyed great popularity in the mid 1950 s and was misused for recreational purposes before its commercialization was discontinued.

b. Phendimetrazine. Phendimetrazine is a prodrug of phenmetrazine and was approved by the FDA for the short-term treatment of obesity in 1959 (Fig. 1). The prodrug character of phendimetrazine is based on the addition of a methyl group onto an amphetamine backbone. This chemical modification renders the drug inactive unless the methyl group is cleaved in the circulation and phendimetrazine is converted to phenmetrazine. Because only a portion of the drug is active after being administered into the circulation, phendimetrazine has a lower abusive potential relative to phenmetrazine. Phendimetrazine is usually given orally and has a half-life of 2-4 hours in humans. When given in a daily dose of $210 \mathrm{mg}(6 \times 35 \mathrm{mg})$, weight loss induced by phendimetrazine is about $7 \%$ relative to the baseline body weight after up to 32 weeks of treatment (Le Riche and Van Belle, 1962). Unfortunately, no placebo group was included in this study (Le Riche and Van Belle, 1962). A dose of $210 \mathrm{mg} / \mathrm{d}$ is reported to be generally well tolerated, with insomnia, dry mouth, and constipation being the most frequently reported side effects. Less frequently reported acute side effects include hyperpyrexia, mydriasis, chest pain, arrhythmias, delirium, and rhabdomylosis (Kwiker et al., 2006), whereas more chronic adverse effects include the development of cardiomyopathies (Rostagno et al., 1996; Landau et al., 2008). As of today, phenmetrazine is approved by the FDA in adjunct to lifestyle changes for the short-term treatment of obesity and is commercialized under the trade name Adipost, Anorex-SR, Appecon, Bontril PDM, Melfiat, Obezine, Phendiet, Plegine, Prelu-2, or Statobex.

c. Diethylpropion. Diethylpropion (a.k.a. amphepramone) was approved by the FDA in 1959 as adjunct 
to diet and exercise for the short-term $(<12$ weeks) treatment of obesity (Fig. 1). Diethylpropion is structurally related to bupropion and is commercialized under the trade name Tenuate. Diethylpropion is usually given either thrice daily in an amount of $25 \mathrm{mg}$, or once daily as an extended release formulation. As demonstrated in a recent meta-analysis comprising 25 clinical studies, placebo-subtracted weight loss attributed to treatment with diethylpropion is on average $1.28 \mathrm{~kg}$ when given for $<180$ days and $6.5 \mathrm{~kg}$ when given $>180$ days (Lucchetta et al., 2017). In a more historic meta-analysis comprising 13 clinical studies published between 1965 and 1983, treatment with diethylpropion for 6-52 weeks in a dose of $75 \mathrm{mg} / \mathrm{d}$ resulted in a placebo-subtracted average weight loss of $3.0 \mathrm{~kg}$ with borderline significance to placebo controls (Li et al., 2005). Notably, although several reports testify that diethylpropion has an anorexigenic nature with virtual absence of adverse effects (Wilson and Long, 1960; Hadden and Lucey, 1961; Nash, 1961; Seaton et al., 1961), there is at least one report of diethylpropion addiction (Clein and Benady, 1962).

$d$. Phentermine. Phentermine was approved by the agency for the treatment of obesity in 1959. The duration of treatment is restricted to 12 weeks and is indicated to be used in adjunct to lifestyle modifications. Phentermine is a sympathomimetic with agonism at the trace amine-associated receptor 1 . The drug stimulates primarily the release of norepinephrine, but to lower extent also dopamine and serotonine. Depending on the dose (which is typically between 30 and $37.5 \mathrm{mg} / \mathrm{d}$ ) the placebo-subtracted weight loss attributed to treatment with phentermine $(30 \mathrm{mg} / \mathrm{d})$ is in the range of $4-8 \mathrm{~kg}$ after 12 weeks of treatment (Kim et al., 2006; Kang et al., 2010; Moldovan et al., 2016). Phentermine is generally well tolerated with little to no abusive potential, even when used chronically for up to 21 years (Hendricks et al., 2009). In a large-scale survey, United States physicians stated that $98 \%$ use pharmacological options to treat obesity, and, from those physicians using pharmacotherapies, $97 \%$ state to prescribe phentermine, $64 \%$ diethylpropion, $60 \%$ phendimetrazine, $50 \%$ topiramate, $49 \%$ sibutramine, and $43 \%$ orlistat (Hendricks et al., 2009).

\section{The Rainbow Pills}

Undiscouraged by the failure of amphetamines and thyroid hormone as stand-alone treatment of obesity, the pharmaceutical industry has long been in search for a proverbial silver bullet to fight obesity. In 1941, Clark \& Clark (Camden, NY) combined the anorectic effect of amphetamines with the thermogenic effect of thyroid hormone to form Clarkotabs, possibly the first commercially distributed polypharmacological diet pills (Fig. 1). Because Clarkotabs came in all sorts of seemingly harmless colors, they became popularized as the rainbow pills. The different colors were commonly misused to pretend their utility as personalized medicine, with the different colors reflecting individual patient need to optimally lose body weight. The first preparations included, in addition to thyroid hormones and amphetamine sulfate, aloin and atropine sulfate to counteract adverse cardiovascular effects (Cohen et al., 2012). The ingredients as well as the primary commercial manufacturer of the rainbow pills changed with time, and the different formulations often constituted a physical cocktail of weight-reducing substances, including $\mathrm{d}$-amphetamine or related analogs (like diethylpropion, fenfluramine, sibutramin, or fenproporex), thyroid hormones, diuretics, laxatives, chlorthalidon, ephedrine, and/or phenolphthalein. Substances such as digitalis, belladonna, benzodiazepines, barbiturates, corticosteroids, cardiac glycosides, beta-blocker, and potassium were common additives used to counteract or mask adverse cardiovascular effects of the drug cocktail (Cohen et al., 2012).

In the decades between the 1940 s and $1960 \mathrm{~s}$, the rainbow pills enjoyed great popularity. In contrast to good medical practice, the pills were often sent directly from the manufacturer to physicians, who then sold the pills to patients. Reflecting the lucrative financial potential in such therapy, at least 2000 United States clinical practices in 1967 focused exclusively on weight reduction (Cohen et al., 2012). According to a congressional investigation, it was estimated that these weight loss clinics earned annually $\sim \$ 250$ million in patient fees, and another $\$ 120$ million was annually spent by patients to acquire the rainbow pills (Cohen et al., 2012). In 1968, a journalist for Life magazine reported on her experience in 10 weight loss clinics where she was prescribed more than 1500 pills, with only superficial counseling and without clear medical necessity to lose body weight (McBee, 1968). The FDA received notice of several fatalities linked to the consumption of rainbow pills and studied the process by which rainbow pills were commercialized (Henry, 1967). A subsequent large-scale investigation by the U.S. Senate ascribed more than 60 deaths to the consumption of rainbow pills, which prompted the FDA in 1968 to seize large quantities of rainbow pills from manufacturers and to prohibit further distribution in the United States (Cohen et al., 2012).

\section{E. Serotonergics}

1. Fenfluramine. Although federal restrictions largely dampened the clinical interest in the use of amphetamines to treat obesity during the decade of the $1960 \mathrm{~s}$, the interest in amphetamines was suddenly revived in 1973 when the first serotonergic, fenfluramine, received approval for the treatment of obesity (Fig. 1).

Fenfluramine promotes its anorectic action via stimulating the release of serotonin (5HT) from CNS neurons, while at the same time inhibiting its axonal reuptake 
(Costa et al., 1971; Garattini, 1981; Garattini et al., 1986). Identified in 1948 for its vasoconstrictive action (Rapport et al., 1948a,b), 5HT is a key central neurotransmitter, and as such is implicated in a myriad of metabolic functions that include the regulation of mood, behavior, and food intake, among many others (Bello and Liang, 2011). In line with a role of $5 \mathrm{HT}$ in regulating energy intake, stimulation of postsynaptic 5HT receptors decreases food intake (Samanin et al., 1980), whereas in rats central $5 \mathrm{HT}$ depletion via intracerebroventricular administration of p-chlorophenylalanine results in overeating and obesity (Breisch et al., 1976). The anorectic action of $5 \mathrm{HT}$ is mediated via at least two central 5HT receptors, 5HT2c and 5HT1b, which are located on neurons expressing either POMC/cocaineand amphetamine-regulated transcript (CART) or AgRP/NPY (Garfield and Heisler, 2009). The current consensus of 5HT-induced inhibition of food consumption includes binding of 5HT to the 5HT2c receptor on POMC/CART neurons with the result being activation (depolorization) of these neurons (Heisler et al., 2002), whereas at the same time neurons expressing AgRP/NPY get inactivated (hyperpolarized) via binding of $5 \mathrm{HT}$ to the $5 \mathrm{HT} 1 \mathrm{~b}$ receptor (Heisler et al., 2006; Garfield and Heisler, 2009).

Fenfluramine inhibits food intake in a variety of species, including rodents, guinea pigs, dogs, and humans (Alphin and Ward, 1969; Pinder et al., 1975). In line with the melanocortinergic system playing a key role in orchestrating this effect, mice lacking either the $5 \mathrm{HT} 1 \mathrm{~b}$ receptor (Lucas et al., 1998) or the melanocortin 4 receptor are unresponsive to the anorectic effect of fenfluramine (Heisler et al., 2006). Of appreciable note, unlike other amphetamines, fenfluramine, when given at anorectic doses, does not affect locomotor activity (Ledouarec and Schmitt, 1964; Garattini, 1981; Lucas et al., 1998) and is largely devoid of abusive potential (Gotestam and Andersson, 1975).

2. Phentermine-Fenfluramine. In 1992, the interest in using fenfluramine to lower body weight was promoted by a clinical report showing it potently lowers body weight when given as an adjunct to phentermine (Weintraub et al., 1992a). In this study, 121 obese individuals were treated for 34 weeks with a combination of $15 \mathrm{mg}$ phentermine and $60 \mathrm{mg}$ fenfluramine. The patients treated with this phentermine-fenfluramine (phen-fen) combination lost an average 14.2\% body weight relative to $4.6 \%$ in placebo-treated controls (Weintraub et al., 1992a). Of appreciable note, dry mouth was the most common reported side effect, with all adverse features vanishing after 4 weeks of treatment (Weintraub et al., 1992a). Continuation of the study (but with varying study designs) for up to 210 weeks corroborated the overall metabolic benefits of the phen-fen combination and suggested that this pharmacotherapy, when given as an adjunct to lifestyle modifications, is of appreciable value for the treatment of obesity (Weintraub et al., 1992a,b,c,d). Of note, not all studies were able to show a superior effect of the phen-fen combination on body weight relative to treatment with phentermine or fenfluramine alone (Weintraub et al., 1984; Li et al., 2003). However, there are some indications that the phen-fen combination has a lower abuse potential relative to treatment with phentermine alone (Brauer et al., 1996). In 1996, it is estimated that phen-fen was prescribed to more than 18 million people in the United States (Connolly et al., 1997), and it was in the same year when the FDA approved the use of dexfenfluramine, the d-isomer of fenfluramine, as a chronic treatment of obesity (Colman, 2005) (Fig. 1).

3. Dexfenfluramine. When dexfenfluramine is given in a dose of $15 \mathrm{mg}$ twice daily, placebo-subtracted weight loss attributed to dexfenfluramine is typically 3-6 kg, depending on the duration of treatment (Finer et al., 1988; Andersen et al., 1992; Geyer et al., 1995; Holdaway et al., 1995). The weight-lowering effect of dexfenfluramine has been confirmed in many, but not all clinical studies (Mathus-Vliegen, 1993; Recasens et al., 1995; Galletly et al., 1996). Beyond its ability to lower food intake via its action on the serotonergic/ melanocortinergic system (Heisler et al., 2002), dexfenfluramine also lowers body weight independent of food intake, as animals treated with dexfenfluramine lose more body weight relative to mice that are pairfed to receive the same amount of food as the dexfenfluramine-treated mice (Blundell et al., 1980). Furthermore, despite not being confirmed in every study (Pfohl et al., 1994), weight loss induced by dexfenfluramine is accompanied by a decrease in blood pressure, lower levels of cholesterol, and improvement of insulin resistance (Holdaway et al., 1995). The improvement in glycemic control following treatment with dexfenfluramine seems to be independent of weight loss because short-term administration of dexfenfluramine to obese patients improves glycemic control without affecting body weight (Andersen et al., 1993). However, shortly after dexfenfluramine was approved in 1996 by the FDA for the treatment of obesity, clinical reports emerged linking fenfluramine and dexfenfluramine to the development of pulmonary hypertension and valvular heart disease (Cannistra et al., 1997; Centers for Disease Control and Prevention (CDC), 1997; Connolly et al., 1997; Kurz and Van Ermen, 1997; Rasmussen et al., 1997). The increased prevalence of valvular regurgitation associated with the use of dexfenfluramine vanished 3-5 months after discontinuation of treatment (Weissman et al., 1999), but nevertheless prompted the manufacturer to voluntarily discontinue the commercialization of fenfluramine and dexfenfluramine in 1997 (Weissman et al., 1998).

4. Sibutramine. In 1997, the same year in which fenfluramine and dexfenfluramine were removed from the market, the FDA approved sibutramine, a serotonin and norepinephrine reuptake inhibitor, for the 
treatment of obesity. In contrast to other monoamine reuptake inhibitors, sibutramine has only little clinical relevance as an antidepressant (Bello and Liang, 2011), but lowers body weight via inhibition of food intake and stimulation of energy expenditure (Heal et al., 1998; McNeely and Goa, 1998; Nelson and Gehlert, 2006; Astrup, 2010). Placebo-subtracted weight loss attributed to treatment with sibutramine is dependent on dose and treatment duration and typically resides in the range of $1.7-4.8 \mathrm{~kg}(1 \%-5 \%)$, but with significantly more patients achieving the $5 \%$ and $10 \%$ weight loss threshold relative to placebo-treated controls (Fujioka et al., 2000; McMahon et al., 2000; Smith et al., 2001; Wooltorton, 2002; Yanovski and Yanovski, 2002; Hauner et al., 2004; Rucker et al., 2007). Weight loss induced by sibutramine is accompanied by improvements in fasting insulin, triglycerides, and high-density lipoprotein cholesterol, but notably with an increase in blood pressure (Fujioka et al., 2000; McMahon et al., 2000; Wooltorton, 2002; Yanovski and Yanovski, 2002) and, even more strikingly, an increased risk for a cardiovascular event such as a cardiac arrhythmia (Wooltorton, 2002; James et al., 2010). The relatively mild weight loss achieved by sibutramine together with an increased risk of cardiovascular adverse effects led the FDA in 2010 to withdraw sibutramine from distribution.

\section{F. Phentermine and Topiramate (Qsymia)}

Although commercialization of fenfluramine was discontinued in 1997 due to cardiovascular adverse effects, phentermine, when used together with other weight-lowering agents, remains approved for the treatment of obesity. It was in 2012, when the FDA approved Qsymia, the combination of phentermine and topiramate as adjunct to lifestyle modification for the treatment of obesity (Fig. 1). Topiramate is a sulphamate-substituted monosaccharide derived from D-fructose (Privitera, 1997; Shank and Maryanoff, 2008; Edvinsson and Linde, 2010) and is commonly used to treat epilepsy (Langtry et al., 1997; Privitera, 1997) and migraine (Storey et al., 2001; Adelman et al., 2008; Edvinsson and Linde, 2010; Linde et al., 2013). The use of topiramate for these clinical applications seems to reside in its ability to selectively decrease CNS neuronal activity via inhibition of certain neuronal $\mathrm{Ca}^{2+}$ channels (Martella et al., 2008) as well as to modulate central glutamate and GABA signaling (White et al., 2000; Edvinsson and Linde, 2010). When used as monotherapy, placebo-subtracted weight loss induced by topiramate typically ranges between $3.8 \%$ and $6.5 \%$ depending on the dose (Aronne et al., 2013). The exact mechanism(s) of how topiramate improves systemic metabolism remains a subject of ongoing investigations. In any case, when given as an adjunct to phentermine, weight loss of this combination is greater as treatment with phentermine or topiramate alone (Aronne et al., 2013). In line with this notion, placebo-subtracted weight loss induced by the phentermine-topiramate combination is typically in the range of 5.9\%-9.6\% (Garvey et al., 2012, 2014a,b; Winslow et al., 2012; Aronne et al., 2013), and is associated with an improvement in glucose management (Garvey et al., 2012, 2014a) and the cardiovascular risk profile (Garvey et al., 2012, 2014b).

\section{G. Orlistat}

Orlistat is a lipase inhibitor that limits the availability of fatty acids for absorption by inhibiting gastrointestinal lipase activity (Drent et al., 1995). The resulting fat malabsorption facilitates a negative energy state leading to a placebo-subtracted weight loss in the range of 2.6\% (Davidson et al., 1999; Khera et al., 2016). Orlistat has additional beneficial effects on glycemic control and nonalcoholic fatty liver disease (Hollander et al., 1998; Zelber-Sagi et al., 2006). The positive effects of orlistat on nonalcoholic fatty liver disease exceed what can be explained by changes in body weight alone (Zelber-Sagi et al., 2006). The glycemic benefits of orlistat can be potentiated by metformin coadministration (Miles et al., 2002). Most common adverse events are of gastrointestinal or digestive nature. In particular, issues with spontaneous defecation and abnormal fecal consistencies are frequently reported, but also deficiencies in fat-soluble vitamins have been linked to orlistat usage (Melia et al., 1996; McDuffie et al., 2002).

\section{H. Lorcaserin}

Lorcaserin (Belviq) is a selective serotonin $2 \mathrm{C}$ agonist, which has often been referred to as third-generation 5-HT-based anti-obesity pharmacology (Burke and Heisler, 2015). Lorcaserin has been reported to promote satiety to elicit a $3.2 \%$ placebo-subtracted body weight loss in overweight and obese adults (Smith et al., 2010; Khera et al., 2016). Mechanism of action presumably involves activation of hypothalamic POMC neurons (Xu et al., 2008; Berglund et al., 2013), without impacting energy expenditure (Martin et al., 2011). Lorcaserin modulates midbrain dopaminergic tone to suppress binge-related food intake (Higgins et al., 2016) and is now being tested for its ability to treat addictive disorders (Higgins and Fletcher, 2015; Shanahan et al., 2017). A series of CNS-related adverse events such as headache, dizziness, fatigue, and nausea have been linked to Lorcaserin treatment. Supporting the notion that the brain plays a seminal role in glycemic control, coadministration of Lorcaserin with metformin or sulfonylureas potentiates the ability of the antidiabetic agents to improve $\mathrm{HbA} 1 \mathrm{c}$ and fasting glucose levels in obese subjects with T2D (Moore, 1990). Preclinical studies have explored the prospect of combinatorial targeting of 5-HT2A/C receptors and GLP-1RAs (Anderberg et al., 2017), and it appears that the benefits of Lorcaserin can be increased in combinatorial settings. 


\section{Rimonabant}

Rimonabant antagonizes, by virtue of inverse agonism, the type I cannabinoid receptor (CB1R) to lower body weight by modulating neurons in both homeostatic and hedonic feeding circuits (Cota et al., 2006). Despite pronounced anti-obesity effects with a placebo-subtracted weight loss of $\sim 2.6-6.3 \mathrm{~kg}$ (Despres et al., 2005; Van Gaal et al., 2005; Pi-Sunyer et al., 2006), the clinical use of rimonabant was discontinued in 2009 due to serious adverse psychiatric effects (Sam et al., 2011). Notably, this termination was preceded by 2 years of approved medicinal use in Europe. The harmful psychiatric effects have been linked to the antagonizing effect of rimonabant on constitutively active CB1Rs in the ventral tegmental area, and in the amygdala (Meye et al., 2013). Before the clinical development was stopped, rimonabant showed promising effects to improve glycemic control and lessen cardiometabolic risk factors (Despres et al., 2005; Nissen et al., 2008; Van Gaal et al., 2008) Research continues to uncouple the metabolic benefits from the harmful events of CB1R targeting (Simon and Cota, 2017), providing hope that a new generation of safe and efficacious CB1R-based agonists might still be possible.

In summary, since the end of the 19th century, there have been a series of weight-lowering drugs of significant promise that have advanced for the treatment of obesity, and, with the exception of the most recent crop, they have largely failed in measures of chronic safety. Although limited by dose-dependent adverse effects, placebo-subtracted pharmacologically induced weight loss has typically been more than 5\%-10\%. This level of efficacy pales in comparison with bariatric surgery, but even this magnitude of weight loss can provide a clinically meaningful lessening of obesity-linked comorbidities, most notably $\mathrm{T} 2 \mathrm{D}$ and cardiovascular risk factors (Wing et al., 2011). The decrease in hepatic and intra-abdominal fat accumulation, the improvement of $\beta$-cell function, as well as enhanced insulin sensitivity in the liver, adipose tissue, and skeletal muscle, are observed with this degree of weight loss (Magkos et al., 2016; Heymsfield and Wadden, 2017). Nevertheless, the proverbial cup is less than half full, and, with the ever-growing burden that obesity and diabetes represent for modern societies, a much more effective and sustainable medicinal solution to complement surgical procedures is desperately needed.

\section{J. Leptin}

The adipocyte hormone leptin has like no other appetite-regulating hormone influenced our understanding of how peripheral endocrine signals integrate into the complex central network that controls energy metabolism. Leptin was identified by Jeffrey Friedman in 1994 by positional cloning of the mouse obese (ob) gene (Zhang et al., 1994). Leptin is primarily produced by white adipocytes, from where it is secreted into the general circulation in direct proportion to body fat mass. Leptin acts on the hypothalamic melanocortinergic system to decrease food intake and to increase energy expenditure by stimulating POMC neuronal activity while at the same time silencing neurons that express NPY and AgRP (Schwartz et al., 2000). Beyond its ability to decrease body weight, leptin exerts a remarkable variety of metabolic effects that, among many others, include the regulation of glucose metabolism (Pelleymounter et al., 1995; Hedbacker et al., 2010), stress and anxiety (Haleem, 2014), reproduction (Hebebrand et al., 2007; Müller et al., 2009), inflammation, and hematopoiesis (Fantuzzi and Faggioni, 2000; Zhang and Wang, 2014).

Notably, the discovery of leptin not only identified the adipose tissue as an endocrine organ, it also shaped our understanding of how lipid metabolism can be targeted pharmacologically. Soon after its discovery, leptin was shown to reverse obesity and to improve insulin sensitivity of leptin-deficient ob/ob mice (Campfield et al., 1995; Halaas et al., 1995; Pelleymounter et al., 1995; Hedbacker et al., 2010). These studies created much excitement for the pharmacological use of leptin to treat human obesity. Indeed, exogenous supplementation of leptin corrects obesity in individuals with otherwise low to absent endogenous levels of leptin, such as in ob/ob mice (Campfield et al., 1995; Halaas et al., 1995; Pelleymounter et al., 1995), congenitally leptin-deficient humans (Montague et al., 1997; Farooqi et al., 1999, 2002; Licinio et al., 2004), and individuals with lipodystrophy (Shimomura et al., 1999; Oral et al., 2002; Petersen et al., 2002; Ebihara et al., 2007; Chong et al., 2010). Unfortunately, however, exogenous administration of leptin is largely ineffective to decrease body weight under coditions of common obesity, which is lifestyle/dietary-induced and does not result from a loss-of-function mutation in a single key metabolic gene (Heymsfield et al., 1999; Hukshorn et al., 2000). Such leptin resistance is limiting the use of leptin as a standalone therapy to treat obesity (Hukshorn et al., 2000, 2002; Westerterp-Plantenga et al., 2001). The mechanisms underlying the development of leptin resistance are complex and object of intense scientific investigation. Potential mechanisms include impaired leptin transport across the blood brain barrier (Caro et al., 1996; Banks et al., 1999) or impaired leptin signaling in first- or second-order CNS neurons (El-Haschimi et al., 2000; Wilsey et al., 2003; Münzberg et al., 2004). Dietary fat and sugar seem to be crucial factors leading to leptin resistance, and leptin resistance can occur even before the onset of obesity and hyperleptinemia (Wang et al., 2001; Vasselli, 2008, 2012; Vasselli et al., 2013). Impaired levels of phosphorylated signal transducer and activator of transcription 3 (p-STAT3) can be observed in the arcuate nucleus as early as after 6 days of high-fat diet (HFD) exposure (Münzberg et al., 2004), and even short-term overfeeding of normal weight rats 
is sufficient to induce leptin resistance (Wang et al., 2001). In mice, administration of leptin is incapable of preventing the development of obesity when lean mice are switched to a high-sugar HFD at the beginning of the leptin therapy (Müller et al., 2015). In mice, chronic HFD exposure has further been demonstrated to decrease in the number of POMC-positive neurons in the arcuate nucleus (Thaler et al., 2013).

Although the pharmacological use of leptin as a stand-alone therapy to treat obesity is hampered by leptin resistance, leptin is still a valuable constituent for more advanced pharmacological approaches. In line with this notion, adjunct administration of leptin with amylin (Roth et al., 2008), fibroblast growth factor 21 (FGF21), exendin4 (Müller et al., 2012), or a GLP-1/glucagon coagonist (Clemmensen et al., 2014) has all been demonstrated to decrease body weight in diet-induced obese (DIO) rodents beyond what is possible with either compound monotherapy alone. Notably, although the restoration of leptin responsiveness induced by amylin, FGF21, or exendin4 required discontinuation of HFD exposure (Müller et al., 2012; Trevaskis et al., 2016), the GLP-1/glucagon coagonist even improved leptin sensitivity under chronic and persistent exposure of mice to a high-sugar HFD comprising 58\% kcal fat (Clemmensen et al., 2014). Also, ER stress has been demonstrated to play a causal role in the development of leptin resistance (Ozcan et al., 2009), and several plant-derived substances, such as celastrol (Liu et al., 2015) and withaferin A (Lee et al., 2016a), have been demonstrated to correct obesity and deranged glycemic control by improving leptin sensitivity in DIO rodents.

\section{From Glucagon-Like Peptide 1 Monoagonism to Multimode Incretin-Based Pharmacology}

Historical pharmacotherapies to treat obesity and T2D were often based on the exogenous supplementation of tissue homogenates or extracts obtained and isolated from experimental animals. Many seminal discoveries are based on these crude applications and have collectively primed our understanding of how key endocrine factors promote their biologic action, including how they get transported in and cleared from the circulation. A prominent example is, for example, the observation that pig-derived intestinal mucose homogenate decreases glucosuria in patients with diabetes, suggesting that gastrointestinal hormones regulate pancreatic glucose metabolism (Moore, 1906). Other examples include the use of sheep-derived thyroid extracts to lower body weight (McCone, 1897) or the famous studies showing that administration of pancreatic extracts lowers blood glucose in diabetic dogs and rabbits (Kleiner, 1919; Paulescu, 1921; Banting et al., 1922), seminal observations that subsequently led to the isolation of insulin in 1921 (Banting et al., 1922) and to the identification of glucagon in 1923 (Kimball and Murlin, 1923). Although a series of groundbreaking discoveries are based on the exogenous supplementation of native hormones, such strategy did not translate into a pharmacotherapy capable of satisfactorily decreasing body weight. However, together with constant refinements in biochemial procedures, such as solidphase peptide synthesis, the knowledge obtained by these historical studies translates nowadays into the ability to synthetically develop pharmaceuticals that differ from the native hormones by improved efficacy and sustained action due to, for example, delayed degradation and clearance from the circulation. Of particular interest emerged biomolecules targeting the receptor for GLP-1.

\section{A. Optimized Glucagon-Like Peptide 1 Monoagonists}

A common approach to improve the metabolic benefits of a drug is through refinement of pharmacokinetics. Factors influencing pharmacokinetics typically alter the fate of a drug after its administration, including effects on its liberation from a formulation, followed by its absorption into the general circulation, systemic distribution, metabolic processing, and eventually excretion. In the second half of the last century, a set of complementary chemical and biochemical methods emerged, such as solid-phase peptide synthesis, that provided for the first time the ability to produce and structurally refine macromolecules for therapeutic purposes. Given the seminal importance of insulin, it emerged as a first target for production of the human form of the hormone, followed by chemical analogs that accelerated or prolonged pharmacology following a single injection. Similar technology has been applied to deliver GLP-1 in quantity, quality, and with structural refinement to support therapeutic application as a once-a-day or less frequently administered medicine. The progression of GLP-1 pharmacology to singlemolecule polyagonists that possess additional hormone action of differentiated mechanism has been repeatedly reported in recent years to achieve superior metabolic action.

Secreted from intestinal L-cells upon exposure to food, GLP-1 acts at the pancreas to enhance the expression and secretion of insulin (Drucker et al., 1987; Kreymann et al., 1987; Mojsov et al., 1987), and to inhibit the release of glucagon (Schirra et al., 2006). Beyond its role as an insulin secretagogue, GLP-1 agonism can lead to decreases in body weight via central-mediated inhibition of food intake (Sisley et al., 2014a,b; Burmeister et al., 2017). Additionally, it can decrease hepatic glucose output via inhibition of gluconeogenesis (Valverde et al., 1994; Alcantara et al., 1997; Prigeon et al., 2003; Lee et al., 2007), improve insulin sensitivity in skeletal muscle (Idris et al., 2002; Gonzalez et al., 2005), slow gastric emptying (Willms et al., 1996), improve cardiac performance (Sonne et al., 2008; Timmers et al., 2009), 
act upon the immune system to decrease inflammation, and stimulate $\beta$-cell proliferation and islet mass in rodents (Edvell and Lindstrom, 1999; Wang et al., 1999; Stoffers et al., 2000; Farilla et al., 2002; Rolin et al., 2002; Hui et al., 2003). The numerous beneficial effects of GLP-1 are highlighted in several comprehensive review articles (Drucker, 2006, 2016; Holst, 2007; Sivertsen et al., 2012; Campbell and Drucker, 2013; Sandoval and D'Alessio, 2015).

The ability of GLP-1 receptor agonism to lower body weight and improve glucose metabolism has been well confirmed in numerous preclinical and clinical studies. However, the native hormone demonstrates a very short half-life measured in minutes when administered to humans by i.v. infusion or s.c. injection (Hui et al., 2002). The most rapid inactivation of GLP-1 is mediated by the dipeptidylpeptidase IV (DPP-IV), which cleaves a dipeptide from the $\mathrm{N}$ terminus of the native peptide to yield an inactive GLP-19-36 amide or GLP-1 ${ }_{9-37}$ (Mentlein et al., 1993; Deacon et al., 1995; Kieffer et al., 1995). Once structurally optimized for improved bioavailability and sustained action, a variety of GLP-1 analogs has advanced to regulatory approval. These medicines include exenatide (Byetta; AstraZeneca, Cambridge, UK), lixisenatide (Lyxumia; Sanofi, Paris, France), liraglutide (Victoza; Novo Nordisk, Copenhagen, Denmark), dulaglutide (Trulicity; Eli Lilly \& Co., Indianapolis, IN), and albiglutide (Tanzeum; GlaskoSmithKline, Middlesex, UK). Semaglutide (Novo Nordisk, Copenhagen, Denmark) is a late-stage, longacting structural refinement related to liraglutide that when coformulated with suitable absorption enhancers is reported to be active in oral application (Gotfredsen et al., 2014; Finan et al., 2015a; Kapitza et al., 2015; Ahren et al., 2017; Blundell et al., 2017).

Exenatide (AstraZeneca, Cambridge, UK) is a 39-amino-acid GLP-1 paralog first identified in the venom of the gila monster (Heloderma suspectum). A glycine residue at the second $\mathrm{N}$-terminal amino acid protects the peptide from DPP-IV inactivation, whereas a nine-amino-acid C-terminal extension (CEX) improves the chemical stability by enhancing secondary structure (Neidigh et al., 2001) (Fig. 2). Lixisenatide (Sanofi, Paris, France) is a 44-amino-acid derivate of exenatide, where the proline at residue 39 of exenatide is omitted and the $\mathrm{C}$ terminus is extended with six additional lysine residues (Thorkildsen et al., 2003) (Fig. 2). Lixisenatide when compared with exenatide demonstrates a slightly enhanced potency to activate the GLP-1 receptor and a near doubling in half-life of 4 hours (Finan et al., 2015a). Unlike the first two GLP-1 analogs, Liraglutide (Novo Nordisk, Copenhagen, Denmark) is an analog based upon the native GLP-1 sequence, but with the exception that the lysine at residue 28 is replaced with arginine (Fig. 2). Liraglutide is palmitoylated (C16:0) at the side chain of lysine 20 via a $\gamma$-glutamic acid spacer. The benefits of this C16 fatty acylation are twofold and pertain to proteolytic stability and time action. Despite being of native sequence, liraglutide is much less susceptible to DPP-IV proteolysis and the fatty acid promotes formation of a self-associated, multimolecular complex at the site of injection to slow diffusion from the site of injection. Furthermore, the palmitic acid facilitates the noncovalent association of the peptide to albumin, resulting in delayed renal clearance and an extended half-life, which in humans is $\sim 12$ hours (Agerso et al., 2002). Semaglutide (Novo Nordisk) is a chemically optimized analog of liraglutide with enhanced pharmacological properties. A dicarboxylic-stearic acid (C18:0) is linked to the lysine 20 residue through a $\gamma$ glutamic acid spacer in a chemical manner that enhances the noncovalent binding to albumin to further decelerate renal clearance (Lau et al., 2015). This enhanced plasma binding results in enhanced pharmacokinetics such that semaglutide manifests a half-life of 160 hours after s.c. injection in humans (Gotfredsen et al., 2014). To support the extended time action, the native alanine at the second residue is substituted with an aminoisobuturic acid (Aib) to further protect against DPP-IV inactivation (Fig. 2). Dulaglutide (Eli Lilly \& Co., Indianapolis, IN) is a biosynthetically manufactured, fusion protein comprising two GLP-1 derivatives, each linked to a human Fc fragment of IgG4 to form a dimeric antibodylike protein (Fig. 2). The GLP-1 agonist employed in dulaglutide has a glycine at the second residue to lessen DPP-IV cleavage. Substitution to glutamic acid at position 16 further enhances the secondary structure and potency, whereas glycine at position 30 serves as the junction point to a linking peptide that connects to the IgG Fc fragment (Glaesner et al., 2010). The Fc fragment improves bioavailability of the protein by slowing down its renal clearance. The half-life in humans is reported to be to 90 hours and supports once-weekly administration (Barrington et al., 2011). Albiglutide possesses a 60 -amino-acid repeating dimeric agonist where the $\mathrm{C}$ terminus of the first GLP-1 agonist is linearly fused to the $\mathrm{N}$ terminus of the second (Fig. 2). As employed elsewhere, a glycine at the second position of each agonist minimizes DPP-IV inactivation, and C-terminal covalent coupling of the dimeric agonist to human albumin reduces renal clearance, to provide a half-life reported to be $\sim 120$ hours in humans (Bush et al., 2009).

Collectively, these structurally optimized GLP-1 agonists form a class of drugs with potency that varies by more than 10-fold and duration of action suitable for twice-daily to once-weekly s.c. injection. As a class, these GLP-1 analogs provide a sizable and clinically meaningful improvement in glycemic control (Juhl et al., 2002; Chang et al., 2003; Degn et al., 2004; Vilsbøll et al., 2007), and with little to no risk of hypoglycemia (Vilsbøll et al., 2007; Irie et al., 2008; Seino et al., 2008). Although improvement in glucose metabolism has been repeatedly confirmed in 
GLP-1 ${ }_{(7-36)}$ amide

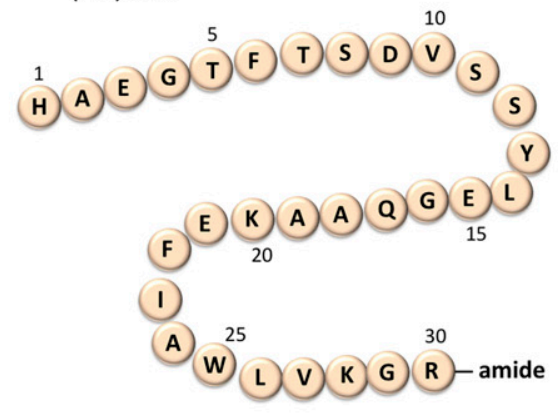

Liraglutide

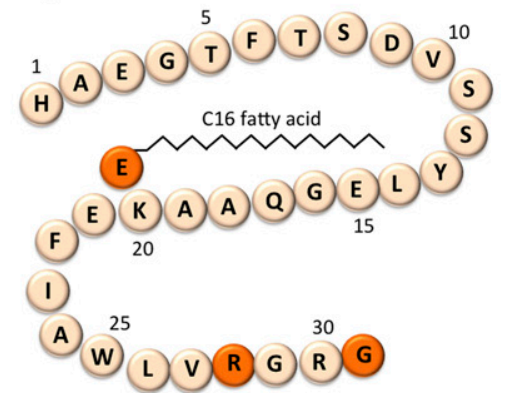

\section{Semaglutide}

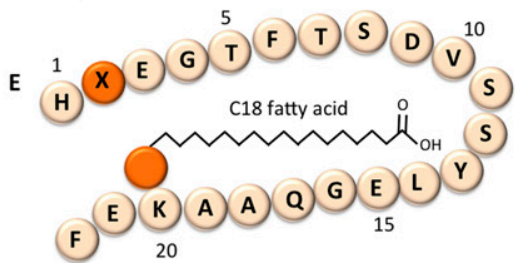

(1)

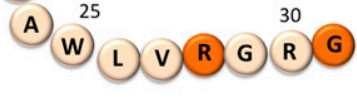

\section{Exendin-4}

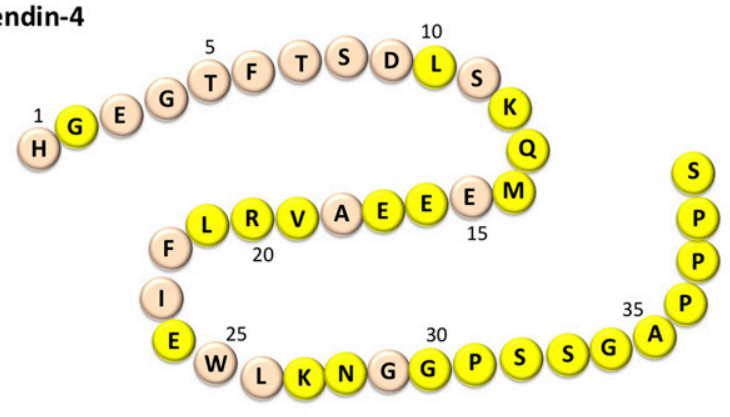

Lixisenatide

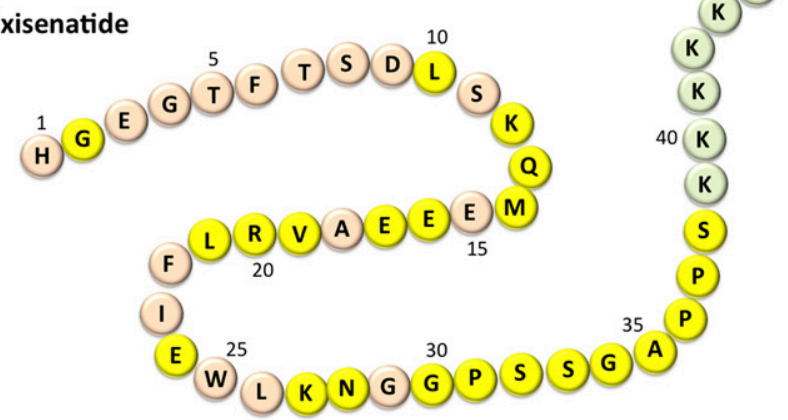

Dulaglutide
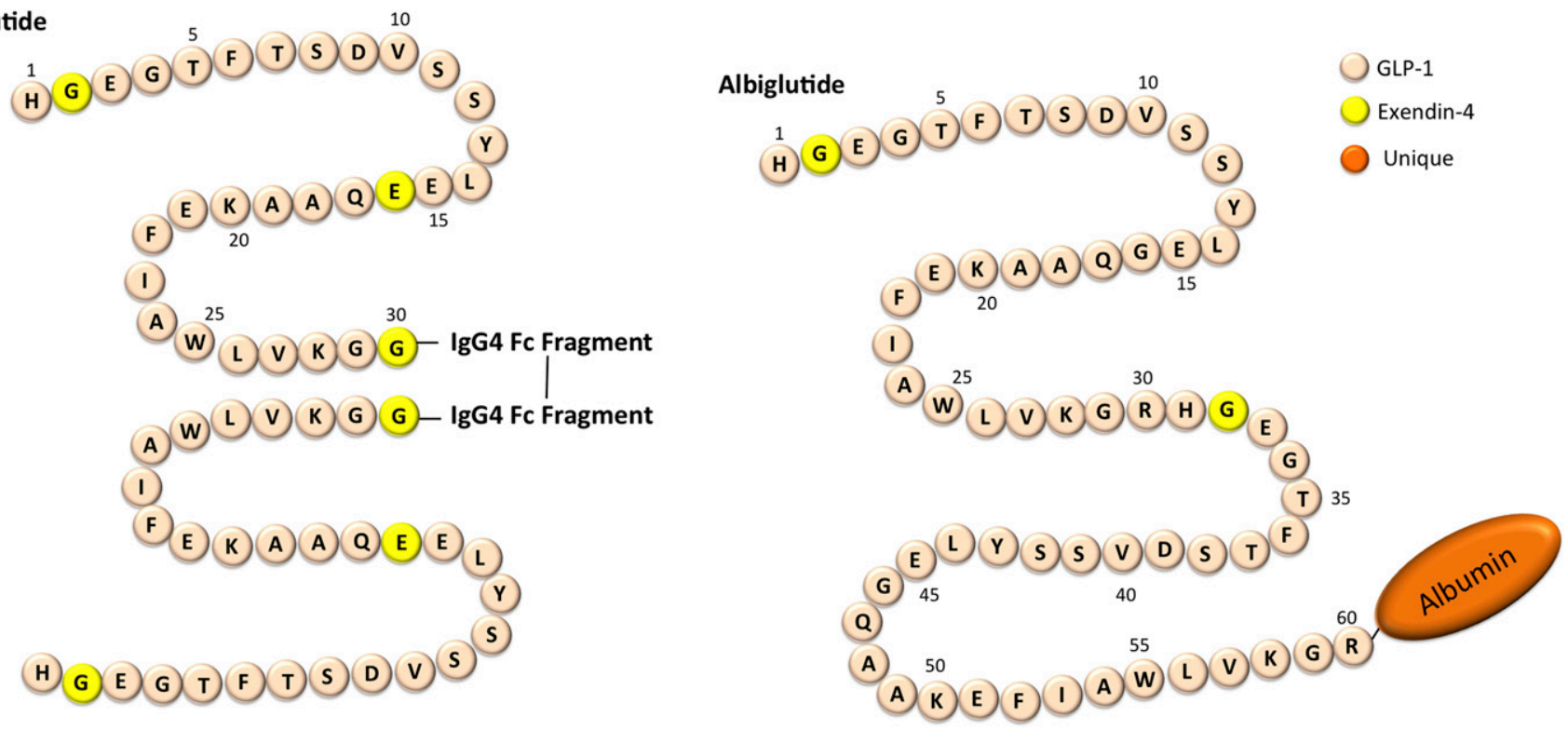

Fig. 2. Schematic of the GLP-1 derivatives approved by the FDA for the treatment of diabetes.

numerous preclinical and clinical studies, higher doses of GLP-1 are required to achieve a meaningful decrease in body weight. Furthermore, GLP-1 agonism confers dose-dependent gastrointestinal adverse effects that serve to limit the therapeutic intensity (Peters, 2013; Bettge et al., 2017). Nevertheless, when used as an adjunct to lifestyle changes, Saxenda (3 mg liraglutide; Novo Nordisk) is approved by the FDA for treatment of obesity. The mean weight loss attributed to Saxenda is $8.4 \mathrm{~kg}$ after 56 weeks of treatment, relative to $2.8 \mathrm{~kg}$ in placebo-treated controls (Pi-Sunyer et al., 2015), with a finite degree of patients achieving more than $10 \%$ absolute body weight reduction.

\section{B. Coadministration of Single Hormones}

Most single-hormone pharmacotherapies evaluated for the treatment of obesity show limited efficacy to lower body weight, typically less than $5 \%$ and rarely more that $10 \%$ relative to placebo-controlled comparison treatment. It seems intuitive to expect that administration of more than one drug, each given at a tolerable dose, might further improve outcomes beyond what is otherwise possible with either hormone alone. Ideally, the 
combinatorial approach would synergistically improve metabolism to a greater degree than the sum of the individual therapies alone. Such a polypharmacologic approach has in principle been practiced historically by physicians when prescribing the so-called rainbow pills and, in a most controlled fashion, the use of Qysmia (combination of phentermine and topiramate). More recent preclinical examples include the combination of leptin with the amylin analog named pramlintide (Roth et al., 2008; Trevaskis et al., 2008, 2010; Chan et al., 2009; Turek et al., 2010), or the combination of leptin with exendin-4 or FGF21 (Müller et al., 2012). In all of these studies, the combination of leptin with amylin, FGF21, or exendin-4 improved weight loss synergistically in diet-induced obese rodents when compared with treatment with the respective monotherapies. Other preclinically evaluated GLP-1-based combination therapies include the salmon calcitonin with exendin-4 (Bello et al., 2010), GLP-1 with PYY (Neary et al., 2005), exenatide with CCK (Trevaskis et al., 2015), and liraglutide with an melanocortin 4 receptor agonist (setmelanotide, RM-493) (Clemmensen et al., 2015), which has recently been shown to correct obesity in POMC-deficient humans (Kuhnen et al., 2016). In all of these reports, the combination therapy demonstrated metabolic benefits greater than what can be achieved by the respective hormone monotherapies.

\section{Unimolecular Multiagonism: Closing the Gap to Bariatric Surgery}

GLP-1 constitutes an appealing target upon which more advanced pharmacological approaches might be built that employ the action of complementary metabolic hormones to a single unimolecular entity. Similar to physical coadministration of single hormones, the basic idea in using a single molecule of dual activity remains common to the belief that simultaneous, complementary biologic mechanisms should enhance metabolic benefits while minimizing adverse effects. One might question whether a single-molecule multiagonist is preferable to administration of multiple independent hormones. The central biologic difference resides in each single hormone possessing a unique pharmacokinetic profile. Consequently, within a comixture, the simultaneously injected hormones differ in rates of absorption, distribution, metabolism, and clearance. Single-molecule polyagonists are ideally suited to function at single target sites where, when possible, they might deliver synergistic or complementary pharmacology. The performance difference that might be obtained is near impossible to predict and needs to be experimentally assessed.

\section{A. Glucagon-Like Peptide 1/Glucagon Coagonism}

A provocative approach was the development of a single molecule that recruits the full pharmacology of glucagon along with GLP-1 for the purpose of treating obesity and glucose intolerance (Day et al., 2009) (Fig. 3). At first glance, the combined agonism at the GLP-1 and glucagon receptors seems counterintuitive in providing powerful, but opposing effects on glycemia. Indeed, the most acknowledged metabolic effect of glucagon is its ability to acutely increase glucose levels, given its direct action at the liver to stimulate gluconeogenesis and glycogenolysis (Jiang and Zhang, 2003; Müller et al., 2017). Consistent with this effect is the demonstration that persistent, excessive glucagon action leads to hyperglycemia and eventually T2D. Reports from Roger Unger and associates in 1970 showed that glucosemediated inhibition of glucagon secretion is impaired in patients with T2D (Müller et al., 1970; Unger et al., 1970). This is a seminal observation that was later confirmed by several independent research groups (Gerich et al., 1976; Felig et al., 1978; Butler and Rizza, 1991; Kelley et al., 1994). Subsequent studies showed that somatostatin-induced inhibition of postprandial glucagon secretion ameliorates hyperglycemia in patients with T2D (Gerich et al., 1974; Dinneen et al., 1995; Shah et al., 2000), and more recently that blocking glucagon action decreases hyperglycemia in a variety of species, including rodents (Mu et al., 2011; Kim et al., 2012b; Okamoto et al., 2017), rabbits (Brand et al., 1996), dogs (Rivera et al., 2007), nonhuman primates (Xiong et al., 2012; Okamoto et al., 2015), and humans (Petersen and Sullivan, 2001; Kelly et al., 2015; van Dongen et al., 2015; Kazda et al., 2016; Kostic et al., 2018). The virtues and limitations of antagonizing glucagon signaling for the treatment of diabetes have recently been highlighted in several review articles (Unger and Cherrington, 2012; Farhy and McCall, 2015; Lee et al., 2016b; Müller et al., 2017), with the implication that excess glucagon action can serve a greater role in the pathology of T2D than impaired insulin action (Unger and Cherrington, 2012). In summary, there is substantial evidence directing inhibition of glucagon action as opposed to enhancing it for the treatment of T2D.

The acute hyperglycemic effect of glucagon argues against its pharmacological use to address excess body weight. However, the glucocentric view of glucagon overshadows the other beneficial effects that it could serve beyond glucose management (Müller et al., 2017). Glucagon acts on the brain to decrease food intake (Salter, 1960; de Castro et al., 1978; Billington et al., 1991); it increases energy expenditure through stimulation of brown fat thermogenesis (Joel, 1966; Kuroshima and Yahata, 1979; Doi and Kuroshima, 1982), inhibits gastric motility (Watanabe et al., 1982; Mochiki et al., 1998; Shibata et al., 2001), decreases fat accumulation via stimulation of lipolysis and inhibition of lipid synthesis (Caren and Corbo, 1960; Salter et al., 1960; Paloyan and Harper, 1961; Amatuzio et al., 1962; De Oya et al., 1971; Eaton, 1973), can improve cardiac performance (Whitehouse and James, 1966; 


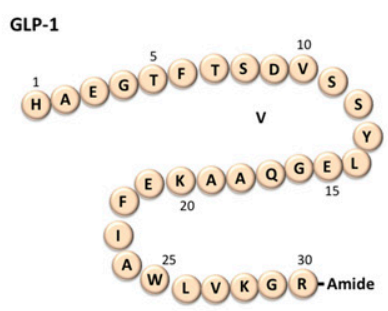

GLP-1/Glucagon co-agonist (Day et al., 2009)

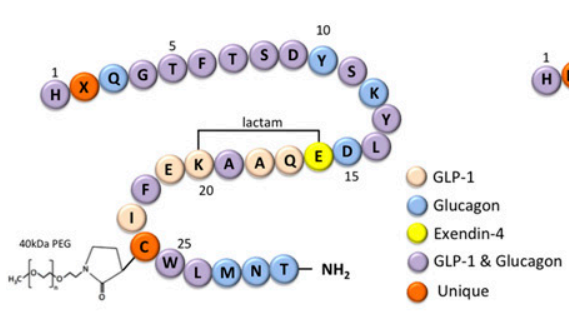

GLP-1/Glucagon co-agonist (Pocai et al., 2009)
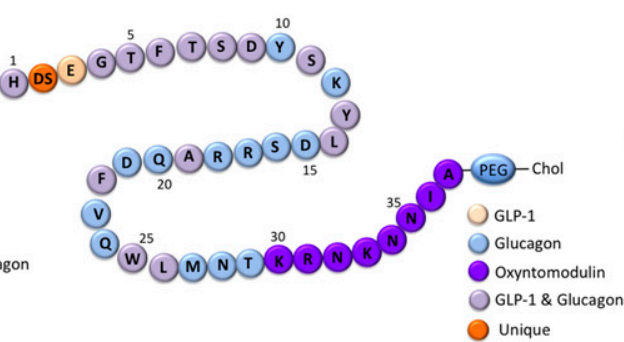

GLP-1/GIP co-agonist (Finan et al., 2013) (Acylated Version)

GLP-1/Glucagon co-agonist (Evers et al., 2017)
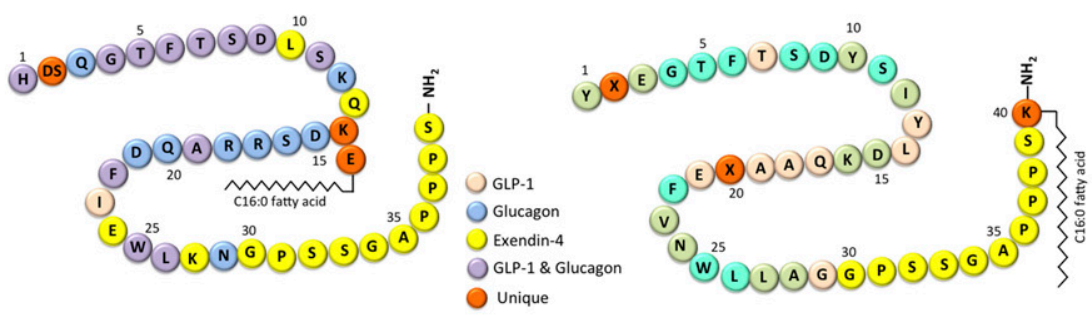

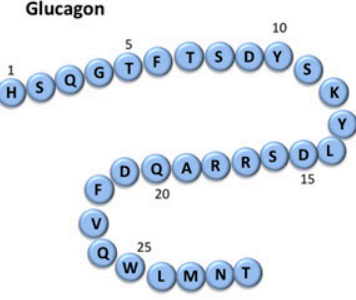

(8)
Oxyntomodulin

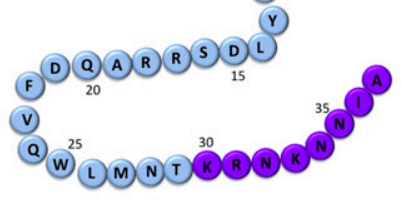

Glucagon

Oxyntomodulin
GLP-1/Glucagon co-agonist (Henderson et al., 2015)

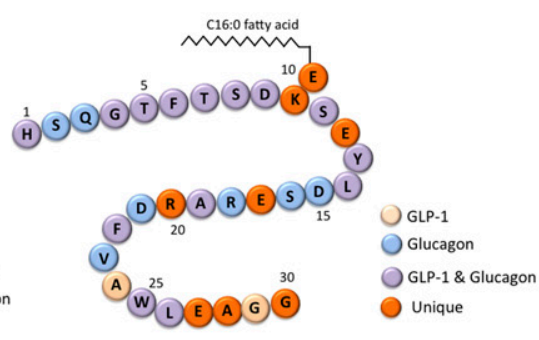

GLP-1/GIP/Glucagon triagonist (Finan et al., 2015)

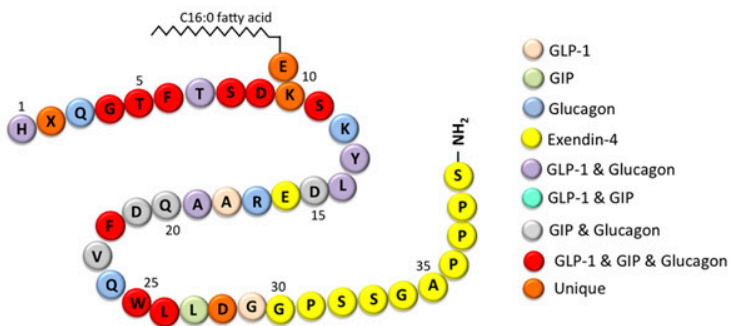

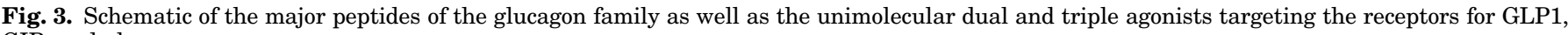
GIP, and glucagon.

Glick et al., 1968; Laraia et al., 1968; Lucchesi, 1968; Katz et al., 1969), and stimulates autophagy (Deter and De Duve, 1967; Arstila and Trump, 1968; Guder et al., 1970; Deter, 1971). Collectively, these nonglycemic effects render glucagon an interesting candidate for pharmacological management of body weight. However, beyond the central dilemma of its diabetogenic liability resides the fact that glucagon is poorly suited as a drug substance, given its short duration of action, poor aqueous solubility, and chemical stability at physiologic pH (Gratzer et al., 1972; Chabenne et al., 2010). The solubility of glucagon in physiologic buffer can be dramatically improved by extension of its sequence at the $\mathrm{C}$ terminus with the CEX terminal end of exendin-4 (Li et al., 2007; Chabenne et al., 2010). Chronic s.c. infusion of DIO mice with glucagon-CEX in physiologic buffer improved body weight and glycemic control with equal efficacy when compared with equimolar administration of exendin-4 (Müller et al., 2017). This observation made in 2006 was seminal to the realization that glucagon could be used to improve body weight and metabolic control, but also emphasized that it possessed a narrow therapeutic index. Consequently, in search of a means to enhance its efficacy and broaden its safety 
emerged the development of unimolecular peptides with full, balanced activity at the receptors for each of these peptide hormones.

Collaborative academic research conducted in the DiMarchi and Tschöp laboratories led to the discovery of a set of peptides of varying degrees of GLP-1 and glucagon coagonism (Day et al., 2009). Conceptually these molecules were based on the assumption that the beneficial glycemic effects of GLP-1 would restrain the hyperglycemic potential of glucagon, whereas the anorectic effect of central GLP-1 agonism would complement glucagon's own anorectic, lipolytic, and thermogenic properties to maximize body weight loss. Fortuitously, these two hormones have high sequence homology, which facilitated the search for full potency, balanced coagonists. The fact that selective recognition of glucagon and GLP-1 by their cognate receptors could be modulated through the exchange of specific amino acids at the peptide terminal ends was something first reported a decade earlier (Hjorth et al., 1994).

The initial GLP-1/glucagon coagonists studied by DiMarchi, Tschöp, and colleagues were glucagonbased in which amino acids 17, 18, 20, 21, and 23 were substituted to the respective GLP-1 residues (Day et al., 2009). The alanine at position 2 of the peptide was substituted with Aib to protect the molecule from DPP-IV inactivation, and a lactam bridge was introduced between glutamic acid 16 and lysine 20 to covalently stabilize the secondary structure to enhance glucagon receptor (GcgR) potency (Fig. 3). To support in vivo studies, a $40-\mathrm{kDa}$ polyethylene glycol (PEG) was site-specifically attached to the side of cysteine 24 to prolong in vivo action. The resulting peptide maintained nearly balanced coagonism at both receptors. It was highly soluble in physiologic buffer $(>25 \mathrm{mg} /$ $\mathrm{ml}$ ) and chemically stable for more than 1 week when incubated in plasma. Despite being slightly less potent than the native hormones, the potency to activate both receptors was still subnanomolar, rendering it a suitable candidate for initial preclinical testing. Onceweekly administration for 4 weeks in diet-induced obese mice $\left(70 \mathrm{nmol} \mathrm{kg}^{-1}\right)$ of this nearly balanced dual agonist was sufficient to correct diet-induced obesity and hepatic steatosis, while improving glucose tolerance and cholesterol metabolism. Notably, the dual agonist showed much superior metabolic action relative to a structurally similar (no lactam bridge) analog with otherwise comparable pharmacokinetics and GLP-1 potency, but reduced 10 -fold in glucagon activity. Weight loss induced by the dual agonist was predominantly due to decreased body fat mass and was accompanied by lower food intake and elevated energy expenditure. The solid increase in energy expenditure was in line with published reports on glucagon agonism (Joel, 1966; Kuroshima and Yahata, 1979; Doi and Kuroshima, 1982) and was not observed with a GLP-1-selective molecule without GcgR agonism.
These observations are consistent with GLP-1's anorectic effect integrated with glucagon's capacity to increase thermogenesis. To a lesser magnitude relative to what was observed in obese wild-type mice, the dual agonist also lowered body weight in mice lacking the GLP-1 receptor, thus corroborating that GcgR agonism is a valuable constituent to the combined pharmacology (Day et al., 2009). Of appreciable note, GLP-1/ glucagon dual agonism also effectively lowers body weight and improves glycemia in nonhuman primates (Tschop et al., 2016), an important observation later also confirmed with another GLP-1/glucagon dual agonist (Henderson et al., 2016). Another interesting and unexpected finding was the ability of such a dual agonist to improve leptin sensitivity of DIO mice, despite continued chronic exposure of the mice to a high-sugar HFD (Clemmensen et al., 2014). In this dietary paradigm, physical combinations of leptin and exendin-4 or FGF21 had failed to similarly improve leptin sensitivity (Müller et al., 2012), implying a synergistic pharmacology inherent to a single-molecule coagonism.

The initial 2009 coagonist report was received with healthy scientific skepticism, but the independent confirmation at other research sites and the translation from obese rodents to nonhuman primates have supported the advancement of the concept to human studies (Day et al., 2009, 2012; Pocai et al., 2009; Henderson et al., 2016). Separately, low-dose coinfusion of GLP-1 and glucagon has been demonstrated to decrease food intake (Cegla et al., 2014) and to increase energy expenditure in humans (Tan et al., 2013). Several unimoleculer GLP-1/glucagon dual agonists that vary in the relative ratio of the two activities are currently in clinical evaluation for the treatment of obesity and diabetes (Finan et al., 2015a; Brandt et al., 2018).

It is worth noting that, independent of the directed synthesis of glucagon-GLP-1 coagonists, work with oxyntomodulin was occurring. This peptide is an endogenous precursor to glucagon of much lower inherent potency, and less balanced in GLP-1 agonism. In a chemical sense, oxyntomodulin constitutes an eight-amino-acid C-terminal extension to glucagon (Fig. 3). It is cosecreted with GLP-1 from intestinal L-cells. As demonstrated by in vitro studies and in isolated tissue samples, oxyntomodulin (OXM) is able to bind and activate both GLP-1R and GegR, but with a 10- to 100-fold lower affinity relative to native GLP-1 and glucagon (Bataille et al., 1982; Baldissera et al., 1988; Gros et al., 1995; Schepp et al., 1996; Jorgensen et al., 2007). OXM reduces food intake and lowers body weight in rodents (Dakin et al., 2001, 2002, 2004) and humans (Wynne et al., 2005, 2006). Notably, OXM inhibition of food intake is abrogated in mice lacking GLP-1R (Baggio et al., 2004; Sowden et al., 2007) but is preserved in mice lacking GcgR (Baggio et al., 2004), suggesting that OXM inhibition of food intake is mediated via only by the GLP-1 receptor. However, side-by-side comparison of OXM to a molecule in which 
the GcgR activity of OXM had been completely removed showed a superior ability of OXM to lower body weight and fat mass. This suggests that the glucagon receptor activity of OXM is a participant in pharmacologically induced weight loss (Kosinski et al., 2012).

Just a few days after the Day et al. (2009) GLP-1/ glucagon coagonist publication, the research group at Merck reported the development of an OXM-based peptide with glucagon and GLP-1 agonism (Pocai et al., 2009). Relative to native OXM, this DualAG peptide showed improved pharmacokinetics and comparable potency to activate GLP-1R and GcgR. A 14-day treatment of DIO mice decreased body weight and improved glucose metabolism. Notably, improvement of systemic metabolism by this DualAG peptide (Fig. 3) was abolished in mice lacking either the GLP-1R or GcgR. This confirmed the complementary activity of this molecule at both receptors when used at pharmacological levels (Pocai et al., 2009). From this point, the chemical optimization of OXM has been guided by the higher inherent potency in glucagon-based analogs, without any apparent need for the cationic C-terminal extension found in nature. To what degree OXM functions endogenously as a physiologic coagonist to modulate glucose and body weight remains an unanswered question, but, given its low inherent bioactivity coupled with the low plasma concentrations, its primary function appears to be the historically viewed biosynthetic precursor to glucagon. Following their introduction in 2009 (Day et al., 2009), several dual agonists targeting the receptors for GLP-1 and glucagon have been developed (Fig. 3) and their efficacy translates from obese rodents to nonhuman primates and humans (Day et al., 2009; Pocai et al., 2009; Henderson et al., 2016; Tschop et al., 2016; Evers et al., 2017).

\section{B. Glucagon-Like Peptide 1/Amylin Coagonism}

Islet amyloid polypeptide is a 37-amino-acid peptide produced and cosecreted with insulin from the pancreatic $\beta$-cells, which is more commonly named amylin. Like insulin, circulating levels of amylin are positively correlated to levels of blood glucose and consequently low in hypoglycemia (Mitsukawa et al., 1990), largely absent in individuals with type 1 diabetes (Clark et al., 1990; Hartter et al., 1990; Ogawa et al., 1990; BrethertonWatt et al., 1991; Young, 2005), and, depending on the progression of the disease, elevated or decreased in individuals with T2D (Cooper et al., 1987, 1988; Westermark et al., 1987; Johnson et al., 1989; Enoki et al., 1992). It is cosecreted with insulin, and, upon glucose stimulation, amylin returns signal back to the $\beta$-cells to suppress insulin secretion, under basal conditions (Silvestre et al., 1990) and after stimulation with either glucose (Ohsawa et al., 1989; Silvestre et al., 1990) or arginine (Inoue et al., 1993). Beyond its ability to regulate the release of insulin, amylin decreases gastric acid secretion, delays gastric emptying, and inhibits glucagon secretion (Woods et al., 2006; Lutz, 2010a,b). Upon central or peripheral administration, amylin dosedependently decreases body weight via inhibition of food intake (Chance et al., 1991; Lutz et al., 1994; Lutz, 2010b). Given its systemic metabolic effects, as expected blocking amylin signaling either through administration of an amylin receptor antagonist (Rushing et al., 2001) or through genetic ablation of amylin (Lutz, 2005) increases food intake and body weight in rodents. Amylin's anorectic action seems to be mediated in the area postrema because selective administration of amylin to this region decreases food intake, whereas lesion of the area postrema blocks amylin's anorectic effect (Lutz et al., 1998; Riediger et al., 2001, 2004; Becskei et al., 2007; Mack et al., 2010). Pramlintide (Amylin Pharmaceuticals, San Diego, CA) is a synthetic amylin analog in which the human amylin sequence has been modified to include prolines at residues 25,28 , and 29 , as occurs in rat sequence. It is a registered medicine for the treatment of diabetes, and treatment with insulin has proven to improve glucose metabolism in individuals with type 1 diabetes (Thompson et al., 1997b; Weinzimer et al., 2012; Herrmann et al., 2013) and as an independent agent in T2D (Thompson et al., 1997a; Riddle et al., 2007). The mechanism of action includes a slowing of gastric motility (Kong et al., 1997, 1998) and inhibition of glucagon secretion (Nyholm et al., 1999; Levetan et al., 2003).

Calcitonin and amylin biochemically signal through a common family of G protein-coupled receptor family B receptors. Intramuscular coadministration of salmon calcitonin with exendin-4 synergistically lowers food intake in nonhuman primates (Bello et al., 2010), an observation that inspired the development of unimolecular peptide hybrids (phybrids) targeting the receptors for GLP-1 and amylin (Sun et al., 2013; Trevaskis et al., 2013). Two of these phybrids are constituted by a $\mathrm{C}$-terminally truncated exenatide, which at its $\mathrm{C}$ terminus is covalently linked to the $\mathrm{N}$ terminus of an amylin analog (davalintide) through either a repeating $\beta$-Ala$\beta$-Ala dipeptide, or through triple-glycine linear repeat (Trevaskis et al., 2013). As assessed in rodent models of obesity, weight loss induced by these phybrids is greater than what is observed with each receptor monoagonist alone, but is similar to what is achieved by a physical comixture of the single hormones (Trevaskis et al., 2013). Another GLP-1/amylin phybrid uses a full-length exenatide sequence that is linked to davalintide via an intervening 40-kDa PEG (Sun et al., 2013). In rodent models of obesity, this phybrid dose-dependently improved glucose handling and body weight with superior in vitro and in vivo potency relative to a side-chain, PEGylated phybrid (Sun et al., 2013).

\section{Glucagon-Like Peptide 1/Glucose-Dependent Insulinotropic Polypeptide Coagonism}

Another unexpected controversial approach was the development of a molecule with dual agonism at the 
receptors for GLP-1 and the GIP, with the primary indication treatment of glucose intolerance (Finan et al., 2013) (Fig. 4). The 42-amino-acid peptide GIP is produced by K-cells in the duodenum and jejunum and is released into the general circulation upon stimulation by dietary nutrients, and especially lipids (Takeda et al., 1987; Lardinois et al., 1988; Inagaki et al., 1989). First isolated from porcine intestinal extracts, GIP was initially shown to inhibit gastric acid secretion in dogs, leading to the characterization as a gastric inhibitory polypeptide (Brown and Pederson, 1970; Brown, 1971). Work by Dupre et al. (1973) then demonstrated that i.v. administered GIP increases plasma levels of insulin in humans, and thus served to identify GIP as the first incretin hormone. Subsequently, GIP was shown to directly act on the pancreas to enhance glucose-stimulated insulin secretion (Dupre et al., 1973; Taminato et al., 1977; Adrian et al., 1978), and with it the reclassification of the hormone as a glucose-dependent insulinotropic polypeptide. Of appreciable note, beyond its ability to stimulate the release of insulin under conditions of hyperglycemia, GIP also stimulates the release of glucagon under conditions of hypoglycemia and thus represents a bifunctional hormone capable of buffering against the extremes in glucose excursion highs and lows (Pederson and Brown, 1978; Meier et al., 2003; Christensen et al., 2011, 2014).

Although the insulinotropic action of GIP renders this peptide an attractive pharmacological target, GIP agonism has long been regarded as a causal factor implicated in the development of obesity and insulin resistance (Finan et al., 2016b). The view of GIP as a putative obesogenic factor was supported by reports that circulating levels of GIP are positively correlated with body weight, and are typically elevated in genetically- and diet-induced obese mice (Flatt et al., 1983; Bailey et al., 1986; Miyawaki et al., 2002) and obese humans (Creutzfeldt et al., 1978; Salera et al., 1982; Calanna et al., 2013). The obesogenic nature of GIP is seemingly also supported by in vitro studies showing that GIP has lipogenic and adipogenic effects on adipocytes through mechanisms that include stimulation of adipogenesis (Eckel et al., 1979), inhibition of lipolysis (Gogebakan et al., 2012), and stimulation of de novo lipogenesis (Oben et al., 1991). Additionally, it stimulates triglyceride release from chylomicrons (Wasada et al., 1981; Ebert et al., 1991), adipocyte glucose and fatty acid uptake (Beck and Max, 1986; Hauner et al., 1988), and adipocyte lipoprotein lipase enzyme activity (Eckel et al., 1979; Knapper et al., 1993; Kim et al., 2007). Consistent with these biochemical properties, a series of studies embellished the belief of GIP as a lipogenic hormone as blocking its action either through targeted ablation of GIP-producing K-cells (Althage et al., 2008), genetic ablation of the GIP receptor (Miyawaki et al., 2002), or through immunoneutralization (Montgomery et al.,
2010), diminished body weight gain, and improved glucose metabolism in mice chronically exposed to a HFD. Notably, selective genetic ablation of the GIP receptor in $\beta$-cells decreases postprandial insulin levels in chow-fed mice, but does not protect them from obesity when exposed to high-fat feeding (Campbell et al., 2016). These data might indicate that the anti-obesogenic effect in inhibition of GIP action might not necessarily reside in the lack of GIP action on adipose tissue, but rather a consequence of diminished insulinotropic action resulting in reduced insulin adipose action (Finan et al., 2016b). Notably, in contrast to a series of historic studies testifying to GIP as an obesogenic hormone, mice overexpressing GIP show improved $\beta$-cell function and improved glycemic control and are resistant to diet-induced obesity (Kim et al., 2012a). Furthermore, chronic GIP receptor (GIPR) agonism was recently shown to improve glucose metabolism in DIO mice, without detrimental effects on body weight (Martin et al., 2013). The importance of functional GIP signaling can clearly be seen in transgenic pigs expressing a dominant-negative (dn) GIP pancreatic receptor (Renner et al., 2010). These GIPR(dn) pigs show impaired glucose tolerance due to delayed insulin secretion, impaired insulinotropic action of GIP, up to $60 \%$ reduced $\beta$-cell proliferation, and reduced islet mass of up to $58 \%$ at the age of 1 year (Renner et al., 2010), all hallmarks of the progression to T2D.

The rationale in combining the pharmacology of GIP and GLP-1 to a single molecule resides in the wellestablished insulinotropic action of both peptides, which they achieve in part by distinct mechanisms (Müller et al., 2017). At minimum, GIP agonism would augment GLP-1's glycemic effect, whereas the anorectic effect of GLP-1 could buffer against the purported obesogenic liability of GIP. Several studies have studied coinfusion of GLP-1 and GIP agonists. In rodents, combined agonism at these two receptors synergistically decreases body weight in DIO rodents (Finan et al., 2013) and improves glucose control relative to monotherapies. There was no additive effect observed on body weight in obese leptin-deficient ob/ob mice (Gault et al., 2011). In humans, coinfusion of GLP1 and GIP analogs additively increases the insulinotropic action relative to infusion with either agonist alone (Nauck et al., 1993a). Importantly, patients with T2D appear unresponsive to the insulinotropic action of the hormone (Nauck et al., 1993b; Vilsbøll et al., 2002), and there are also reports indicating that GIP agonism does not potentiate the glycemic benefits of GLP-1 agonism in hyperglycemic patients (Mentis et al., 2011). Nevertheless, two unimolecular GLP-1/GIP coagonists were developed and preclinically tested by DiMarchi, Tschöp, and colleagues (Finan et al., 2013). The conceptual design of these GLP-1/GIP coagonists was similar to that of the previously reported GLP-1/ glucagon coagonists, where a single peptide of mixed 


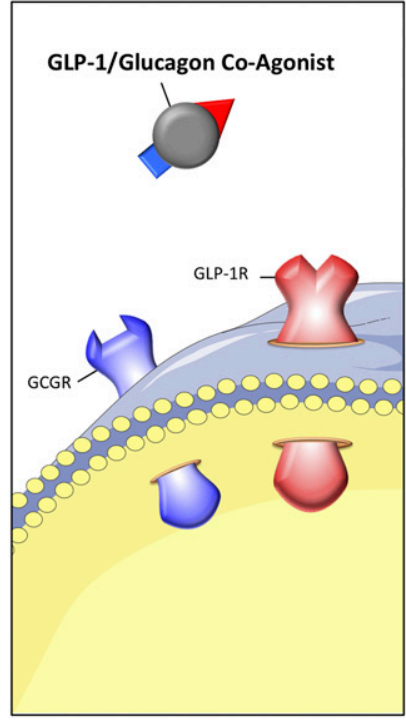

Improves

Body weight

Energy Expenditure

Glycemic control

Cholesterol

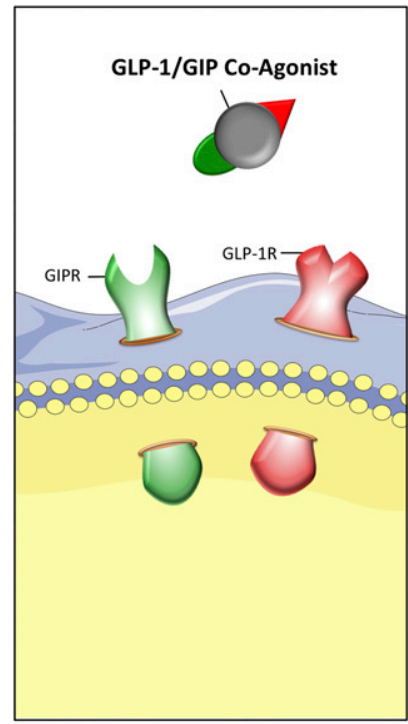

Improves

\section{Glycemic control}

Body weight

Lipolysis

Cholesterol

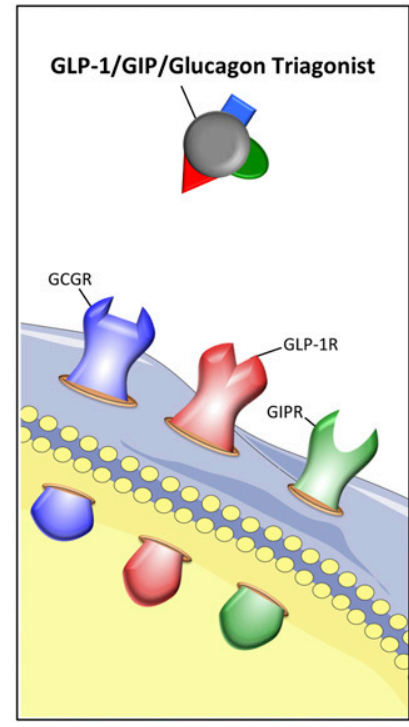

$\underline{\text { Improves }}$

Body weight Glycemic control

Hepatosteatosis

Cholesterol

Energy Expenditure

Lipolysis

Fig. 4. Schematic on the principle and metabolic action of GLP-1/glucagon, GLP-1/GIP, and GLP-1/GIP/glucagon.

sequence was identified that displayed full and balanced potency at both receptors. GIP residues were introduced in the middle and C-terminal part of the peptide, whereas certain modifications that enhanced GcgR activity were removed (Finan et al., 2013). The C terminus of the peptide ended with the nine-amino-acid extension (CEX) found in exendin-4, and an Aib at position 2 to protect against DPP-IV inactivation (Fig. 3 ). To extend in vivo time action, the dual-agonist peptides were either site-specifically modified with a 40-kDa PEG at Cys-24, or directly fatty-acylated at the Lys40 with palmitic acid. Both peptides possess balanced receptor activities of slightly enhanced (fatty-acylated) or slightly diminished potency (PEG) relative to the native hormones. In preclinical evaluation in diet-induced obese and diabetic, leptin-deficient $\mathrm{db} / \mathrm{db}$ mice, each of these coagonists demonstrated superior weight-lowering and enhanced improvement of insulin resistance and glucose control relative to pharmacokinetically-matched, best-in-class GLP-1 monoagonists (Finan et al., 2013). Glycemic improvements as expected were achieved through enhanced insulinotropic efficacy, and this notably translated from rodent models of obesity to nonhuman primates and humans (Finan et al., 2013; Portron et al., 2017; Schmitt et al., 2017). Notably, weight loss induced by this twincretin peptide was mediated by inhibition of food intake with no effects on energy expenditure (Finan et al., 2013).

\section{Glucagon-Like Peptide 1/Glucagon/Glucose- Dependent Insulinotropic Polypeptide Triagonism}

GLP-1, GIP, and glucagon are peptides of similar size with a high degree of homology in sequence that biochemically signal through homologous G proteincoupled surface receptors. The common structural features render them attractive candidates for purposefully achieving full agonism at all three receptors, although there is no precedent for doing so and nature has designed them to be specific for their individual receptors. Based on the demonstrated metabolic benefits of the already published GLP-1/glucagon and GLP-1/GIP coagonists (Day et al., 2009; Finan et al., 2013), it was envisioned that simultaneous balanced agonism at all three target receptors could provide unrivaled metabolic benefits, beyond what had already been achieved with each dual agonist relative to monotherapy (Fig. 4).

The strategic design was based on GLP-1 anorectic effect synergizing with glucagon's lipolytic and thermogenic properties to decrease body weight, whereas the combined insulinotropic action of GLP-1 and GIP would doubly restrain glucagon's hyperglycemic liability to potentially allow more aggressive use. 
Relative to GLP-1/GIP coagonists, which are reported to not increase energy expenditure, the glucagon component of the triagonist contributed energy expenditure mechanisms, thus allowing greater body weightlowering potency. Conversely, the relative potency ratio of the glucagon component in GLP-1/glucagon coagonists will ultimately have to be reduced to favor of GLP-1 potency to avoid any remnant of a glucagon-driven diabetogenic effect. With GIP activity integrated into a triagonist, an independent mechanism is dialed into the molecule that further buffers against glucagon-induced hyperglycemia. This ultimately permits a mixed agonist profile in which the relative potency at each receptor can be balanced such that glucagon activity can be kept at a maximum. Lastly, the GIP component contributes additional improvements in hormonal sensitivity, notably insulin sensitivity, thus reducing basal insulin levels. In doing so, the GIP component lessens the obesogenic drive from hyperinsulinemia.

The triple agonist was based upon the structureactivity studies that had associated with the achieving balanced GLP-1/glucagon and GLP-1/GIP coagonists (Day et al., 2009; Finan et al., 2013). An Aib at position 2 protected the molecule from DPP-IV inactivation, and the lysine at residue 10 was fatty-acylated with a palmitic acid through a $\gamma$ glutamic acid linker (Fig. 3). Similar to liraglutide, the lipidation promotes noncovalent binding to albumin to slow renal clearance and extend duration of in vivo action. The Aib at position 2 inhibits DPPIV degradation, but also decreases potency at the glucagon receptor. As such, Glu16, Arg17, Gln20, Leu27, and Asp28 were introduced to restore balanced glucagon bioactivity at this receptor. The peptide contains the C-terminal exendin- 4 extension sequence (CEX) and displays balanced and full agonism at all three receptors, with 10 -fold superior potency relative to the native hormones (Finan et al., $2015 \mathrm{~b}$ ). As shown in a variety of genetically and dietinduced obese and glucose-intolerant mouse models, the triagonist potently decreased body weight through inhibition of food intake and stimulation of energy expenditure. It improved insulin sensitivity, glucose, and lipid metabolism, lowering plasma cholesterol and reversing hepatic steatosis (Finan et al., 2015b). Of appreciable note, the triagonist lowered food consumption and improved glycemic control with similar efficacy relative to the GLP-1/GIP coagonist, yet with greater weight loss given the lipolytic and thermogenic actions attributed to agonism at the glucagon receptor. Validation of the molecular source of the efficacy was established in specific loss-of-function mouse models, including GLP-1R ${ }^{-/-}$, GcgR ${ }^{-1-}$, and $\mathrm{GIPR}^{-/-}$mice (Finan et al., 2015b). Importantly, the triagonist lowered body weight with equal efficacy in obese male and female mice (Jall et al., 2017) and translated from obese rodent models to nonhuman primates (Tschop et al., 2016).
Building upon the initial triple-agonist report, a protein with activity at all these three receptors was reported. In this molecule, coding sequences for GLP-1, GIP, and glucagon in various combinations were genetically fused to the $\mathrm{N}$ terminus of the heavy or light chain of a registered monoclonal antibody (Synagis) that is widely used to treat respiratory-syncytial-virus infections (Wang et al., 2016). Relative to the native hormone, this triple agonist displayed comparable in vitro potency at each of the three receptors and half-life that was extended by more than 100 -fold. This triple-agonist, antibody-based protein synergistically improved body weight and glucose metabolism in DIO rodents (Wang et al., 2016).

\section{Peptide-Mediated Delivery of Nuclear Hormones}

Nuclear hormones are powerful medicinal agents of exceptionally high potency and pleiotropic action profile and have proven particularly useful in treatment of endocrine disorders such as the metabolic syndrome. However, their broad systemic action often results in unwanted adverse effects that restrict the use of these powerful hormones. Many nuclear hormones have multiple receptor isoforms that are believed to serve different physiologic functions and have different tissue distribution patterns. Traditional small-molecule medicinal chemistry has been employed to engineer ligands that selectively function at a specific receptor isoform. However, this approach has failed in most instances to generate drug candidates that demonstrate pharmacology sufficiently selective for chronic human use. An alternative strategy employs macromolecules such as peptides or proteins to direct the biodistribution of the nuclear hormones. The tissue preference is dependent upon the receptor distribution of the targeting ligand, and in theory can be finely tuned by appropriate selection. An additional benefit of this approach is the potential to integrate the inherent pharmacology of the targeting peptide to complement that of the nuclear hormone. In analogy, antibody-based chemotherapy has been employing a similar targeting strategy devoid of the supplemental pharmacology of the targeting ligand to enhance the narrow therapeutic window of high-potency cytotoxic agents. In endocrine applications, the magnitude of therapeutic improvement is considerably less as many of these nuclear hormones, such as estrogens, androgens, and thyroid hormones, are currently used, but with careful dose management.

This strategy employs a covalent linkage of a nuclear hormone to a peptide, preferably through linker that would metabolize to release the nuclear hormone only within the targeted cell (Fig. 5). In principle, such a design restricts the otherwise passive transport of a nuclear hormone through virtually all cell membranes 


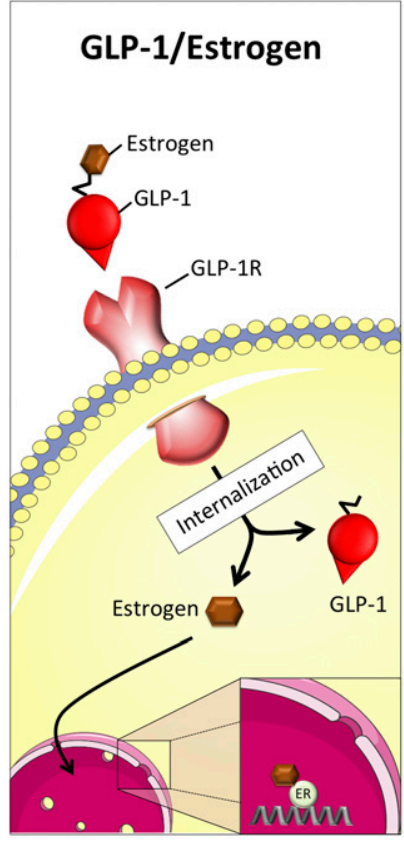

Improves

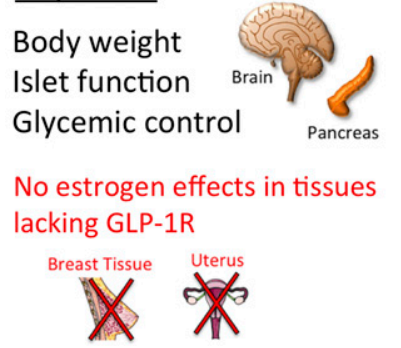

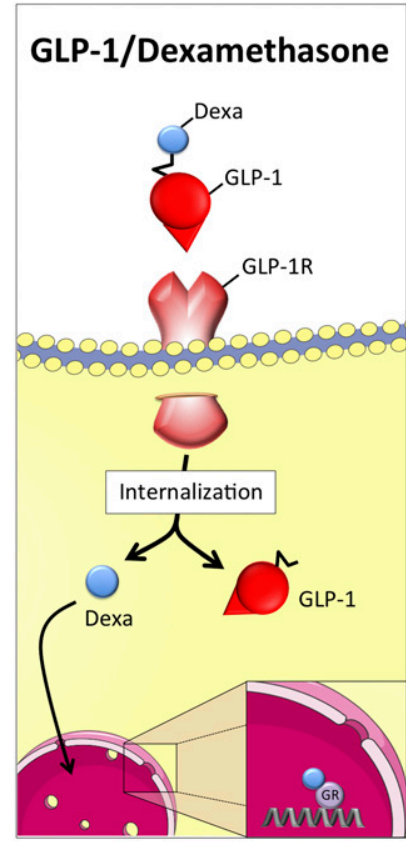

Improves

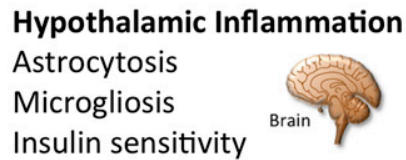

No Dexa effects in tissues lacking GLP-1R

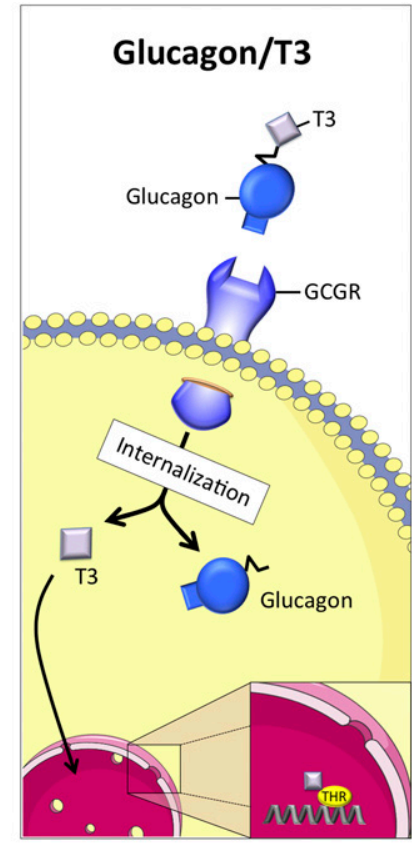

Improves

LDL Cholesterol

Hepatic Lipid Metabolism

Hepatosteatosis Liver

Body weight

Glycemic control

Limited T3 off-target effects

in the bone and heart

Fig. 5. Schematic on the principle of peptide-mediated nuclear hormone delivery and metabolic effects of GLP-1/estrogen, GLP-1/dexamethasone, and glucagon/T3.

or restricts the presentation of the nuclear hormone to endogenous cellular transporters, and thus lessens the adverse effects in undesirable tissues. However, in cell types that possess the peptide receptor, activation of the cell surface receptor should lead to internalization of the ligand-nuclear hormone receptor complex. In essence, the peptide receptor serves as a gateway into the cell. Upon internalization, biologic processing of a suitably designed linker would release the nuclear hormone and allow it to activate its intracellular receptor. In certain instances, it could be beneficial to release a chemically modified nuclear hormone such that cellular efflux is prevented, or alternatively use an isoform-selective nuclear hormone analog to achieve selectivity otherwise not possible in targeting the native nuclear hormone. As long as there is sufficient nuclear hormone released intracellularly and that it retains sufficient potency at its receptor, complementary biologic effects should result.

There are many inherent concerns and limitations to the approach that require optimization for each application. Potency alignment is one of the uncertainties inherent to all combinatorial therapies, and, unquestionably, physical mixtures are more easily titrated to determine the optimal balance. Additionally, because the peptide works to concentrate the nuclear hormone at target cells, it is more challenging than coagonism at two cell surface family B G proteincoupled receptors where the ligand typically loses all receptor potency with biometabolism of the peptide. Furthermore, whether this approach can be used with peptide ligands that are designed to target more than one target tissue remains to be determined, as it would potentially broaden the pharmacology to increase efficacy, but also toxicity.

Expanding the peptide and nuclear hormone pairings to target additional metabolic pathways or treat other diseases is an exciting proposition. However, the hormone selection requires a judicial choice as not all nuclear hormones are compatible, and many surfaceacting agonists are insufficiently selective in sites of action, such as insulin or insulin-like growth factor-1. One inherent attraction to peptide and nuclear hormone pairing is that both entities are typically of high inherent potency, and most peptides have fairly high tissue selectivity. In this regard, peptide receptor antagonists 
and intracellularly acting, small-molecule inhibitors are less attractive candidates. Peptide antagonists relative to agonists exhibit slower and more restricted internalization of bound-receptor complexes. Furthermore, not all peptide receptors are internalized. Lastly, most small-molecule inhibitors require appreciably high concentrations, which present challenges to transport a sufficient quantity of material and would potentially require a reduction in peptide potency to achieve balanced compatibility. The latter of these can present biophysical and synthetic obstacles to realizing successful pharmacology.

\section{A. Glucagon-Like Peptide 1-Mediated Delivery of Estrogen}

Estrogens have substantial regulatory actions to influence metabolic control. Appreciable experimental evidence exists that demonstrate that many female rodent models are protected from dietary- and genetically-induced metabolic dysfunction (MauvaisJarvis et al., 2017a). The most often cited evidence of estrogen's regenerative benefits derives from the many studies of estrogen replacement therapy in postmenopausal women improving multiple cardiometabolic parameters (Mauvais-Jarvis et al., 2017b). Specifically, estrogens have been reported to have protective, anabolic, and insulinotropic effects in rodent pancreatic islets that serve to improve glycemic control (MauvaisJarvis, 2016). Separately, estrogens have potent anorectic effects that originate in distinct brain regions that promote body weight loss after exogenous administration (Gao et al., 2007). Interestingly, these pharmacological actions of estrogen coincide with many biologic aspects in GLP-1 receptor agonism.

The rationale for building single-molecule conjugates of GLP-1 and estrogen arose from the overlapping, yet presumed nonredundant mechanisms of GLP-1 and estrogen in metabolic control. By leveraging the preferential sites of GLP-1 action, most notably the endocrine pancreas and hypothalamic feeding circuits, it was hypothesized that GLP-1 could selectively deliver estrogen to these tissues. Restricting the site of estrogen action would in theory limit the reproductive endocrine toxicity and oncogenic liability of unopposed, systemic estrogen. Whether this could provide a meaningful enhancement in GLP-1 pharmacology and an improved therapeutic window for chronic estrogen use is difficult to know without experimentation. Consequently, a series of GLP-1 and estradiol (E2) conjugates were generated using a DPP-IV-resistant GLP-1 analog with stable, ether-based linker between the peptide and E2 (Finan et al., 2012) (Fig. 5). In addition, a series of meta-stable linkers were explored that were rationally designed to be selectively sensitive to intracellular degradation, yet stable in plasma by taking advantage of the different physiologic conditions inside of a cell. Numerous control compounds included the following: a peptide with selective chemical knockout of the GLP-1 potency through the use of point mutations or complete d-amino acid substitution of the sequence, a conjugate with a labile phenolic ester-based linker that rapidly decomposes in circulation after administration to release systemic E2, a peptide conjugated to lithocholic acid as a pharmacokinetic control because the bile salt has similar lipophilicity as E2, and finally a GIP-E2 conjugate to impart differential tissue delivery of E2.

Administration of a stable GLP-1/E2 conjugate dosedependently decreased body weight and improved glycemic control in various rodent models of the metabolic syndrome, including diet-induced obese mice and $\mathrm{db} / \mathrm{db}$ mice (Finan et al., 2012). The weight-lowering benefits were the result of collective effects to suppress food intake, and the GLP-1/E2 conjugate showed greater potency relative to the GLP-1 analog or E2 control to reduce food intake and lower body weight. Subsequent studies have reported effects of the GLP-1/ E2 conjugate on feeding behavior and reward (Cao et al., 2014; Vogel et al., 2016). These enhanced metabolic benefits were noticeably absent following treatment with chemically-inactive GLP-1 conjugates, or conjugates with a labile linkage to estrogen, or stable conjugates to bile acids, and the stable E2 conjugate to GIP. The absence of amplification with these control peptides demonstrates the targeting in the combined pharmacodynamics of the enhanced performing GLP-1/ E2 conjugate. Furthermore, the superior benefits are not solely the consequence of a protracted time action despite subtle differences in exposure observed with the GLP-1/E2 conjugate relative to the GLP-1 analog. The body weight improvement observed with GLP-1/E2 treatment was completely abolished in global GLP-1 $\mathrm{R}^{-/-}$mice and substantially blunted in CNS-specific GLP-1R ${ }^{-/-}$mice, which demonstrates the primary mechanism of action for body weight lowering resides in the CNS. The specific contribution of islet GLP-1 receptors to the activity of GLP-1/E2 is most likely involved in the glycemic benefits. Subsequent studies have shown the additive contribution of GLP-1/E2 on pancreatic islet function, cytoarchitecture, and protection from deleterious insults such as lipotoxicity (Schwenk et al., 2015; Tiano et al., 2015). Body weight lowering of GLP-1/E2 was partially ameliorated in estrogen receptor $\alpha$ and estrogen receptor $\beta$ knockout mice. The contribution of membraneanchored or membrane-embedded estrogen receptors remains to be determined. Further testing in mouse models with the knockout of estrogen receptors in select brain regions and islet cell populations would provide mechanistic insight into how these two hormones coordinately influence systemic metabolism.

Despite the powerful metabolic benefits associated with estrogen action, effects on the reproductive endocrine system and oncogenic potential have restricted the clinical use of estrogens to replacement therapy in 
postmenopausal women. Importantly, GLP-1 receptors have not been reported to be expressed in these reproductive tissues, and, together with the complementary effects of GLP-1 and estrogen, support the logic that GLP-1-mediated targeting is an advantageous strategy. It appears to improve the therapeutic index of E2 and capture the benefit of more than one mode of action to positively affect metabolism. Biochemical signatures indicative of estrogen signaling were evident in those tissues and cells possessing GLP-1R expression, yet appreciably absent in cells without such receptor. Treatment with the stable GLP-1/E2 conjugate did not cause uterine hypertrophy in ovariectomized female rodents, whereas the labile conjugate, which increased circulating estrogen, caused significant uterine growth. Furthermore, the labile conjugate stimulated the proliferation of MCF-7 cells in vitro and accelerated growth of MCF-7 xenograft tumors in chronically treated mice as result of the systemically released estrogen. Unlike the labile conjugate, the stable GLP-1/E2 conjugate did not show tumorigenic toxicity, confirming the stability of the conjugate in circulation and that GLP-1 does not target the estrogen cargo to these cell types (Finan et al., 2012). More exhaustive toxicity studies are required to quantify the magnitude of improved therapeutic index for the stable GLP-1/E2 conjugate, including an examination of on-target and off-target effects in multiple species. Those cells that possess both GLP-1 and estrogen receptors are of noteworthy concern, as are pancreatic $\beta$-cells, as there is risk of promoting any pre-existing pancreatic tumors. As GLP-1 receptors are also broadly expressed, albeit at lower relative levels compared with what is observed in the CNS and pancreatic islets, there is potential to deliver unwanted estrogen at low levels and cause adverse effects. Independent from potential oncogenic or gynecologic toxicities, targeting neuronal circuitries involved in feeding behavior has risks as well. It is now evident that subsets of these neuronal populations involved in energy homeostasis are functionally connected to nonmetabolic, higher-order behaviors (Dietrich and Horvath, 2012). Despite evidence that GLP-1/E2 conveys positive effects on feeding behaviors such as reward and binge eating (Cao et al., 2014; Vogel et al., 2016), pharmaceutical agents with potent anorexigenic effects have shown adverse effects on behavior that include increased prevalence of depressive mood disorders (Christensen et al., 2007).

Although the medicinal benefits of the stable GLP-1/E2 conjugates have been demonstrated in these preclinical studies, many aspects of the molecular pharmacology and mechanism of action remain unresolved. In particular, the precise intracellular processing of the GLP-1/E2 conjugate that results in the release of an active estrogen cargo has not been determined, and, as such, the molecular identity that delivers estrogen activity remains unknown. Furthermore, whereas the estrogen appeared to have minimal impact on the pharmacokinetic profile of the GLP-1 conjugate and did not enhance the terminal half-life, it is still plausible to believe that the estrogen can alter the biodistribution of the conjugate to more privileged sites of CNS action, if only by enhancing brain penetration.

\section{B. Glucagon-Mediated Delivery of Thyroid Hormone Tri-iodothyronine}

Glucagon and thyroid hormone can individually promote weight loss and improve dyslipidemia in humans, which positions these two hormones as attractive candidates in development of a multifaceted medicine for treatment of cardiometabolic diseases. Many of the individual actions of these endogenous hormones overlap and suggest that a pairing could result in additional metabolic benefit. Thyroid hormones are classic mediators of multiple nodes of metabolic homeostasis due to diverse actions in broad tissues, as discussed early in this review. Primarily by hepatic action, thyroid hormone therapy can lower the circulating concentration of cholesterol and lipoproteins (Angelin and Rudling, 2010). In adipose depots, thyroid hormone can promote energy expenditure and lipolysis (Lin et al., 2015; Weiner et al., 2016). Central actions of thyroid hormone include hyperphagia and sympathetic outflow, which can also increase energy expenditure and cardiovascular adrenergic input (Lopez et al., 2010; Mittag et al., 2013). However, the adverse effects of excessive thyroid hormone are numerous and well-categorized, including cardiac hypertrophy, tachycardia, muscle catabolism, and bone deterioration. Despite the substantial metabolic attributes, thyroid hormone therapy must be dose titrated and carefully monitored, even in those receiving replacement therapy for thyroid deficiencies, including thyroidectomy.

Recognizing the benefits of liver-specific thyroid hormone action while attempting to mitigate the systemic toxicities, research has focused on chemical analogs with selective $\beta$ receptor (TRb) selectivity, or analogs with preferential uptake in hepatocytes. The rationale of liverselective thyromimetics was largely guided by studies showing enhanced hepatic presence and only trace expression in the heart. The chemical optimization to TRb selectivity was guided by molecular structures that identified different interactions of native thyroid hormones between the two predominant isoforms (Borngraeber et al., 2003; Bleicher et al., 2008). These medicinal chemistry refinements resulted in compounds that show favorable effects on lipoprotein profiles without influencing cardiac function, but body weight lowering was not observed and purportedly not expected based on hepatic action (Baxter and Webb, 2009). However, dosedependent effects on hypothalamic-pituitary-thyroid axis suppression were evident for a few of these thyromimetics at higher doses. These effects were underscored in the reports (Erion et al., 2007), but now appear of appreciable importance. Possibly this biology is not structure or receptor specific, but instead identifies a previously 
unrealized mechanism in hypothalamic-pituitary-thyroid feedback that originates in the liver. In this regard, unexpected toxicity pertaining to cartilage damage was observed in dogs following chronic treatment with a liverselective thyromimetic eprotirome (Sjouke et al., 2014). It is unknown whether this is a class effect or something specific to this one TRb agonist. Consequently, there is a continued need for more thorough on-target toxicity studies with these thyromimetics. Possibly, these toxicology studies have been conducted, but yet to be reported, because they would have been required to support the advanced, unsuccessful clinical studies that terminated the development.

The peptide-based approach to delivery of estrogen seemed an attractive strategy for delivery of T3, and in particular its integrated use with glucagon. Glucagon receptors are highly concentrated in the liver, which is the preferred site for T3 action, but it is also present at low levels in adipose tissues, kidney, and throughout the cardiovascular system. These secondary sites represent areas for beneficial action to improve metabolism, but more importantly represent a risk for toxicity. A single molecule was designed with an equimolar equivalent of native T3 covalently conjugated to a DPP-IV-protected, C-terminally extended glucagon analog via a peptide spacer (Finan et al., 2016a) (Fig. 5). This design provided full inherent potency at the glucagon receptor for the T3 conjugate. Several control compounds were also generated to permit appropriate pharmacological comparisons. These additional peptides included the following: a conjugate with selective chemical substitution to the peptide to suppress glucagon activity, a compound with a linker that proved metabolically stable and was incapable of intracellular T3 release, and a third control conjugate that bore a metabolically-inert thyroid hormone.

The fully active glucagon/T3 conjugate restricted thyroid hormone action to tissues expressing the glucagon receptor with selective accumulation of T3 in the liver, which was confirmed in using labeled compound. Accumulation of thyroid hormone was not evident in tissues where its action was unwanted and devoid of glucagon receptor, most notably the heart and bone. Studies using glucagon receptor knockout mice confirmed the receptor selectivity in the conjugate and provides indirect evidence that the glucagon receptor is a necessary ingredient to T3 transport and biologic action. As a result of this hepatictargeted biodistribution profile, the glucagon-T3 conjugate dose-dependently corrected dyslipidemia in various rodent models of dietary-induced metabolic syndrome, most notably mice fed HFD and Western-style diets (Finan et al., 2016a). Importantly, the benefits on lipid metabolism were muted when studied in mice with selective hepatic knockout of TRb, demonstrating the tissue and target selectivity of the conjugate. Evidence suggests that the weight-lowering efficacy of the conjugate can partially be governed by actions in adipose depots because glucagon receptors are present in rodent adipocytes, but to a much lesser degree than in liver. Indeed, the weight- and lipid-lowering effects of the glucagon/T3 conjugate can be partially attributed to uncoupling protein 1-mediated thermogenesis, enhanced FGF21 secretion, and biased PGC-1 cofactor signaling. Many agents have been shown to correct various forms of obesity in rodent models, but very few have shown reversal of arterial plaque deposition in rodent models of heart disease, and even fewer have reversed hepatic fibrosis in mouse models of nonalcoholic steatohepatitis. Emphasizing the translational aspects of combining the actions of these two hormones, intervention with this glucagon/T3 conjugate lessened arterial plaque area in diseased LDL receptor $^{-1-}$ mice, and also lessened fibrosis in mice with advanced fatty liver disease. These findings collectively demonstrate regenerative medicinal quality and enhanced safety of this specific hormone pair in cardiometabolic diseases.

In addition to enhancing the metabolic benefits of T3 by predominantly focusing its action at the liver via glucagon, this hormonal pair allowed for the reciprocal countersuppression of their individual inherent liabilities that restrict their individual medicinal use. The liver-directed thyroid hormone action offset the diabetogenic liability of glucagon, whereas the deleterious effects of thyroid hormone on cardiac muscle and its catabolic properties were minimal, indicating an improved therapeutic index. The magnitude of the improved therapeutic index will need to be more thoroughly studied to determine whether it is of sufficient magnitude to support chronic use in higher mammals, and most importantly humans. Although the original report provides compelling evidence about the potential benefits of glucagon-mediated targeting of thyroid hormone, progression toward clinical development will likely require chemical maturation. Further chemical refinement is possible and can be directed at fine-tuning the relative potency of the two hormones. Additionally, controlled metabolic stability of the conjugate, particularly the linker, may also be required to further enhance the potency and safety of the first reported conjugate candidate.

\section{Glucagon-Like Peptide 1-Mediated Delivery of Dexamethasone}

Chronic peripheral and central inflammation is a frequently reported feature of dietary-induced obesity and is commonly believed to play a causal role in the pathogenesis of the disease (Hotamisligil, 2006; Hotamisligil and Erbay, 2008; Gregor and Hotamisligil, 2011; Thaler et al., 2012, 2013). Although solid evidence supports a direct role of immunometabolic pathways in the development of obesity-linked insulin resistance (Hotamisligil et al., 1993, 1996; Hotamisligil and Spiegelman, 1994), therapeutic options to improve systems metabolism via counteracting obesity-associated inflammation 
are scarce. Glucocorticoids are known for decades for their anti-inflammatory properties, but, as with other nuclear-acting hormones, their ubiquitous action profile limits their therapeutic utility and can lead to off-target effects. Expanding the concept of peptide-mediated nuclear hormone delivery, collaborative research of the DiMarchi/Tschöp laboratories recently let to the development of a molecule, which selectively restricts the action of dexamethasone to cells expressing the receptor for GLP-1, such as brain and the pancreas (Quarta et al., 2017) (Fig. 5). The GLP-1/dexamethasone chimera synergistically improved body weight in DIO mice, notably with superior metabolic action relative to treatment with GLP-1 or dexamethasone alone. In line with its action on key hypothalamic neurocircuits, weight loss induced by GLP-1/dexamethasone was a result of decreased food intake and increased energy expenditure and was associated with improved glucose metabolism and restored insulin sensitivity. Notably, the targeted delivery of dexamethasone to GLP-1Rpositive cells prevented typical dexamethasone off-target effects on glucose handling, bone integrity, and hypothalamus-pituitary-adrenal axis activity (Quarta et al., 2017).

\section{Outlook}

The integration of the small- and large-molecule pharmacology as exemplified in these first peptidenuclear hormone conjugates is just a beginning of what could constitute a full class of novel drug candidates. The enhanced convenience in the infrequent administration offered by best-in-class GLP-1 agonists may not be ideal for drugs of this type. It is just one element that needs to be considered, as the preferential action profile of thyroid hormone or estrogen might require more intermittent dosing given the different pharmacodynamic manner in which nuclear hormones biochemically signal relative to a peptide acting at a surface receptor. Obviously, the primary consideration is performance to achieve the right balance between safety and efficacy, with convenience being an important but secondary consideration. These first reports of peptide-directed nuclear hormone pharmacology hold much promise, but it is best to maintain healthy scientific skepticism as the improvement in therapeutic index is quantified and relative risk-benefit in chronic treatment of multiple metabolic diseases is assessed.

So we come full circle with more than a century of experiences in search of medicinal agents that can provide the magnitude of metabolic improvement and weight lowering that has been demonstrated in the last decade with bariatric surgeries. It is a daunting challenge, exacerbated by the enormity of the public need and the growing realization of the personal and public consequences of chronic obesity. We can take confidence that we have never been better equipped scientifically to address the challenge, and medicinal advances in individually addressing cholesterol, glucose, and blood pressure are examples of what is possible. It seems inevitable that more than one solution will emerge and that each of them will require more than one mechanism of action. Possibly, what is most transformative in the emerging trend championed with peptide-based therapeutics is not the polyagonism, as combination therapy is a common feature in treating multiple chronic diseases. It is the use of hormones that were highly restricted in their use or, in fact, counterindicated. Glucagon may be the poster child where for more than half a century the focus has been exclusively on glucose and antagonism. When viewed in a more holistic sense, we now perceive how we can achieve indirect improvements in glucose through glucagon agonism associated with lower body weight when used in concert with a second or third hormone. We certainly do not want to repeat the errors of the rainbow pills in camouflaging toxicity. As such, the historical context that we present in this review and the body of literature it represents constitute a foundation for current and future research.

\section{Acknowledgments}

The figures were made using material provided by Servier Medical Art (Servier), under consideration of a Creative Commons Attribution 3.0 Unported License.

\section{Authorship Contributions}

Wrote or contributed to the writing of the manuscript: Müller, Clemmensen, Finan, DiMarchi, Tschöp.

\section{References}

Adan RA (2013) Mechanisms underlying current and future anti-obesity drugs. Trends Neurosci 36:133-140.

Adelman J, Freitag FG, Lainez M, Shi Y, Ascher S, Mao L, Greenberg S, and Hulihan $\mathrm{J}$ (2008) Analysis of safety and tolerability data obtained from over 1,500 patients receiving topiramate for migraine prevention in controlled trials. Pain Med 9: 175-185.

Adrian TE, Bloom SR, Hermansen K, and Iversen J (1978) Pancreatic polypeptide, glucagon and insulin secretion from the isolated perfused canine pancreas. Diabetologia 14:413-417.

Agers $\emptyset$ H, Jensen LB, Elbrønd B, Rolan P, and Zdravkovic M (2002) The pharmacokinetics, pharmacodynamics, safety and tolerability of NN2211, a new longacting GLP-1 derivative, in healthy men. Diabetologia 45:195-202.

Ahrén B, Masmiquel L, Kumar H, Sargin M, Karsbøl JD, Jacobsen SH, and Chow F (2017) Efficacy and safety of once-weekly semaglutide versus once-daily sitagliptin as an add-on to metformin, thiazolidinediones, or both, in patients with type 2 diabetes (SUSTAIN 2): a 56-week, double-blind, phase 3a, randomised trial. Lancet Diabetes Endocrinol 5:341-354.

Alcántara AI, Morales M, Delgado E, López-Delgado MI, Clemente F, Luque MA Malaisse WJ, Valverde I, and Villanueva-Peñacarrillo ML (1997) Exendin-4 agonist and exendin(9-39)amide antagonist of the GLP-1(7-36)amide effects in liver and muscle. Arch Biochem Biophys 341:1-7.

Allison DB, Fontaine KR, Manson JE, Stevens J, and VanItallie TB (1999) Annual deaths attributable to obesity in the United States. JAMA 282:1530-1538.

Alphin RS and Ward JW (1969) Anorexigenic effects of fenfluramine hydrochloride in rats, guinea pigs, and dogs. Toxicol Appl Pharmacol 14:182-191.

Althage MC, Ford EL, Wang S, Tso P, Polonsky KS, and Wice BM (2008) Targeted ablation of glucose-dependent insulinotropic polypeptide-producing cells in transgenic mice reduces obesity and insulin resistance induced by a high fat diet. J Biol Chem 283:18365-18376.

Alvarez-Crespo M, Csikasz RI, Martínez-Sánchez N, Diéguez C, Cannon B, Nedergaard J, and López M (2016) Essential role of UCP1 modulating the central effects of thyroid hormones on energy balance. Mol Metab 5:271-282.

Amatuzio DS, Grande F, and Wada S (1962) Effect of glucagon on the serum lipids in essential hyperlipemia and in hypercholesterolemia. Metabolism 11:1240-1249.

Anderberg RH, Richard JE, Eerola K, López-Ferreras L, Banke E, Hansson C, Nissbrandt H, Berqquist F, Gribble FM, Reimann F, et al. (2017) Glucagon-like peptide 1 and its analogs act in the dorsal raphe and modulate central serotonin to reduce appetite and body weight. Diabetes 66:1062-1073. 
Andersen PH, Richelsen B, Bak J, Schmitz O, Sørensen NS, Lavielle R, and Pedersen O (1993) Influence of short-term dexfenfluramine therapy on glucose and lipid metabolism in obese non-diabetic patients. Acta Endocrinol (Copenh) 128:251-258.

Andersen T, Astrup A, and Quaade F (1992) Dexfenfluramine as adjuvant to a lowcalorie formula diet in the treatment of obesity: a randomized clinical trial. Int $J$ Obes Relat Metab Disord 16:35-40.

Angelin B and Rudling M (2010) Lipid lowering with thyroid hormone and thyromimetics. Curr Opin Lipidol 21:499-506.

Aronne LJ, Wadden TA, Peterson C, Winslow D, Odeh S, and Gadde KM (2013) Evaluation of phentermine and topiramate versus phentermine/topiramate extended-release in obese adults. Obesity (Silver Spring) 21:2163-2171.

Arstila AU and Trump BF (1968) Studies on cellular autophagocytosis: the formation of autophagic vacuoles in the liver after glucagon administration. Am J Pathol $\mathbf{5 3}$ $687-733$.

Astrup A (2010) Drug management of obesity-efficacy versus safety. $N$ Engl J Med 363:288-290

Baggio LL, Huang Q, Brown TJ, and Drucker DJ (2004) Oxyntomodulin and glucagon-like peptide-1 differentially regulate murine food intake and energy expenditure. Gastroenterology 127:546-558.

Bailey CJ, Flatt PR, Kwasowski P, Powell CJ, and Marks V (1986) Immunoreactive gastric inhibitory polypeptide and $\mathrm{K}$ cell hyperplasia in obese hyperglycaemic (ob/ob) mice fed high fat and high carbohydrate cafeteria diets. Acta Endocrinol (Copenh) 112:224-229.

Baldissera FG, Holst JJ, Knuhtsen S, Hilsted L, and Nielsen OV (1988) Oxyntomodulin (glicentin-(33-69)): pharmacokinetics, binding to liver cell membranes, effects on isolated perfused pig pancreas, and secretion from isolated perfused lower small intestine of pigs. Regul Pept 21:151-166.

Balster RL and Schuster CR (1973) A comparison of d-amphetamine, l-amphetamine, and methamphetamine self-administration in rhesus monkeys. Pharmacol Biochem Behav 1:67-71.

Banks WA, DiPalma CR, and Farrell CL (1999) Impaired transport of leptin across the blood-brain barrier in obesity. Peptides 20:1341-1345.

Banting FG, Best CH, Collip JB, Campbell WR, and Fletcher AA (1922) Pancreatic extracts in the treatment of diabetes mellitus. Can Med Assoc J 12:141-146.

Barbe P, Larrouy D, Boulanger C, Chevillotte E, Viguerie N, Thalamas C, Oliva Trastoy M, Roques M, Vidal H, and Langin D (2001) Triiodothyronine-mediated up-regulation of UCP2 and UCP3 mRNA expression in human skeletal muscle without coordinated induction of mitochondrial respiratory chain genes. FASEB J 15:13-15.

Barrington P, Chien JY, Tibaldi F, Showalter HD, Schneck K, and Ellis B (2011) LY2189265, a long-acting glucagon-like peptide-1 analogue, showed a dosedependent effect on insulin secretion in healthy subjects. Diabetes Obes Metab 13:434-438.

Bataille D, Tatemoto K, Gespach C, Jörnvall H, Rosselin G, and Mutt V (1982) Isolation of glucagon-37 (bioactive enteroglucagon/oxyntomodulin) from porcine jejuno-ileum: characterization of the peptide. FEBS Lett 146:79-86.

Bauer UE, Briss PA, Goodman RA, and Bowman BA (2014) Prevention of chronic disease in the 21st century: elimination of the leading preventable causes of premature death and disability in the USA. Lancet 384:45-52.

Baxter JD and Webb P (2009) Thyroid hormone mimetics: potential applications in atherosclerosis, obesity and type 2 diabetes. Nat Rev Drug Discov 8:308-320.

Bayham BE, Greenway FL, Bellanger DE, and O'Neil CE (2012) Early resolution of type 2 diabetes seen after Roux-en-Y gastric bypass and vertical sleeve gastrectomy. Diabetes Technol Ther 14:30-34.

Beck B and Max JP (1986) Direct metabolic effects of gastric inhibitory polypeptide (GIP): dissociation at physiological levels of effects on insulin-stimulated fatty acid and glucose incorporation in rat adipose tissue. Diabetologia 29:68.

Becskei C, Grabler V, Edwards GL, Riediger T, and Lutz TA (2007) Lesion of the lateral parabrachial nucleus attenuates the anorectic effect of peripheral amylin and CCK. Brain Res 1162:76-84.

Bello NT, Kemm MH, Ofeldt EM, and Moran TH (2010) Dose combinations of exendin-4 and salmon calcitonin produce additive and synergistic reductions in food intake in nonhuman primates. Am J Physiol Regul Integr Comp Physiol 299 R945-R952.

Bello NT and Liang NC (2011) The use of serotonergic drugs to treat obesity-is there any hope? Drug Des Devel Ther 5:95-109.

Berglund ED, Liu C, Sohn JW, Liu T, Kim MH, Lee CE, Vianna CR, Williams KW, $\mathrm{Xu} \mathrm{Y}$, and Elmquist JK (2013) Serotonin 2C receptors in pro-opiomelanocortin neurons regulate energy and glucose homeostasis [published correction appears in $J$ Clin Invest (2014) 124:1868]. J Clin Invest 123:5061-5070.

Bethell MF (1957) Toxic psychosis caused by preludin. BMJ 1:30-31.

Bettge K, Kahle M, Abd El Aziz MS, Meier JJ, and Nauck MA (2017) Occurrence of nausea, vomiting and diarrhoea reported as adverse events in clinical trials studying glucagon-like peptide-1 receptor agonists: a systematic analysis of published clinical trials. Diabetes Obes Metab 19:336-347.

Bhasin S, Wallace W, Lawrence JB, and Lesch M (1981) Sudden death associated with thyroid hormone abuse. Am J Med 71:887-890.

Billington CJ, Briggs JE, Link JG, and Levine AS (1991) Glucagon in physiological concentrations stimulates brown fat thermogenesis in vivo. Am $J$ Physiol 261 R501-R507.

Bleicher L, Aparicio R, Nunes FM, Martinez L, Gomes Dias SM, Figueira AC, Santos MA, Venturelli WH, da Silva R, Donate PM, et al. (2008) Structural basis of GC-1 selectivity for thyroid hormone receptor isoforms. BMC Struct Biol 8:8.

Blundell J, Finlayson G, Axelsen M, Flint A, Gibbons C, Kvist T, and Hjerpsted JB (2017) Effects of once-weekly semaglutide on appetite, energy intake, control of eating, food preference and body weight in subjects with obesity. Diabetes Obes Metab 19:1242-1251.

Blundell JE, Tombros E, Rogers PJ, and Latham CJ (1980) Behavioural analysis of feeding: implications for the pharmacological manipulation of food intake in animals and man. Prog Neuropsychopharmacol 4:319-326.
Bojsen-Møller KN, Dirksen C, Jørgensen NB, Jacobsen SH, Serup AK, Albers PH, Hansen DL, Worm D, Naver L, Kristiansen VB, et al. (2014) Early enhancements of hepatic and later of peripheral insulin sensitivity combined with increased postprandial insulin secretion contribute to improved glycemic control after Roux-en-Y gastric bypass. Diabetes 63:1725-1737.

Borngraeber S, Budny MJ, Chiellini G, Cunha-Lima ST, Togashi M, Webb P, Baxter JD, Scanlan TS, and Fletterick RJ (2003) Ligand selectivity by seeking hydrophobicity in thyroid hormone receptor. Proc Natl Acad Sci USA 100: 15358-15363.

Brand CL, Jørgensen PN, Svendsen I, and Holst JJ (1996) Evidence for a major role for glucagon in regulation of plasma glucose in conscious, nondiabetic, and alloxaninduced diabetic rabbits. Diabetes 45:1076-1083.

Brandt SJ, Götz A, Tschöp MH, and Müller TD (2018) Gut hormone polyagonists for the treatment of type 2 diabetes. Peptides 100:190-201.

Brauer LH, Johanson CE, Schuster CR, Rothman RB, and de Wit H (1996) Evaluation of phentermine and fenfluramine, alone and in combination, in normal, healthy volunteers. Neuropsychopharmacology 14:233-241.

Breisch ST, Zemlan FP, and Hoebel BG (1976) Hyperphagia and obesity following serotonin depletion by intraventricular p-chlorophenylalanine. Science 192: $382-385$

Bretherton-Watt D, Ghatei MA, Legon S, Jamal H, Suda K, and Bloom SR (1991) Depletion of islet amyloid polypeptide in the spontaneously diabetic (BB) Wistar rat. J Mol Endocrinol 6:3-7.

Briggs JH, Newland PM, and Bishop PM (1960) Phenmetrazine hydrochloride in treatment of obesity. BMJ 2:911-912.

Brolin RE, Robertson LB, Kenler HA, and Cody RP (1994) Weight loss and dietary intake after vertical banded gastroplasty and Roux-en-Y gastric bypass. Ann Surg 220:782-790.

Brown JC (1971) A gastric inhibitory polypeptide. I. The amino acid composition and the tryptic peptides. Can J Biochem 49:255-261.

Brown JC and Pederson RA (1970) A multiparameter study on the action of preparations containing cholecystokinin-pancreozymin. Scand $J$ Gastroenterol 5 $537-541$.

Burge JC, Schaumburg JZ, Choban PS, DiSilvestro RA, and Flancbaum L (1995) Changes in patients' taste acuity after Roux-en-Y gastric bypass for clinically severe obesity. J Am Diet Assoc 95:666-670.

Burke LK and Heisler LK (2015) 5-Hydroxytryptamine medications for the treatment of obesity. J Neuroendocrinol 27:389-398.

Burmeister MA, Ayala JE, Smouse H, Landivar-Rocha A, Brown JD, Drucker DJ, Stoffers DA, Sandoval DA, Seeley RJ, and Ayala JE (2017) The hypothalamic glucagon-like peptide 1 receptor is sufficient but not necessary for the regulation of energy balance and glucose homeostasis in mice. Diabetes 66:372-384

Bush MA, Matthews JE, De Boever EH, Dobbins RL, Hodge RJ, Walker SE, Holland MC, Gutierrez M, and Stewart MW (2009) Safety, tolerability, pharmacodynamics and pharmacokinetics of albiglutide, a long-acting glucagon-like peptide-1 mimetic in healthy subjects. Diabetes Obes Metab 11:498-505.

Butler PC and Rizza RA (1991) Contribution to postprandial hyperglycemia and effect on initial splanchnic glucose clearance of hepatic glucose cycling in glucoseintolerant or NIDDM patients. Diabetes 40:73-81.

Calanna S, Christensen M, Holst JJ, Laferrère B, Gluud LL, Vilsbøll T, and Knop FK (2013) Secretion of glucose-dependent insulinotropic polypeptide in patients with type 2 diabetes: systematic review and meta-analysis of clinical studies. Diabetes Care 36:3346-3352.

Campbell JE and Drucker DJ (2013) Pharmacology, physiology, and mechanisms of incretin hormone action. Cell Metab 17:819-837.

Campbell JE, Ussher JR, Mulvihill EE, Kolic J, Baggio LL, Cao X, Liu Y, Lamont BJ, Morii T, Streutker CJ, et al. (2016) TCF1 links GIPR signaling to the control of beta cell function and survival. Nat Med 22:84-90.

Campfield LA, Smith FJ, Guisez Y, Devos R, and Burn P (1995) Recombinant mouse OB protein: evidence for a peripheral signal linking adiposity and central neura networks. Science 269:546-549.

Cannistra LB, Davis SM, and Bauman AG (1997) Valvular heart disease associated with dexfenfluramine. $N$ Engl J Med 337:636.

Cao X, Xu P, Oyola MG, Xia Y, Yan X, Saito K, Zou F, Wang C, Yang Y, Hinton A Jr, et al. (2014) Estrogens stimulate serotonin neurons to inhibit binge-like eating in mice. J Clin Invest 124:4351-4362.

Caren R and Corbo L (1960) Glucagon and cholesterol metabolism. Metabolism 9 938-945.

Carlsson LM, Peltonen M, Ahlin S, Anveden Å, Bouchard C, Carlsson B, Jacobson P, Lönroth H, Maglio C, Näslund I, et al. (2012) Bariatric surgery and prevention of type 2 diabetes in Swedish obese subjects. N Engl J Med 367:695-704.

Caro JF, Kolaczynski JW, Nyce MR, Ohannesian JP, Opentanova I, Goldman WH Lynn RB, Zhang PL, Sinha MK, and Considine RV (1996) Decreased cerebrospinalfluid/serum leptin ratio in obesity: a possible mechanism for leptin resistance. Lancet 348:159-161.

Carswell KA, Vincent RP, Belgaumkar AP, Sherwood RA, Amiel SA, Patel AG, and le Roux CW (2014) The effect of bariatric surgery on intestinal absorption and transit time. Obes Surg 24:796-805.

Cegla J, Troke RC, Jones B, Tharakan G, Kenkre J, McCullough KA, Lim CT, Parvizi N, Hussein M, Chambers ES, et al. (2014) Coinfusion of low-dose GLP-1 and glucagon in man results in a reduction in food intake. Diabetes 63:3711-3720.

Centers for Disease Control and Prevention (CDC) (1997) Cardiac valvulopathy associated with exposure to fenfluramine or dexfenfluramine: U.S. Department of Health and Human Services interim public health recommendations, November 1997. MMWR Morb Mortal Wkly Rep 46:1061-1066.

Chabenne JR, DiMarchi MA, Gelfanov VM, and DiMarchi RD (2010) Optimization of the native glucagon sequence for medicinal purposes. J Diabetes Sci Technol 4 1322-1331.

Chakradhar S (2016) All in one: researchers create combination drugs for diabetes and obesity. Nat Med 22:694-696. 
Chan JL, Roth JD, and Weyer C (2009) It takes two to tango: combined amylin/leptin agonism as a potential approach to obesity drug development. J Investig Med 57: 777-783.

Chance WT, Balasubramaniam A, Zhang FS, Wimalawansa SJ, and Fischer JE (1991) Anorexia following the intrahypothalamic administration of amylin. Brain Res 539:352-354.

Chang AM, Jakobsen G, Sturis J, Smith MJ, Bloem CJ, An B, Galecki A, and Halter JB (2003) The GLP-1 derivative NN2211 restores beta-cell sensitivity to glucose in type 2 diabetic patients after a single dose. Diabetes $\mathbf{5 2}$ 1786-1791.

Chong AY, Lupsa BC, Cochran EK, and Gorden P (2010) Efficacy of leptin therapy in the different forms of human lipodystrophy. Diabetologia 53:27-35.

Christensen M, Vedtofte L, Holst JJ, Vilsbøll T, and Knop FK (2011) Glucosedependent insulinotropic polypeptide: a bifunctional glucose-dependent regulator of glucagon and insulin secretion in humans. Diabetes 60:3103-3109.

Christensen MB, Calanna S, Holst JJ, Vilsbøll T, and Knop FK (2014) Glucosedependent insulinotropic polypeptide: blood glucose stabilizing effects in patients with type 2 diabetes. J Clin Endocrinol Metab 99:E418-E426.

Christensen R, Kristensen PK, Bartels EM, Bliddal H, and Astrup A (2007) Efficacy and safety of the weight-loss drug rimonabant: a meta-analysis of randomised trials. Lancet 370:1706-1713.

Chu SC, Chen PN, Hsieh YS, Yu CH, Lin MH, Lin YH, and Kuo DY (2014) Involvement of hypothalamic PI3K-STAT3 signalling in regulating appetite suppression mediated by amphetamine. Br J Pharmacol 171:3223-3233.

Clark A, Saad MF, Nezzer T, Uren C, Knowler WC, Bennett PH, and Turner RC (1990) Islet amyloid polypeptide in diabetic and non-diabetic Pima Indians. Diabetologia 33:285-289.

Clarke Z (2007) xPharm: The Comprehensive Pharmacology Reference, Elsevier, Boston.

Clein LJ and Benady DR (1962) Case of diethylpropion addiction. BMJ 2:456.

Clemmensen C, Chabenne J, Finan B, Sullivan L, Fischer K, Küchler D, Sehrer L, Ograjsek T, Hofmann SM, Schriever SC, et al. (2014) GLP-1/glucagon coagonism restores leptin responsiveness in obese mice chronically maintained on an obesogenic diet. Diabetes 63:1422-1427.

Clemmensen C, Finan B, Fischer K, Tom RZ, Legutko B, Sehrer L, Heine D, Grassl N, Meyer CW, Henderson B, et al. (2015) Dual melanocortin-4 receptor and GLP-1 receptor agonism amplifies metabolic benefits in diet-induced obese mice. $E M B O$ Mol Med 7:288-298.

Cohen PA, Goday A, and Swann JP (2012) The return of rainbow diet pills. Am J Public Health 102:1676-1686.

Colman E (2005) Anorectics on trial: a half century of federal regulation of prescription appetite suppressants. Ann Intern Med 143:380-385.

Colman E (2007) Dinitrophenol and obesity: an early twentieth-century regulatory dilemma. Regul Toxicol Pharmacol 48:115-117.

Connolly HM, Crary JL, McGoon MD, Hensrud DD, Edwards BS, Edwards WD, and Schaff HV (1997) Valvular heart disease associated with fenfluraminephentermine. $N$ Engl J Med 337:581-588.

Contreras C, González-García I, Martínez-Sánchez N, Seoane-Collazo P, Jacas J, Morgan DA, Serra D, Gallego R, Gonzalez F, Casals N, et al. (2014) Central ceramide-induced hypothalamic lipotoxicity and ER stress regulate energy balance. Cell Reports 9:366-377.

Cooper GJ, Leighton B, Dimitriadis GD, Parry-Billings M, Kowalchuk JM, Howland K, Rothbard JB, Willis AC, and Reid KB (1988) Amylin found in amyloid deposits in human type 2 diabetes mellitus may be a hormone that regulates glycogen metabolism in skeletal muscle. Proc Natl Acad Sci USA 85:7763-7766.

Cooper GJ, Willis AC, Clark A, Turner RC, Sim RB, and Reid KB (1987) Purification and characterization of a peptide from amyloid-rich pancreases of type 2 diabetic patients. Proc Natl Acad Sci USA 84:8628-8632.

Costa E, Groppetti A, and Revuelta A (1971) Action of fenfluramine on monoamine stores of rat tissues. $\mathrm{Br}$ J Pharmacol 41:57-64.

Cota D, Tschöp MH, Horvath TL, and Levine AS (2006) Cannabinoids, opioids and eating behavior: the molecular face of hedonism? Brain Res Brain Res Rev 51: 85-107.

Creutzfeldt W, Ebert R, Willms B, Frerichs H, and Brown JC (1978) Gastric inhibitory polypeptide (GIP) and insulin in obesity: increased response to stimulation and defective feedback control of serum levels. Diabetologia 14:15-24.

Cummings DE, Weigle DS, Frayo RS, Breen PA, Ma MK, Dellinger EP, and Purnell JQ (2002) Plasma ghrelin levels after diet-induced weight loss or gastric bypass surgery. N Engl J Med 346:1623-1630.

Cutting WC, Mehrtens HG, and Tainter ML (1933) Actions and uses of dinitrophenol. JAMA 101:193-195.

Dakin CL, Gunn I, Small CJ, Edwards CM, Hay DL, Smith DM, Ghatei MA, and Bloom SR (2001) Oxyntomodulin inhibits food intake in the rat. Endocrinology 142:4244-4250.

Dakin CL, Small CJ, Batterham RL, Neary NM, Cohen MA, Patterson M, Ghatei MA, and Bloom SR (2004) Peripheral oxyntomodulin reduces food intake and body weight gain in rats. Endocrinology 145:2687-2695.

Dakin CL, Small CJ, Park AJ, Seth A, Ghatei MA, and Bloom SR (2002) Repeated ICV administration of oxyntomodulin causes a greater reduction in body weight gain than in pair-fed rats. Am J Physiol Endocrinol Metab 283: E1173-E1177.

Davidson MH, Hauptman J, DiGirolamo M, Foreyt JP, Halsted CH, Heber D, Heimburger DC, Lucas CP, Robbins DC, Chung J, et al. (1999) Weight control and risk factor reduction in obese subjects treated for 2 years with orlistat: a randomized controlled trial. JAMA 281:235-242.

Day JW, Gelfanov V, Smiley D, Carrington PE, Eiermann G, Chicchi G, Erion MD, Gidda J, Thornberry NA, Tschöp MH, et al. (2012) Optimization of co-agonism at GLP-1 and glucagon receptors to safely maximize weight reduction in DIO-rodents. Biopolymers 98:443-450.
Day JW, Ottaway N, Patterson JT, Gelfanov V, Smiley D, Gidda J, Findeisen H, Bruemmer D, Drucker DJ, Chaudhary N, et al. (2009) A new glucagon and GLP-1 co-agonist eliminates obesity in rodents. Nat Chem Biol 5:749-757.

Deacon CF, Johnsen AH, and Holst JJ (1995) Degradation of glucagon-like peptide-1 by human plasma in vitro yields an N-terminally truncated peptide that is a major endogenous metabolite in vivo. J Clin Endocrinol Metab 80:952-957.

de Castro JM, Paullin SK, and DeLugas GM (1978) Insulin and glucagon as determinants of body weight set point and microregulation in rats. J Comp Physiol Psychol 92:571-579.

Degn KB, Juhl CB, Sturis J, Jakobsen G, Brock B, Chandramouli V, Rungby J, Landau BR, and Schmitz O (2004) One week's treatment with the long-acting glucagon-like peptide 1 derivative liraglutide (NN2211) markedly improves 24-h glycemia and alpha- and beta-cell function and reduces endogenous glucose release in patients with type 2 diabetes. Diabetes 53:1187-1194.

De Oya M, Prigge WF, Swenson DE, and Grande F (1971) Role of glucagon on fatty liver production in birds. Am J Physiol 221:25-30.

Després JP, Golay A, and Sjöström L; Rimonabant in Obesity-Lipids Study Group (2005) Effects of rimonabant on metabolic risk factors in overweight patients with dyslipidemia. N Engl J Med 353:2121-2134.

Deter RL (1971) Quantitative characterization of dense body, autophagic vacuole, and acid phosphatase-bearing particle populations during the early phases of glucagon-induced autophagy in rat liver. J Cell Biol 48:473-489.

Deter RL and De Duve C (1967) Influence of glucagon, an inducer of cellular autophagy, on some physical properties of rat liver lysosomes. J Cell Biol 33:437-449. Dietrich MO and Horvath TL (2012) Limitations in anti-obesity drug development: the critical role of hunger-promoting neurons. Nat Rev Drug Discov 11:675-691.

Dinneen S, Alzaid A, Turk D, and Rizza R (1995) Failure of glucagon suppression contributes to postprandial hyperglycaemia in IDDM. Diabetologia 38:337-343.

Doi K and Kuroshima A (1982) Modified metabolic responsiveness to glucagon in cold-acclimated and heat-acclimated rats. Life Sci 30:785-791.

Drent ML, Larsson I, William-Olsson T, Quaade F, Czubayko F, von Bergmann K, Strobel W, Sjöström L, and van der Veen EA (1995) Orlistat (Ro 18-0647), a lipase inhibitor, in the treatment of human obesity: a multiple dose study. Int J Obes Relat Metab Disord 19:221-226.

Drucker DJ (2006) The biology of incretin hormones. Cell Metab 3:153-165.

Drucker DJ (2016) The cardiovascular biology of glucagon-like peptide-1. Cell Metab 24:15-30.

Drucker DJ, Philippe J, Mojsov S, Chick WL, and Habener JF (1987) Glucagon-like peptide I stimulates insulin gene expression and increases cyclic AMP levels in a rat islet cell line. Proc Natl Acad Sci USA 84:3434-3438.

Dunlop DM (1934) The use of 2-4 dinitrophenol as a metabolic stimulant. BMJ 1: 524-527.

Dupre J, Ross SA, Watson D, and Brown JC (1973) Stimulation of insulin secretion by gastric inhibitory polypeptide in man. J Clin Endocrinol Metab 37:826-828.

Eaton RP (1973) Hypolipemic action of glucagon in experimental endogenous lipemia in the rat. $J$ Lipid Res 14:312-318.

Ebert R, Nauck M, and Creutzfeldt W (1991) Effect of exogenous or endogenous gastric inhibitory polypeptide (GIP) on plasma triglyceride responses in rats. Horm Metab Res 23:517-521.

Ebihara K, Kusakabe T, Hirata M, Masuzaki H, Miyanaga F, Kobayashi N, Tanaka T, Chusho H, Miyazawa T, Hayashi T, et al. (2007) Efficacy and safety of leptinreplacement therapy and possible mechanisms of leptin actions in patients with generalized lipodystrophy. J Clin Endocrinol Metab 92:532-541.

Eckel RH, Fujimoto WY, and Brunzell JD (1979) Gastric inhibitory polypeptide enhanced lipoprotein lipase activity in cultured preadipocytes. Diabetes 28: 1141-1142.

Edvell A and Lindström P (1999) Initiation of increased pancreatic islet growth in young normoglycemic mice (Umeå +/?). Endocrinology 140:778-783.

Edvinsson L and Linde M (2010) New drugs in migraine treatment and prophylaxis: telcagepant and topiramate. Lancet 376:645-655.

El-Haschimi K, Pierroz DD, Hileman SM, Bjørbaek C, and Flier JS (2000) Two defects contribute to hypothalamic leptin resistance in mice with diet-induced obesity. J Clin Invest 105:1827-1832.

Enoki S, Mitsukawa T, Takemura J, Nakazato M, Aburaya J, Toshimori H, and Matsukara S (1992) Plasma islet amyloid polypeptide levels in obesity, impaired glucose tolerance and non-insulin-dependent diabetes mellitus. Diabetes Res Clin Pract 15:97-102.

Erion MD, Cable EE, Ito BR, Jiang H, Fujitaki JM, Finn PD, Zhang BH, Hou J, Boyer $\mathrm{SH}$, van Poelje PD, et al. (2007) Targeting thyroid hormone receptor-beta agonists to the liver reduces cholesterol and triglycerides and improves the therapeutic index. Proc Natl Acad Sci USA 104:15490-15495.

Evers A, Haack T, Lorenz M, Bossart M, Elvert R, Henkel B, Stengelin S, Kurz M, Glien M, Dudda A, et al. (2017) Design of novel exendin-based dual glucagon-like peptide 1 (GLP-1)/glucagon receptor agonists. J Med Chem 60:4293-4303.

Fantuzzi G and Faggioni R (2000) Leptin in the regulation of immunity, inflammation, and hematopoiesis. J Leukoc Biol 68:437-446.

Farhy LS and McCall AL (2015) Glucagon: the new 'insulin' in the pathophysiology of diabetes. Curr Opin Clin Nutr Metab Care 18:407-414.

Faria G, Preto J, da Costa EL, Guimarães JT, Calhau C, and Taveira-Gomes A (2013) Acute improvement in insulin resistance after laparoscopic Roux-en-Y gastric bypass: is 3 days enough to correct insulin metabolism? Obes Surg 23:103-110.

Farilla L, Hui H, Bertolotto C, Kang E, Bulotta A, Di Mario U, and Perfetti R (2002) Glucagon-like peptide-1 promotes islet cell growth and inhibits apoptosis in Zucker diabetic rats. Endocrinology 143:4397-4408

Farooqi IS, Jebb SA, Langmack G, Lawrence E, Cheetham CH, Prentice AM, Hughes IA, McCamish MA, and O'Rahilly S (1999) Effects of recombinant leptin therapy in a child with congenital leptin deficiency. $N$ Engl J Med 341:879-884.

Farooqi IS, Matarese G, Lord GM, Keogh JM, Lawrence E, Agwu C, Sanna V, Jebb SA, Perna F, Fontana S, et al. (2002) Beneficial effects of leptin on obesity, T cell 
hyporesponsiveness, and neuroendocrine/metabolic dysfunction of human congenital leptin deficiency. $J$ Clin Invest 110:1093-1103.

Felig P, Wahren J, and Hendler R (1978) Influence of maturity-onset diabetes on splanchnic glucose balance after oral glucose ingestion. Diabetes 27:121-126.

Finan B, Clemmensen C, and Müller TD (2015a) Emerging opportunities for the treatment of metabolic diseases: glucagon-like peptide-1 based multi-agonists. $\mathrm{Mol}$ Cell Endocrinol 418:42-54.

Finan B, Clemmensen C, Zhu Z, Stemmer K, Gauthier K, Muller L, De Angelis M, Moreth K, Neff F, Perez-Tilve D, et al. (2016a) Chemical hybridization of glucagon and thyroid hormone optimizes therapeutic impact for metabolic disease. Cell 167: 843-857.e14.

Finan B, Ma T, Ottaway N, Müller TD, Habegger KM, Heppner KM, Kirchner H, Holland J, Hembree J, Raver C, et al. (2013) Unimolecular dual incretins maximize metabolic benefits in rodents, monkeys, and humans. Sci Transl Med $\mathbf{5}$ : 209 ra151.

Finan B, Müller TD, Clemmensen C, Perez-Tilve D, DiMarchi RD, and Tschöp MH (2016b) Reappraisal of GIP pharmacology for metabolic diseases. Trends Mol Med 22:359-376.

Finan B, Yang B, Ottaway N, Smiley DL, Ma T, Clemmensen C, Chabenne J, Zhang L, Habegger KM, Fischer K, et al. (2015b) A rationally designed monomeric peptide triagonist corrects obesity and diabetes in rodents. Nat Med 21:27-36.

Finan B, Yang B, Ottaway N, Stemmer K, Müller TD, Yi CX, Habegger K, Schriever SC, García-Cáceres C, Kabra DG, et al. (2012) Targeted estrogen delivery reverses the metabolic syndrome. Nat Med 18:1847-1856.

Finer N, Craddock D, Lavielle R, and Keen H (1988) Effect of 6 months therapy with dexfenfluramine in obese patients: studies in the United Kingdom. Clin Neuropharmacol 11 (Suppl 1):S179-S186.

Flatt PR, Bailey CJ, Kwasowski P, Swanston-Flatt SK, and Marks V (1983) Abnormalities of GIP in spontaneous syndromes of obesity and diabetes in mice. Diabetes 32:433-435.

Freake HC, Schwartz HL, and Oppenheimer JH (1989) The regulation of lipogenesis by thyroid hormone and its contribution to thermogenesis. Endocrinology 125: $2868-2874$.

Fujioka K, Seaton TB, Rowe E, Jelinek CA, Raskin P, Lebovitz HE, and Weinstein SP; Sibutramine/Diabetes Clinical Study Group (2000) Weight loss with sibutramine improves glycaemic control and other metabolic parameters in obese patients with type 2 diabetes mellitus. Diabetes Obes Metab 2:175-187.

Galletly C, Clark A, and Tomlinson L (1996) Evaluation of dexfenfluramine in a weight loss program for obese infertile women. Int $J$ Eat Disord 19:209-212.

Galløe AM, Rolff M, Nordin H, Ladefoged SD, and Mogensen NB (1993) Cardiac performance and thyroid function: the correlation between systolic time intervals, heart rate and thyroid hormone levels. Dan Med Bull 40:492-495.

Gao Q, Mezei G, Nie Y, Rao Y, Choi CS, Bechmann I, Leranth C, Toran-Allerand D, Priest CA, Roberts JL, et al. (2007) Anorectic estrogen mimics leptin's effect on the rewiring of melanocortin cells and Stat3 signaling in obese animals. Nat Med 13: 89-94

Garattini S (1981) Central mechanisms of fenfluramine and related anorectic drugs. Jpn J Pharmacol 31 (Suppl):29P-35P.

Garattini S, Mennini T, Bendotti C, Invernizzi R, and Samanin R (1986) Neurochemical mechanism of action of drugs which modify feeding via the serotoninergic system. Appetite 7 (Suppl):15-38.

Garfield AS and Heisler LK (2009) Pharmacological targeting of the serotonergic system for the treatment of obesity. J Physiol 587:49-60.

Garvey WT, Ryan DH, Bohannon NJ, Kushner RF, Rueger M, Dvorak RV, and Troupin B (2014a) Weight-loss therapy in type 2 diabetes: effects of phentermine and topiramate extended release. Diabetes Care 37:3309-3316.

Garvey WT, Ryan DH, Henry R, Bohannon NJ, Toplak H, Schwiers M, Troupin B, and Day WW (2014b) Prevention of type 2 diabetes in subjects with prediabetes and metabolic syndrome treated with phentermine and topiramate extended release. Diabetes Care 37:912-921.

Garvey WT, Ryan DH, Look M, Gadde KM, Allison DB, Peterson CA, Schwiers M, Day WW, and Bowden CH (2012) Two-year sustained weight loss and metabolic benefits with controlled-release phentermine/topiramate in obese and overweight adults (SEQUEL): a randomized, placebo-controlled, phase 3 extension study. Am J Clin Nutr 95:297-308.

Gault VA, Kerr BD, Harriott P, and Flatt PR (2011) Administration of an acylated GLP-1 and GIP preparation provides added beneficial glucose-lowering and insulinotropic actions over single incretins in mice with type 2 diabetes and obesity. Clin Sci (Lond) 121:107-117.

Gerich JE, Langlois M, Noacco C, Lorenzi M, Karam JH, and Korsham PH (1976) Comparison of the suppressive effects of elevated plasma glucose and free fatty acid levels on glucagon secretion in normal and insulin-dependent diabetic subjects: evidence for selective alpha-cell insensitivity to glucose in diabetes mellitus. $J$ Clin Invest 58:320-325.

Gerich JE, Lorenzi M, Schneider V, Karam JH, Rivier J, Guillemin R, and Forsham PH (1974) Effects of somatostatin on plasma glucose and glucagon levels in human diabetes mellitus: pathophysiologic and therapeutic implications. $N$ Engl J Med 291:544-547.

Geyer G, Haidinger G, Francesconi M, Langmayr N, Prager R, Schoberberger R, Toplak H, von Kalckreuth G, and Kunze M (1995) Effect of dexfenfluramine on eating behavior and body weight of obese patients: results of a field study of Isomeride in Austrian general practice. Acta Med Austriaca 22:95-101, 104-109.

Glaesner W, Vick AM, Millican R, Ellis B, Tschang SH, Tian Y, Bokvist K, Brenner M, Koester A, Porksen N, et al. (2010) Engineering and characterization of the long-acting glucagon-like peptide-1 analogue LY2189265, an Fc fusion protein Diabetes Metab Res Rev 26:287-296.

Glick G, Parmley WW, Wechsler AS, and Sonnenblick EH (1968) Glucagon: its en hancement of cardiac performance in the cat and dog and persistence of its inotropic action despite beta-receptor blockade with propranolol. Circ Res 22:789-799.
Gögebakan O, Andres J, Biedasek K, Mai K, Kühnen P, Krude H, Isken F, Rudovich N, Osterhoff MA, Kintscher U, et al (2012) Glucose-dependent insulinotropic polypeptide reduces fat-specific expression and activity of $11 \beta$-hydroxysteroid dehydrogenase type 1 and inhibits release of free fatty acids. Diabetes 61:292-300.

Gong DW, He Y, Karas M, and Reitman M (1997) Uncoupling protein-3 is a mediator of thermogenesis regulated by thyroid hormone, beta3-adrenergic agonists, and leptin. J Biol Chem 272:24129-24132.

González N, Acitores A, Sancho V, Valverde I, and Villanueva-Peñacarrillo ML (2005) Effect of GLP-1 on glucose transport and its cell signalling in human myocytes. Regul Pept 126:203-211.

Götestam KG and Andersson BE (1975) Self-administration of amphetamine analogues in rats. Pharmacol Biochem Behav 3:229-233.

Gotfredsen CF, Mølck AM, Thorup I, Nyborg NC, Salanti Z, Knudsen LB, and Larsen MO (2014) The human GLP-1 analogs liraglutide and semaglutide: absence of histopathological effects on the pancreas in nonhuman primates. Diabetes 63 $2486-2497$.

Gratzer WB, Creeth JM, and Beaven GH (1972) Presence ot trimers in glucagon solution. Eur J Biochem 31:505-509.

Gregor MF and Hotamisligil GS (2011) Inflammatory mechanisms in obesity. Annu Rev Immunol 29:415-445.

Gros L, Hollande F, Thorens B, Kervran A, and Bataille D (1995) Comparative effects of GLP-1-(7-36) amide, oxyntomodulin and glucagon on rabbit gastric parietal cell function. Eur $J$ Pharmacol 288:319-327.

Grover GJ, Mellstrom K, and Malm J (2005) Development of the thyroid hormone receptor beta-subtype agonist KB-141: a strategy for body weight reduction and lipid lowering with minimal cardiac side effects. Cardiovasc Drug Rev 23: $133-148$

Grover GJ, Mellström K, Ye L, Malm J, Li YL, Bladh LG, Sleph PG, Smith MA George R, Vennström B, et al. (2003) Selective thyroid hormone receptor-beta activation: a strategy for reduction of weight, cholesterol, and lipoprotein (a) with reduced cardiovascular liability. Proc Natl Acad Sci USA 100:10067-10072.

Grundlingh J, Dargan PI, El-Zanfaly M, and Wood DM (2011) 2,4-Dinitrophenol (DNP): a weight loss agent with significant acute toxicity and risk of death. $J \mathrm{Med}$ Toxicol 7:205-212.

Guder W, Hepp KD, and Wieland O (1970) The catabolic action of glucagon in rat liver: the influence of age, nutritional state and adrenal function on the effect of glucagon on lysosomal N-acetyl-beta, D-glucosaminidase. Biochim Biophys Acta 222:593-605.

Guo F and Garvey WT (2016) Trends in cardiovascular health metrics in obese adults: National Health and Nutrition Examination Survey (NHANES), 1988-2014. J Am Heart Assoc 5 DOI:10.1161/JAHA.116.003619.

Gustafsson R, Tata JR, Lindberg O, and Ernster L (1965) The relationship between the structure and activity of rat skeletal muscle mitochondria after thyroidectomy and thyroid hormone treatment. J Cell Biol 26:555-578.

Hadden DR and Lucey C (1961) Diethylpropion in the treatment of obesity: a crossover trial of a long-acting preparation. Ulster Med $J$ 30:109-113.

Halaas JL, Gajiwala KS, Maffei M, Cohen SL, Chait BT, Rabinowitz D, Lallone RL, Burley SK, and Friedman JM (1995) Weight-reducing effects of the plasma protein encoded by the obese gene. Science 269:543-546.

Haleem DJ (2014) Investigations into the involvement of leptin in responses to stress. Behav Pharmacol 25:384-397.

Hall VE, Fiel J II, Sahyun M, Cutting WC, and Tainter ML (1933) Carbohydrate metabolism, respiration and circulation in animals with basal metabolism heightened by dinitrophenol. Am J Physiol 106:432-440.

Harper JA, Dickinson K, and Brand MD (2001) Mitochondrial uncoupling as a target for drug development for the treatment of obesity. Obes Rev 2:255-265.

Hartter E, Svoboda T, Lell B, Schuller M, Ludvik B, Woloszczuk W, and Prager R (1990) Reduced islet-amyloid polypeptide in insulin-dependent diabetes mellitus. Lancet 335:854.

Hauner H, Glatting G, Kaminska D, and Pfeiffer EF (1988) Effects of gastric inhibitory polypeptide on glucose and lipid metabolism of isolated rat adipocytes. Ann Nutr Metab 32:282-288.

Hauner H, Meier M, Wendland G, Kurscheid T, and Lauterbach K; Study Group SA SAT Study (2004) Weight reduction by sibutramine in obese subjects in primary care medicine: the SAT study. Exp Clin Endocrinol Diabetes 112:201-207.

Heal DJ, Aspley S, Prow MR, Jackson HC, Martin KF, and Cheetham SC (1998) Sibutramine: a novel anti-obesity drug: a review of the pharmacological evidence to differentiate it from d-amphetamine and d-fenfluramine. Int $J$ Obes Relat Metab Disord 22 (Suppl 1):S18-S28; discussion S29.

Hebebrand J, Muller TD, Holtkamp K, and Herpertz-Dahlmann B (2007) The role of leptin in anorexia nervosa: clinical implications. Mol Psychiatry 12:23-35.

Hedbacker K, Birsoy K, Wysocki RW, Asilmaz E, Ahima RS, Farooqi IS, and Friedman JM (2010) Antidiabetic effects of IGFBP2, a leptin-regulated gene. Cell Metab 11:11-22.

Heisler LK, Cowley MA, Tecott LH, Fan W, Low MJ, Smart JL, Rubinstein M, Tatro JB, Marcus JN, Holstege H, et al. (2002) Activation of central melanocortin pathways by fenfluramine. Science 297:609-611.

Heisler LK, Jobst EE, Sutton GM, Zhou L, Borok E, Thornton-Jones Z, Liu HY, Zigman JM, Balthasar N, Kishi T, et al. (2006) Serotonin reciprocally regulates melanocortin neurons to modulate food intake. Neuron 51:239-249.

Henderson SJ, Konkar A, Hornigold DC, Trevaskis JL, Jackson R, Fritsch Fredin M Jansson-Löfmark R, Naylor J, Rossi A, Bednarek MA, et al. (2016) Robust antiobesity and metabolic effects of a dual GLP-1/glucagon receptor peptide agonist in rodents and non-human primates. Diabetes Obes Metab 18:1176-1190.

Hendricks EJ, Rothman RB, and Greenway FL (2009) How physician obesity specialists use drugs to treat obesity. Obesity (Silver Spring) 17:1730-1735.

Henry RC (1967) Weight reduction pills. JAMA 201:895-896.

Herrmann K, Frias JP, Edelman SV, Lutz K, Shan K, Chen S, Maggs D, and Kolterman OG (2013) Pramlintide improved measures of glycemic control and 
body weight in patients with type 1 diabetes mellitus undergoing continuous subcutaneous insulin infusion therapy. Postgrad Med 125:136-144.

Hess B and Martius C (1951) The mode of action of thyroxin. Arch Biochem Biophys 33:486-487.

Heymsfield SB, Greenberg AS, Fujioka K, Dixon RM, Kushner R, Hunt T, Lubina JA, Patane J, Self B, Hunt P, et al. (1999) Recombinant leptin for weight loss in obese and lean adults: a randomized, controlled, dose-escalation trial. JAMA 282 $1568-1575$.

Heymsfield SB and Wadden TA (2017) Mechanisms, pathophysiology, and management of obesity. $N$ Engl $J$ Med 376:254-266.

Higgins GA and Fletcher PJ (2015) Therapeutic potential of 5-HT2C receptor agonists for addictive disorders. ACS Chem Neurosci 6:1071-1088.

Higgins GA, Silenieks LB, Altherr EB, MacMillan C, Fletcher PJ, and Pratt WE (2016) Lorcaserin and CP-809101 reduce motor impulsivity and reinstatement of food seeking behavior in male rats: implications for understanding the anti-obesity property of 5-HT2C receptor agonists. Psychopharmacology (Berl) 233:2841-2856.

Hjorth SA, Adelhorst K, Pedersen BB, Kirk O, and Schwartz TW (1994) Glucagon and glucagon-like peptide 1: selective receptor recognition via distinct peptide epitopes. J Biol Chem 269:30121-30124.

Holdaway IM, Wallace E, Westbrooke L, and Gamble G (1995) Effect of dexfenfluramine on body weight, blood pressure, insulin resistance and serum cholesterol in obese individuals. Int J Obes Relat Metab Disord 19:749-751.

Hollander PA, Elbein SC, Hirsch IB, Kelley D, McGill J, Taylor T, Weiss SR, Crockett SE, Kaplan RA, Comstock J, et al. (1998) Role of orlistat in the treatment of obese patients with type 2 diabetes: a 1-year randomized double-blind study. Diabetes Care 21:1288-1294.

Holst JJ (2007) The physiology of glucagon-like peptide 1. Physiol Rev 87:1409-1439.

Horner WD (1936) Cataract following dinitrophenol treatment for obesity. Arch Ophthal 16:447-461.

Horner WD (1941) A study of dinitrophenol and its relation to cataract formation. Trans Am Ophthalmol Soc 39:405-437.

Horner WD, Jones RB, and Boardman WW (1935) Cataracts following the use of dinitrophenol, preliminary report of 3 cases. JAMA 13:108-110.

Hotamisligil GS (2006) Inflammation and metabolic disorders. Nature 444:860-867.

Hotamisligil GS and Erbay E (2008) Nutrient sensing and inflammation in metabolic diseases. Nat Rev Immunol 8:923-934.

Hotamisligil GS, Peraldi P, Budavari A, Ellis R, White MF, and Spiegelman BM (1996) IRS-1-mediated inhibition of insulin receptor tyrosine kinase activity in TNF-alpha- and obesity-induced insulin resistance. Science 271:665-668.

Hotamisligil GS, Shargill NS, and Spiegelman BM (1993) Adipose expression of tumor necrosis factor-alpha: direct role in obesity-linked insulin resistance. Science 259:87-91.

Hotamisligil GS and Spiegelman BM (1994) Tumor necrosis factor alpha: a key component of the obesity-diabetes link. Diabetes 43:1271-1278.

Hsiao AL, Santucci KA, Seo-Mayer P, Mariappan MR, Hodsdon ME, Banasiak KJ, and Baum CR (2005) Pediatric fatality following ingestion of dinitrophenol: postmortem identification of a "dietary supplement." Clin Toxicol (Phila) 43: $281-285$

Hui H, Farilla L, Merkel P, and Perfetti R (2002) The short half-life of glucagon-like peptide-1 in plasma does not reflect its long-lasting beneficial effects. Eur $J$ Endocrinol 146:863-869.

Hui H, Nourparvar A, Zhao X, and Perfetti R (2003) Glucagon-like peptide-1 inhibits apoptosis of insulin-secreting cells via a cyclic $5^{\prime}$-adenosine monophosphatedependent protein kinase A- and a phosphatidylinositol 3-kinase-dependent pathway. Endocrinology 144:1444-1455.

Hukshorn CJ, Saris WH, Westerterp-Plantenga MS, Farid AR, Smith FJ, and Campfield LA (2000) Weekly subcutaneous pegylated recombinant native human leptin (PEG-OB) administration in obese men. J Clin Endocrinol Metab 85: $4003-4009$

Hukshorn CJ, van Dielen FM, Buurman WA, Westerterp-Plantenga MS, Campfield LA and Saris WH (2002) The effect of pegylated recombinant human leptin (PEG-OB) on weight loss and inflammatory status in obese subjects. Int $J$ Obes Relat Metab Disord 26:504-509.

Idris I, Patiag D, Gray S, and Donnelly R (2002) Exendin-4 increases insulin sensitivity via a PI-3-kinase-dependent mechanism: contrasting effects of GLP-1. Biochem Pharmacol 63:993-996.

Inagaki N, Seino Y, Takeda J, Yano H, Yamada Y, Bell GI, Eddy RL, Fukushima Y, Byers MG, Shows TB, et al. (1989) Gastric inhibitory polypeptide: structure and chromosomal localization of the human gene. Mol Endocrinol 3:1014-1021.

Inoue K, Hiramatsu S, Hisatomi A, Umeda F, and Nawata H (1993) Effects of amylin on the release of insulin and glucagon from the perfused rat pancreas. Horm Metab Res 25:135-137.

Irie S, Matsumura Y, Zdravkovic M, Jacobsen LV, and Kageyama S (2008) Tolerability, pharmacokinetics and pharmacodynamics of the once-daily human GLP-1 analog liraglutide in Japanese healthy subjects: a randomized, double-blind, placebo-controlled dose-escalation study. Int J Clin Pharmacol Ther 46:273-279.

Isbell JM, Tamboli RA, Hansen EN, Saliba J, Dunn JP, Phillips SE, Marks-Shulman PA, and Abumrad NN (2010) The importance of caloric restriction in the early improvements in insulin sensitivity after Roux-en-Y gastric bypass surgery. Diabetes Care 33:1438-1442.

Izmail-Beigi F and Edelman IS (1970) Mechanism of thyroid calorigenesis: role of active sodium transport. Proc Natl Acad Sci USA 67:1071-1078.

Jacobsen SH, Olesen SC, Dirksen C, Jørgensen NB, Bojsen-Møller KN, Kielgast U, Worm D, Almdal T, Naver LS, Hvolris LE, et al. (2012) Changes in gastrointestinal hormone responses, insulin sensitivity, and beta-cell function within 2 weeks after gastric bypass in non-diabetic subjects. Obes Surg 22:1084-1096.

Jall S, Sachs S, Clemmensen C, Finan B, Neff F, DiMarchi RD, Tschöp MH, Müller TD, and Hofmann SM (2017) Monomeric GLP-1/GIP/glucagon triagonism corrects obesity, hepatosteatosis, and dyslipidemia in female mice. Mol Metab 6:440-446.
James WP, Caterson ID, Coutinho W, Finer N, Van Gaal LF, Maggioni AP, TorpPedersen C, Sharma AM, Shepherd GM, Rode RA, et al.; SCOUT Investigators (2010) Effect of sibutramine on cardiovascular outcomes in overweight and obese subjects. N Engl J Med 363:905-917.

Jekabsons MB, Gregoire FM, Schonfeld-Warden NA, Warden CH, and Horwitz BA (1999) T(3) stimulates resting metabolism and UCP-2 and UCP-3 mRNA but not nonphosphorylating mitochondrial respiration in mice. Am $J$ Physiol 277: E380-E389.

Jiang G and Zhang BB (2003) Glucagon and regulation of glucose metabolism. Am J Physiol Endocrinol Metab 284:E671-E678.

Joel CD (1966) Stimulation of metabolism of rat brown adipose tissue by addition of lipolytic hormones in vitro. J Biol Chem 241:814-821.

Johannsen DL, Galgani JE, Johannsen NM, Zhang Z, Covington JD, and Ravussin E (2012) Effect of short-term thyroxine administration on energy metabolism and mitochondrial efficiency in humans. PLoS One 7:e40837.

Johnson KH, O'Brien TD, Jordan K, and Westermark P (1989) Impaired glucose tolerance is associated with increased islet amyloid polypeptide (IAPP) immunoreactivity in pancreatic beta cells. Am $J$ Pathol 135:245-250.

Jones BJ and Bloom SR (2015) The new era of drug therapy for obesity: the evidence and the expectations. Drugs 75:935-945.

Jørgensen NB, Jacobsen SH, Dirksen C, Bojsen-Møller KN, Naver L, Hvolris L, Clausen TR, Wulff BS, Worm D, Lindqvist Hansen D, et al. (2012) Acute and longterm effects of Roux-en-Y gastric bypass on glucose metabolism in subjects with type 2 diabetes and normal glucose tolerance. Am J Physiol Endocrinol Metab 303: E122-E131.

Jorgensen R, Kubale V, Vrecl M, Schwartz TW, and Elling CE (2007) Oxyntomodulin differentially affects glucagon-like peptide-1 receptor beta-arrestin recruitment and signaling through Galpha(s). J Pharmacol Exp Ther 322:148-154.

Jucker BM, Dufour S, Ren J, Cao X, Previs SF, Underhill B, Cadman KS, and Shulman GI (2000) Assessment of mitochondrial energy coupling in vivo by 13C/31P NMR. Proc Natl Acad Sci USA 97:6880-6884.

Juhl CB, Hollingdal M, Sturis J, Jakobsen G, Agersø H, Veldhuis J, Pørksen N, and Schmitz O (2002) Bedtime administration of NN2211, a long-acting GLP-1 derivative, substantially reduces fasting and postprandial glycemia in type 2 diabetes. Diabetes 51:424-429.

Kang JG, Park CY, Kang JH, Park YW, and Park SW (2010) Randomized controlled trial to investigate the effects of a newly developed formulation of phentermine diffuse-controlled release for obesity. Diabetes Obes Metab 12:876-882.

Kapitza C, Nosek L, Jensen L, Hartvig H, Jensen CB, and Flint A (2015) Semaglutide, a once-weekly human GLP-1 analog, does not reduce the bioavailability of the combined oral contraceptive, ethinylestradiol/levonorgestrel. J Clin Pharmacol 55: 497-504.

Katz RL, Hinds L, and Mills CJ (1969) Ability of glucagon to produce cardiac stimulation without arrhythmias in halothane-anaesthetized animals. $\mathrm{Br}$ J Anaesth 41: $574-578$.

Kazda CM, Ding Y, Kelly RP, Garhyan P, Shi C, Lim CN, Fu H, Watson DE, Lewin AJ, Landschulz WH, et al. (2016) Evaluation of efficacy and safety of the glucagon receptor antagonist LY2409021 in patients with type 2 diabetes: 12- and 24-week phase 2 studies. Diabetes Care 39:1241-1249.

Kelley D, Mokan M, and Veneman T (1994) Impaired postprandial glucose utilization in non-insulin-dependent diabetes mellitus. Metabolism 43:1549-1557.

Kelly RP, Garhyan P, Raddad E, Fu H, Lim CN, Prince MJ, Pinaire JA, Loh MT, and Deeg MA (2015) Short-term administration of the glucagon receptor antagonist LY2409021 lowers blood glucose in healthy people and in those with type 2 diabetes. Diabetes Obes Metab 17:414-422.

Khera R, Murad MH, Chandar AK, Dulai PS, Wang Z, Prokop LJ, Loomba R, Camilleri M, and Singh S (2016) Association of pharmacological treatments for obesity with weight loss and adverse events: a systematic review and meta-analysis. JAMA 315: $2424-2434$

Kieffer TJ, McIntosh CH, and Pederson RA (1995) Degradation of glucose-dependent insulinotropic polypeptide and truncated glucagon-like peptide 1 in vitro and in vivo by dipeptidyl peptidase IV. Endocrinology 136:3585-3596.

Kim KK, Cho HJ, Kang HC, Youn BB, and Lee KR (2006) Effects on weight reduction and safety of short-term phentermine administration in Korean obese people. Yonsei Med J 47:614-625.

Kim SJ, Nian C, Karunakaran S, Clee SM, Isales CM, and McIntosh CH (2012a) GIP-overexpressing mice demonstrate reduced diet-induced obesity and steatosis, and improved glucose homeostasis. PLoS One 7:e40156.

Kim SJ, Nian C, and McIntosh CH (2007) Resistin is a key mediator of glucosedependent insulinotropic polypeptide (GIP) stimulation of lipoprotein lipase (LPL) activity in adipocytes. $J$ Biol Chem 282:34139-34147.

Kim WD, Lee YH, Kim MH, Jung SY, Son WC, Yoon SJ, and Lee BW (2012b) Human monoclonal antibodies against glucagon receptor improve glucose homeostasis by suppression of hepatic glucose output in diet-induced obese mice. PLoS One 7: e50954.

Kimball C and Murlin J (1923) Aqueous extracts of pancreas. III. Some precipitation reactions of insulin. J Biol Chem 58:337-348.

Kleiner I (1919) The action of intravenous injections of pancreas emulsions in experimental diabetes. $J$ Biol Chem 40:153-170.

Knapper JM, Puddicombe SM, Morgan LM, Fletcher JM, and Marks V (1993) Glucose dependent insulinotropic polypeptide and glucagon-like peptide-1(7-36)amide: effects on lipoprotein lipase activity. Biochem Soc Trans 21:135S.

Kong MF, King P, Macdonald IA, Stubbs TA, Perkins AC, Blackshaw PE, Moyses C, and Tattersall RB (1997) Infusion of pramlintide, a human amylin analogue, delays gastric emptying in men with IDDM. Diabetologia 40:82-88.

Kong MF, Stubbs TA, King P, Macdonald IA, Lambourne JE, Blackshaw PE, Perkins AC, and Tattersall RB (1998) The effect of single doses of pramlintide on gastric emptying of two meals in men with IDDM. Diabetologia 41:577-583.

Korner J, Bessler M, Inabnet W, Taveras C, and Holst JJ (2007) Exaggerated glucagon-like peptide-1 and blunted glucose-dependent insulinotropic peptide 
secretion are associated with Roux-en-Y gastric bypass but not adjustable gastric banding. Surg Obes Relat Dis 3:597-601.

Kosinski JR, Hubert J, Carrington PE, Chicchi GG, Mu J, Miller C, Cao J, Bianchi E Pessi A, Sinharoy R, et al. (2012) The glucagon receptor is involved in mediating the body weight-lowering effects of oxyntomodulin. Obesity (Silver Spring) 20: $1566-1571$.

Kostic A, King TA, Yang F, Chan KC, Yancopoulos GD, Gromada J, and Harp JB (2018) A first-in-human pharmacodynamic and pharmacokinetic study of a fully human anti-glucagon receptor monoclonal antibody in normal healthy volunteers. Diabetes Obes Metab 20:283-291.

Kreymann B, Williams G, Ghatei MA, and Bloom SR (1987) Glucagon-like peptide-1 7-36: a physiological incretin in man. Lancet 2:1300-1304.

Kühnen P, Clément K, Wiegand S, Blankenstein O, Gottesdiener K, Martini LL, Mai K, Blume-Peytavi U, Grüters A, and Krude H (2016) Proopiomelanocortin deficiency treated with a melanocortin-4 receptor agonist. $N$ Engl J Med 375:240-246.

Kuo DY (2005) Involvement of hypothalamic neuropeptide $\mathrm{Y}$ in regulating the amphetamine-induced appetite suppression in streptozotocin diabetic rats. Regul Pept 127:19-26.

Kuo DY (2006) Hypothalamic neuropeptide Y (NPY) and the attenuation of hyperphagia in streptozotocin diabetic rats treated with dopamine D1/D2 agonists. $B r J$ Pharmacol 148:640-647.

Kuo DY, Chen PN, Yu CH, Kuo MH, Hsieh YS, and Chu SC (2012) Involvement of neuropeptide Y Y1 receptor in the regulation of amphetamine-mediated appetite suppression. Neuropharmacology 63:842-850.

Kuo DY, Yang SF, Chu SC, Chu SC, Chen CH, and Hsieh YS (2009) Amphetamineevoked changes of oxidative stress and neuropeptide $\mathrm{Y}$ gene expression in hypothalamus: regulation by the protein kinase C-delta signaling. Chem Biol Interact 180:193-201.

Kuroshima A and Yahata T (1979) Thermogenic responses of brown adipocytes to noradrenaline and glucagon in heat-acclimated and cold-acclimated rats. Jpn $J$ Physiol 29:683-690.

Kurt TL, Anderson R, Petty C, Bost R, Reed G, and Holland J (1986) Dinitrophenol in weight loss: the poison center and public health safety. Vet Hum Toxicol 28: $574-575$.

Kurz X and Van Ermen A (1997) Valvular heart disease associated with fenfluramine-phentermine. $N$ Engl J Med 337:1772-1773; author reply 1775

Kwiker D, Godkar D, Lokhandwala N, and Yakoby M (2006) Rare case of rhabdomyolysis with therapeutic doses of phendimetrazine tartrate. Am J Ther 13:175-176.

Landau D, Jackson J, and Gonzalez G (2008) A case of demand ischemia from phendimetrazine. Cases $J$ 1:105.

Langtry HD, Gillis JC, and Davis R (1997) Topiramate: a review of its pharmacodynamic and pharmacokinetic properties and clinical efficacy in the management of epilepsy. Drugs 54:752-773.

Laraia PJ, Craig RJ, and Reddy WJ (1968) Glucagon: effect on adenosine 3', 5' monophosphate in the rat heart. Am J Physiol 215:968-970.

Lardinois CK, Starich GH, and Mazzaferri EL (1988) The postprandial response of gastric inhibitory polypeptide to various dietary fats in man. J Am Coll Nutr 7: 241-247.

Lardy HA and Feldott G (1951) Metabolic effects of thyroxine in vitro. Ann N Y Acad Sci 54:636-648.

Larkin S, Mull E, Miao W, Pittner R, Albrandt K, Moore C, Young A, Denaro M, and Beaumont K (1997) Regulation of the third member of the uncoupling protein family, UCP3, by cold and thyroid hormone. Biochem Biophys Res Commun 240: $222-227$

Lau J, Bloch P, Schäffer L, Pettersson I, Spetzler J, Kofoed J, Madsen K, Knudsen LB, McGuire J, Steensgaard DB, et al. (2015) Discovery of the once-weekly glucagon-like peptide-1 (GLP-1) analogue semaglutide. J Med Chem 58:7370-7380.

Laurenius A, Larsson I, Bueter M, Melanson KJ, Bosaeus I, Forslund HB, Lönroth H, Fändriks L, and Olbers T (2012) Changes in eating behaviour and meal pattern following Roux-en-Y gastric bypass. Int J Obes 36:348-355.

Laurenius A, Larsson I, Melanson KJ, Lindroos AK, Lönroth H, Bosaeus I, and Olbers T (2013) Decreased energy density and changes in food selection following Roux-en-Y gastric bypass. Eur J Clin Nutr 67:168-173.

Lebon V, Dufour S, Petersen KF, Ren J, Jucker BM, Slezak LA, Cline GW, Rothman DL, and Shulman GI (2001) Effect of triiodothyronine on mitochondrial energy coupling in human skeletal muscle. J Clin Invest 108:733-737.

Ledouarec JC and Schmitt H (1964) Pharmacological comparison of 7 anorexigenic drugs. Therapie 19:831-841.

Lee J, Liu J, Feng X, Salazar Hernández MA, Mucka P, Ibi D, Choi JW, and Ozcan U (2016a) Withaferin A is a leptin sensitizer with strong antidiabetic properties in mice. Nat Med 22:1023-1032.

Lee YH, Wang MY, Yu XX, and Unger RH (2016b) Glucagon is the key factor in the development of diabetes. Diabetologia 59:1372-1375.

Lee YS, Shin S, Shigihara T, Hahm E, Liu MJ, Han J, Yoon JW, and Jun HS (2007) Glucagon-like peptide-1 gene therapy in obese diabetic mice results in long-term cure of diabetes by improving insulin sensitivity and reducing hepatic gluconeogenesis. Diabetes 56:1671-1679.

Leith W and Beck JC (1958) The use of phenmetrazine hydrochloride (preludin) in the obese diabetic. Can Med Assoc J 79:897-898.

Le Riche WH and Van Belle G (1962) Study of phendimetrazine bitartrate as an appetite suppressant in relation to dosage, weight loss and side effects. Can Med Assoc $J$ 87:29-31.

le Roux CW, Aylwin SJ, Batterham RL, Borg CM, Coyle F, Prasad V, Shurey S, Ghatei MA, Patel AG, and Bloom SR (2006) Gut hormone profiles following bariatric surgery favor an anorectic state, facilitate weight loss, and improve metabolic parameters. Ann Surg 243:108-114.

Levetan C, Want LL, Weyer C, Strobel SA, Crean J, Wang Y, Maggs DG, Kolterman OG, Chandran M, Mudaliar SR, et al. (2003) Impact of pramlintide on glucose fluctuations and postprandial glucose, glucagon, and triglyceride excursions among patients with type 1 diabetes intensively treated with insulin pumps. Diabetes Care 26:1-8.

Li P, Rogers T, Smiley D, DiMarchi RD, and Zhang F (2007) Design, synthesis and crystallization of a novel glucagon analog as a therapeutic agent. Acta Crystallogr Sect F Struct Biol Cryst Commun 63:599-601.

Li Z, Hong K, Yip I, Huerta S, Bowerman S, Walker J, Wang H, Elashoff R, Go VL, and Heber D (2003) Body weight loss with phentermine alone versus phentermine and fenfluramine with very-low-calorie diet in an outpatient obesity management program: a retrospective study. Curr Ther Res Clin Exp 64:447-460.

Li Z, Maglione M, Tu W, Mojica W, Arterburn D, Shugarman LR, Hilton L, Suttorp M, Solomon V, Shekelle PG, et al. (2005) Meta-analysis: pharmacologic treatment of obesity. Ann Intern Med 142:532-546.

Licinio J, Caglayan S, Ozata M, Yildiz BO, de Miranda PB, O'Kirwan F, Whitby R, Liang L, Cohen P, Bhasin S, et al. (2004) Phenotypic effects of leptin replacement on morbid obesity, diabetes mellitus, hypogonadism, and behavior in leptin-deficient adults. Proc Natl Acad Sci USA 101:4531-4536.

Lin JZ, Martagón AJ, Cimini SL, Gonzalez DD, Tinkey DW, Biter A, Baxter JD, Webb P, Gustafsson JA, Hartig SM, et al. (2015) Pharmacological activation of thyroid hormone receptors elicits a functional conversion of white to brown fat. Cell Reports 13:1528-1537.

Linde M, Mulleners WM, Chronicle EP, and McCrory DC (2013) Topiramate for the prophylaxis of episodic migraine in adults. Cochrane Database Syst Rev (6): CD010610.

Liu J, Lee J, Salazar Hernandez MA, Mazitschek R, and Ozcan U (2015) Treatment of obesity with celastrol. Cell 161:999-1011.

López M, Varela L, Vázquez MJ, Rodríguez-Cuenca S, González CR, Velagapudi VR, Morgan DA, Schoenmakers E, Agassandian K, Lage R, et al. (2010) Hypothalamic AMPK and fatty acid metabolism mediate thyroid regulation of energy balance. Nat Med 16:1001-1008.

Lucas JJ, Yamamoto A, Scearce-Levie K, Saudou F, and Hen R (1998) Absence of fenfluramine-induced anorexia and reduced c-Fos induction in the hypothalamus and central amygdaloid complex of serotonin $1 \mathrm{~B}$ receptor knock-out mice. $J$ Neurosci 18:5537-5544.

Lucchesi BR (1968) Cardiac actions of glucagon. Circ Res 22:777-787.

Lucchetta RC, Riveros BS, Pontarolo R, Radominski RB, Otuki MF, Fernandez-Llimos F, and Correr CJ (2017) Systematic review and meta-analysis of the efficacy and safety of amfepramone and mazindol as a monotherapy for the treatment of obese or overweight patients. Clinics (São Paulo) 72:317-324.

Lutz TA (2005) Pancreatic amylin as a centrally acting satiating hormone. Curr Drug Targets 6:181-189.

Lutz TA (2010a) The role of amylin in the control of energy homeostasis. Am J Physiol Regul Integr Comp Physiol 298:R1475-R1484.

Lutz TA (2010b) Roles of amylin in satiation, adiposity and brain development. Forum Nutr 63:64-74

Lutz TA, Del Prete E, and Scharrer E (1994) Reduction of food intake in rats by intraperitoneal injection of low doses of amylin. Physiol Behav 55:891-895.

Lutz TA, Senn M, Althaus J, Del Prete E, Ehrensperger F, and Scharrer E (1998) Lesion of the area postrema/nucleus of the solitary tract (AP/NTS) attenuates the anorectic effects of amylin and calcitonin gene-related peptide (CGRP) in rats. Peptides 19:309-317.

MacBryde CM and Taussig BL (1935) Functional changes in liver, heart and muscle, and loss of dextrose tolerance resulting from dinitrophenol. JAMA 6:13-17.

Mack CM, Soares CJ, Wilson JK, Athanacio JR, Turek VF, Trevaskis JL, Roth JD, Smith PA, Gedulin B, Jodka CM, et al. (2010) Davalintide (AC2307), a novel amylin-mimetic peptide: enhanced pharmacological properties over native amylin to reduce food intake and body weight. Int J Obes 34:385-395.

Macnab AJ and Fielden SJ (1998) Successful treatment of dinitrophenol poisoning in a child. Pediatr Emerg Care 14:136-138.

Magkos F, Fraterrigo G, Yoshino J, Luecking C, Kirbach K, Kelly SC, de Las Fuentes L, He S, Okunade AL, Patterson BW, et al. (2016) Effects of moderate and subsequent progressive weight loss on metabolic function and adipose tissue biology in humans with obesity. Cell Metab 23:591-601.

Marcotte E and Chand B (2016) Management and prevention of surgical and nutritional complications after bariatric surgery. Surg Clin North Am 96: 843-856.

Martella G, Costa C, Pisani A, Cupini LM, Bernardi G, and Calabresi P (2008) Antiepileptic drugs on calcium currents recorded from cortical and PAG neurons: therapeutic implications for migraine. Cephalalgia 28:1315-1326.

Martin CK, Redman LM, Zhang J, Sanchez M, Anderson CM, Smith SR, and Ravussin E (2011) Lorcaserin, a 5-HT(2C) receptor agonist, reduces body weight by decreasing energy intake without influencing energy expenditure. $J$ Clin Endocrinol Metab 96:837-845.

Martin CM, Irwin N, Flatt PR, and Gault VA (2013) A novel acylated form of (d-Ala(2))GIP with improved antidiabetic potential, lacking effect on body fat stores. Biochim Biophys Acta 1830:3407-3413.

Martinez-Sanchez N, Seoane-Collazo P, Contreras C, Varela L, Villarroya J, RialPensado E, Buque X, Aurrekoetxea I, Delgado TC, Vazquez-Martinez R, et al. (2017) Hypothalamic AMPK-ER stress-JNK1 axis mediates the central actions of thyroid hormones on energy balance. Cell Metab 26:212-229.e12.

Masaki T, Yoshimatsu H, and Sakata T (2000) Expression of rat uncoupling protein family mRNA levels by chronic treatment with thyroid hormone. Int J Obes Relat Metab Disord 24 (Suppl 2):S162-S164.

Mathers CD and Loncar D (2006) Projections of global mortality and burden of disease from 2002 to 2030 . PLoS Med 3:e442.

Mathes CM and Spector AC (2012) Food selection and taste changes in humans after Roux-en-Y gastric bypass surgery: a direct-measures approach. Physiol Behav 107: 476-483.

Mathus-Vliegen EM (1993) Prolonged surveillance of dexfenfluramine in severe obesity. Neth J Med 43:246-253. 
Mauvais-Jarvis F (2016) Role of sex steroids in $\beta$ cell function, growth, and survival. Trends Endocrinol Metab 27:844-855.

Mauvais-Jarvis F, Arnold AP, and Reue K (2017a) A guide for the design of preclinical studies on sex differences in metabolism. Cell Metab 25:1216-1230.

Mauvais-Jarvis F, Manson JE, Stevenson JC, and Fonseca VA (2017b) Menopausal hormone therapy and type 2 diabetes prevention: evidence, mechanisms, and clinical implications. Endocr Rev 38:173-188.

McBee S (1968) The dangerous diet pills. Life 64:22-29.

McCone JF (1897) Thyroid extract in obesity, with report of a case. Pac Rec Med Sur 12:288-289.

McDuffie JR, Calis KA, Booth SL, Uwaifo GI, and Yanovski JA (2002) Effects of orlistat on fat-soluble vitamins in obese adolescents. Pharmacotherapy 22: 814-822.

McMahon FG, Fujioka K, Singh BN, Mendel CM, Rowe E, Rolston K, Johnson F, and Mooradian $\mathrm{AD}$ (2000) Efficacy and safety of sibutramine in obese white and African American patients with hypertension: a 1-year, double-blind, placebocontrolled, multicenter trial. Arch Intern Med 160:2185-2191.

McNeely W and Goa KL (1998) Sibutramine: a review of its contribution to the management of obesity. Drugs 56:1093-1124.

Meier JJ, Gallwitz B, Siepmann N, Holst JJ, Deacon CF, Schmidt WE, and Nauck MA (2003) Gastric inhibitory polypeptide (GIP) dose-dependently stimulates glucagon secretion in healthy human subjects at euglycaemia. Diabetologia 46 798-801.

Melia AT, Koss-Twardy SG, and Zhi J (1996) The effect of orlistat, an inhibitor of dietary fat absorption, on the absorption of vitamins $\mathrm{A}$ and $\mathrm{E}$ in healthy volunteers. J Clin Pharmacol 36:647-653.

Mentis N, Vardarli I, Köthe LD, Holst JJ, Deacon CF, Theodorakis M, Meier JJ, and Nauck MA (2011) GIP does not potentiate the antidiabetic effects of GLP-1 in hyperglycemic patients with type 2 diabetes. Diabetes 60:1270-1276.

Mentlein R, Gallwitz B, and Schmidt WE (1993) Dipeptidyl-peptidase IV hydrolyses gastric inhibitory polypeptide, glucagon-like peptide-1(7-36)amide, peptide histidine methionine and is responsible for their degradation in human serum. Eur $J$ Biochem 214:829-835.

Meye FJ, Trezza V, Vanderschuren LJ, Ramakers GM, and Adan RA (2013) Neutral antagonism at the cannabinoid 1 receptor: a safer treatment for obesity. Mol Psychiatry 18:1294-1301.

Miles JM, Leiter L, Hollander P, Wadden T, Anderson JW, Doyle M, Foreyt J, Aronne L, and Klein S (2002) Effect of orlistat in overweight and obese patients with type 2 diabetes treated with metformin. Diabetes Care 25:1123-1128.

Miras AD and le Roux CW (2010) Bariatric surgery and taste: novel mechanisms of weight loss. Curr Opin Gastroenterol 26:140-145.

Mitsukawa T, Takemura J, Asai J, Nakazato M, Kangawa K, Matsuo H, and Matsukura S (1990) Islet amyloid polypeptide response to glucose, insulin, and somatostatin analogue administration. Diabetes 39:639-642

Mittag J, Lyons DJ, Sällström J, Vujovic M, Dudazy-Gralla S, Warner A, Wallis K, Alkemade A, Nordström K, Monyer H, et al. (2013) Thyroid hormone is required for hypothalamic neurons regulating cardiovascular functions. J Clin Invest 123: 509-516.

Miyawaki K, Yamada Y, Ban N, Ihara Y, Tsukiyama K, Zhou H, Fujimoto S, Oku A Tsuda K, Toyokuni S, et al. (2002) Inhibition of gastric inhibitory polypeptide signaling prevents obesity. Nat Med 8:738-742.

Mochiki E, Suzuki H, Takenoshita S, Nagamachi Y, Kuwano H, Mizumoto A, and Itoh Z (1998) Mechanism of inhibitory effect of glucagon on gastrointestinal motility and cause of side effects of glucagon. $J$ Gastroenterol 33: $835-841$

Mojsov S, Weir GC, and Habener JF (1987) Insulinotropin: glucagon-like peptide I (737) co-encoded in the glucagon gene is a potent stimulator of insulin release in the perfused rat pancreas. $J$ Clin Invest 79:616-619.

Moldovan CP, Weldon AJ, Daher NS, Schneider LE, Bellinger DL, Berk LS, Hermé AC, Aréchiga AL, Davis WL, and Peters WR (2016) Effects of a meal replacement system alone or in combination with phentermine on weight loss and food cravings. Obesity (Silver Spring) 24:2344-2350.

Montague CT, Farooqi IS, Whitehead JP, Soos MA, Rau H, Wareham NJ, Sewter CP, Digby JE, Mohammed SN, Hurst JA, et al. (1997) Congenital leptin deficiency is associated with severe early-onset obesity in humans. Nature 387:903-908.

Montgomery IA, Irwin N, and Flatt PR (2010) Active immunization against (Pro(3)) GIP improves metabolic status in high-fat-fed mice. Diabetes Obes Metab 12: 744-751.

Moore B (1906) On the treatment of diabetus mellitus by acid extract of duodenal mucous membrane. Biochem J 1:28-38.

Moore GT (1990) Health maintenance organizations and medical education: breaking the barriers. Acad Med 65:427-432.

Mu J, Jiang G, Brady E, Dallas-Yang Q, Liu F, Woods J, Zycband E, Wright M, Li Z, $\mathrm{Lu} \mathrm{K}$, et al. (2011) Chronic treatment with a glucagon receptor antagonist lowers glucose and moderately raises circulating glucagon and glucagon-like peptide 1 without severe alpha cell hypertrophy in diet-induced obese mice. Diabetologia 54:2381-2391.

Müller TD, Clemmensen C, Finan B, DiMarchi RD, and Tschöp MH (2015) Novel combinatorial therapies involving leptin: opportunities for mechanistic advances and therapeutic translation in human diseases, in Leptin: Regulation and Clinical Applications (Dagogo-Jack S ed) pp 267-279, Springer, New York.

Müller TD, Finan B, Clemmensen C, DiMarchi RD, and Tschöp MH (2017) The new biology and pharmacology of glucagon. Physiol Rev 97:721-766.

Müller TD, Föcker M, Holtkamp K, Herpertz-Dahlmann B, and Hebebrand J (2009) Leptin-mediated neuroendocrine alterations in anorexia nervosa: somatic and behavioral implications. Child Adolesc Psychiatr Clin N Am 18:117-129.

Müller TD, Sullivan LM, Habegger K, Yi CX, Kabra D, Grant E, Ottaway N, Krishna R, Holland J, Hembree J, et al. (2012) Restoration of leptin responsiveness in dietinduced obese mice using an optimized leptin analog in combination with exendin4 or FGF21. J Pept Sci 18:383-393.
Müller WA, Faloona GR, Aguilar-Parada E, and Unger RH (1970) Abnormal alphacell function in diabetes: response to carbohydrate and protein ingestion. $N$ Engl J Med 283:109-115.

Münzberg H, Flier JS, and Bjørbaek C (2004) Region-specific leptin resistance within the hypothalamus of diet-induced obese mice. Endocrinology 145:4880-4889.

Münzberg H, Laque A, Yu S, Rezai-Zadeh K, and Berthoud HR (2015) Appetite and body weight regulation after bariatric surgery. Obes Rev 16 (Suppl 1):77-90.

Nash J (1961) The treatment of obesity by control of appetite with diethylproprion (Tenuate). J Ir Med Assoc 48:15-17.

Nauck MA, Bartels E, Orskov C, Ebert R, and Creutzfeldt W (1993a) Additive insulinotropic effects of exogenous synthetic human gastric inhibitory polypeptide and glucagon-like peptide-1-(7-36) amide infused at near-physiological insulinotropic hormone and glucose concentrations. J Clin Endocrinol Metab 76:912-917.

Nauck MA, Heimesaat MM, Orskov C, Holst JJ, Ebert R, and Creutzfeldt W (1993b) Preserved incretin activity of glucagon-like peptide 1 [7-36 amide] but not of synthetic human gastric inhibitory polypeptide in patients with type-2 diabetes mellitus. J Clin Invest 91:301-307.

Neary NM, Small CJ, Druce MR, Park AJ, Ellis SM, Semjonous NM, Dakin CL, Filipsson K, Wang F, Kent AS, et al. (2005) Peptide YY3-36 and glucagon-like peptide-17-36 inhibit food intake additively. Endocrinology 146:5120-5127.

Neidigh JW, Fesinmeyer RM, Prickett KS, and Andersen NH (2001) Exendin-4 and glucagon-like-peptide-1: NMR structural comparisons in the solution and micelleassociated states. Biochemistry 40:13188-13200.

Nelson DL and Gehlert DR (2006) Central nervous system biogenic amine targets for control of appetite and energy expenditure. Endocrine 29:49-60.

Newsholme EA and Crabtree B (1976) Substrate cycles in metabolic regulation and in heat generation. Biochem Soc Symp 41:61-109.

Nissen SE, Nicholls SJ, Wolski K, Rodés-Cabau J, Cannon CP, Deanfield JE, Després JP, Kastelein JJ, Steinhubl SR, Kapadia S, et al.; STRADIVARIUS Investigators (2008) Effect of rimonabant on progression of atherosclerosis in patients with abdominal obesity and coronary artery disease: the STRADIVARIUS randomized controlled trial. JAMA 299:1547-1560.

Norheim G (1973) A fatal case of phenmetrazine poisoning. J Forensic Sci Soc 13: $287-289$.

Nyholm B, Orskov L, Hove KY, Gravholt CH, Møller N, Alberti KG, Moyses C, Kolterman O, and Schmitz O (1999) The amylin analog pramlintide improves glycemic control and reduces postprandial glucagon concentrations in patients with type 1 diabetes mellitus. Metabolism 48:935-941.

Oben J, Morgan L, Fletcher J, and Marks V (1991) Effect of the entero-pancreatic hormones, gastric inhibitory polypeptide and glucagon-like polypeptide-1(7-36) amide, on fatty acid synthesis in explants of rat adipose tissue. $J$ Endocrinol 130 $267-272$.

Odstrcil EA, Martinez JG, Santa Ana CA, Xue B, Schneider RE, Steffer KJ, Porter JL, Asplin J, Kuhn JA, and Fordtran JS (2010) The contribution of malabsorption to the reduction in net energy absorption after long-limb Roux-en-Y gastric bypass. Am J Clin Nutr 92:704-713.

Ogawa A, Harris V, McCorkle SK, Unger RH, and Luskey KL (1990) Amylin secretion from the rat pancreas and its selective loss after streptozotocin treatment. $J$ Clin Invest 85:973-976.

Oh SS and Kaplan ML (1994) Early treatment of obese (ob/ob) mice with triiodothyronine increases oxygen consumption and temperature and decreases body fat content. Proc Soc Exp Biol Med 207:260-267.

Ohsawa H, Kanatsuka A, Yamaguchi T, Makino H, and Yoshida S (1989) Islet amyloid polypeptide inhibits glucose-stimulated insulin secretion from isolated rat pancreatic islets. Biochem Biophys Res Commun 160:961-967.

Okamoto H, Cavino K, Na E, Krumm E, Kim SY, Cheng X, Murphy AJ, Yancopoulos GD, and Gromada J (2017) Glucagon receptor inhibition normalizes blood glucose in severe insulin-resistant mice. Proc Natl Acad Sci USA 114:2753-2758.

Okamoto H, Kim J, Aglione J, Lee J, Cavino K, Na E, Rafique A, Kim JH, Harp J, Valenzuela DM, et al. (2015) Glucagon receptor blockade with a human antibody normalizes blood glucose in diabetic mice and monkeys. Endocrinology 156: 2781-2794.

Olbers T, Björkman S, Lindroos A, Maleckas A, Lönn L, Sjöström L, and Lönroth H (2006) Body composition, dietary intake, and energy expenditure after laparoscopic Roux-en-Y gastric bypass and laparoscopic vertical banded gastroplasty: a randomized clinical trial. Ann Surg 244:715-722.

Oral EA, Simha V, Ruiz E, Andewelt A, Premkumar A, Snell P, Wagner AJ, DePaol AM, Reitman ML, Taylor SI, et al. (2002) Leptin-replacement therapy for lipodystrophy. N Engl J Med 346:570-578.

Ozcan L, Ergin AS, Lu A, Chung J, Sarkar S, Nie D, Myers MG Jr, and Ozcan U (2009) Endoplasmic reticulum stress plays a central role in development of leptin resistance. Cell Metab 9:35-51.

Ozcan U, Cao Q, Yilmaz E, Lee AH, Iwakoshi NN, Ozdelen E, Tuncman G, Görgün C, Glimcher LH, and Hotamisligil GS (2004) Endoplasmic reticulum stress links obesity, insulin action, and type 2 diabetes. Science 306:457-461.

Paloyan E and Harper PV Jr (1961) Glucagon as a regulating factor of plasma lipids. Metabolism 10:315-323.

Paulescu NC (1921) Recherche sur le rôle du pancréas dans l'assimilation nutritive. Arch Int Physiol 17:85-103.

Pederson RA and Brown JC (1978) Interaction of gastric inhibitory polypeptide, glucose, and arginine on insulin and glucagon secretion from the perfused rat pancreas. Endocrinology 103:610-615.

Pelleymounter MA, Cullen MJ, Baker MB, Hecht R, Winters D, Boone T, and Collins F (1995) Effects of the obese gene product on body weight regulation in ob/ob mice. Science 269:540-543.

Perkins RG (1919) A study of munitions intoxications in France. Public Health Rep 34:2335.

Peterli R, Wölnerhanssen B, Peters T, Devaux N, Kern B, Christoffel-Courtin C, Drewe J, von Flüe M, and Beglinger C (2009) Improvement in glucose metabolism after bariatric surgery: comparison of laparoscopic Roux-en-Y gastric bypass and 
laparoscopic sleeve gastrectomy: a prospective randomized trial. Ann Surg 250: 234-241.

Peters KR (2013) Liraglutide for the treatment of type 2 diabetes: a clinical update. Am $J$ Ther 20:178-188.

Petersen KF, Oral EA, Dufour S, Befroy D, Ariyan C, Yu C, Cline GW, DePaoli AM, Taylor SI, Gorden P, et al. (2002) Leptin reverses insulin resistance and hepatic steatosis in patients with severe lipodystrophy. J Clin Invest 109:1345-1350.

Petersen KF and Sullivan JT (2001) Effects of a novel glucagon receptor antagonist (Bay 27-9955) on glucagon-stimulated glucose production in humans. Diabetologia 44:2018-2024.

Pfohl M, Luft D, Blomberg I, and Schmülling RM (1994) Long-term changes of body weight and cardiovascular risk factors after weight reduction with group therapy and dexfenfluramine. Int J Obes Relat Metab Disord 18:391-395.

Pinder RM, Brogden RN, Sawyer PR, Speight TM, and Avery GS (1975) Fenfluramine: a review of its pharmacological properties and therapeutic efficacy in obesity. Drugs 10:241-323.

Pi-Sunyer FX, Aronne LJ, Heshmati HM, Devin J, and Rosenstock J; RIO-North America Study Group (2006) Effect of rimonabant, a cannabinoid-1 receptor blocker, on weight and cardiometabolic risk factors in overweight or obese patients: RIO-North America: a randomized controlled trial. JAMA 295:761-775.

Pi-Sunyer X, Astrup A, Fujioka K, Greenway F, Halpern A, Krempf M, Lau DC, le Roux CW, Violante Ortiz R, Jensen CB, et al.; SCALE Obesity and Prediabetes NN8022-1839 Study Group (2015) A randomized, controlled trial of $3.0 \mathrm{mg}$ of liraglutide in weight management. $N$ Engl J Med 373:11-22.

Pocai A, Carrington PE, Adams JR, Wright M, Eiermann G, Zhu L, Du X, Petrov A, Lassman ME, Jiang G, et al. (2009) Glucagon-like peptide 1/glucagon receptor dual agonism reverses obesity in mice. Diabetes 58:2258-2266.

Pories WJ, Swanson MS, MacDonald KG, Long SB, Morris PG, Brown BM, Barakat HA, deRamon RA, Israel G, and Dolezal JM (1995) Who would have thought it? An operation proves to be the most effective therapy for adult-onset diabetes mellitus. Ann Surg 222:339-350; discussion 350-332.

Portron A, Jadidi S, Sarkar N, DiMarchi R, and Schmitt C (2017) Pharmacodynamics, pharmacokinetics, safety and tolerability of the novel dual glucosedependent insulinotropic polypeptide/glucagon-like peptide-1 agonist RG7697 after single subcutaneous administration in healthy subjects. Diabetes Obes Metab 19: 1446-1453.

Prigeon RL, Quddusi S, Paty B, and D'Alessio DA (2003) Suppression of glucose production by GLP-1 independent of islet hormones: a novel extrapancreatic effect. Am J Physiol Endocrinol Metab 285:E701-E707.

Privitera MD (1997) Topiramate: a new antiepileptic drug. Ann Pharmacother 31: 1164-1173.

Quarta C, Clemmensen C, Zhu Z, Yang B, Joseph SS, Lutter D, Yi CX, Graf E, Garcia-Caceres C, Legutko B, et al. (2017) Molecular integration of incretin and glucocorticoid action reverses immunometabolic dysfunction and obesity. Cell Metab 26:620-632.e6.

Rapport MM, Green AA, and Page IH (1948a) Crystalline serotonin. Science 108: 329-330.

Rapport MM, Green AA, and Page IH (1948b) Serum vasoconstrictor, serotonin; isolation and characterization. J Biol Chem 176:1243-1251.

Rasmussen S, Corya BC, and Glassman RD (1997) Valvular heart disease associated with fenfluramine-phentermine. $N$ Engl J Med 337:1773-1774; author reply 1775

Ray HM (1947) The obese patient; a statistical study and analysis of symptoms, diagnosis and metabolic abnormalities; sex differences; treatment. Am J Dig Dis 14:153-162.

Recasens MA, Barenys M, Sola R, Blanch S, Masana L, and Salas-Salvadó J (1995) Effect of dexfenfluramine on energy expenditure in obese patients on a very-lowcalorie-diet. Int J Obes Relat Metab Disord 19:162-168.

Renner S, Fehlings C, Herbach N, Hofmann A, von Waldthausen DC, Kessler B, Ulrichs K, Chodnevskaja I, Moskalenko V, Amselgruber W, et al. (2010) Glucose intolerance and reduced proliferation of pancreatic beta-cells in transgenic pigs with impaired glucose-dependent insulinotropic polypeptide function. Diabetes $\mathbf{5 9}$ 1228-1238.

Ressler C (1957) Treatment of obesity with phenmetrazine hydrochloride, a new anorexiant. J Am Med Assoc 165:135-138.

Riddle M, Frias J, Zhang B, Maier H, Brown C, Lutz K, and Kolterman O (2007) Pramlintide improved glycemic control and reduced weight in patients with type 2 diabetes using basal insulin. Diabetes Care 30:2794-2799.

Riediger T, Schmid HA, Lutz T, and Simon E (2001) Amylin potently activates AP neurons possibly via formation of the excitatory second messenger cGMP. Am $J$ Physiol Regul Integr Comp Physiol 281:R1833-R1843.

Riediger T, Zuend D, Becskei C, and Lutz TA (2004) The anorectic hormone amylin contributes to feeding-related changes of neuronal activity in key structures of the gut-brain axis. Am J Physiol Regul Integr Comp Physiol 286:R114-R122.

Rivera N, Everett-Grueter CA, Edgerton DS, Rodewald T, Neal DW, Nishimura E, Larsen MO, Jacobsen LO, Kristensen K, Brand CL, et al. (2007) A novel glucagon receptor antagonist, NNC 25-0926, blunts hepatic glucose production in the conscious dog. J Pharmacol Exp Ther 321:743-752.

Robert TA and Hagardorn AN (1985) Plasma levels and kinetic disposition of 2,4dinitrophenol and its metabolites 2-amino-4-nitrophenol and 4-amino-2nitrophenol in the mouse. J Chromatogr A 344:177-186.

Robillard R (1957) Preludin treatment of obesity in diabetes mellitus; preliminary report. Can Med Assoc J 76:938-940.

Robinson MK (2009) Surgical treatment of obesity-weighing the facts. $N$ Engl J Med 361:520-521.

Rodgers RJ, Tschöp MH, and Wilding JP (2012) Anti-obesity drugs: past, present and future. Dis Model Mech 5:621-626.

Roepke TA, Smith AW, Rønnekleiv OK, and Kelly MJ (2012) Serotonin 5-HT2C receptor-mediated inhibition of the M-current in hypothalamic POMC neurons. Am J Physiol Endocrinol Metab 302:E1399-E1406.
Rolin B, Larsen MO, Gotfredsen CF, Deacon CF, Carr RD, Wilken M, and Knudsen LB (2002) The long-acting GLP-1 derivative NN2211 ameliorates glycemia and increases beta-cell mass in diabetic mice. Am J Physiol Endocrinol Metab 283: E745-E752.

Rostagno C, Caciolli S, Felici M, Gori F, and Neri Serneri GG (1996) Dilated cardiomyopathy associated with chronic consumption of phendimetrazine. Am Heart $J$ 131:407-409.

Roth JD, Roland BL, Cole RL, Trevaskis JL, Weyer C, Koda JE, Anderson CM, Parkes DG, and Baron AD (2008) Leptin responsiveness restored by amylin agonism in diet-induced obesity: evidence from nonclinical and clinical studies. Proc Natl Acad Sci USA 105:7257-7262.

Rothman RB and Baumann MH (2006) Therapeutic potential of monoamine transporter substrates. Curr Top Med Chem 6:1845-1859.

Rubino F, Nathan DM, Eckel RH, Schauer PR, Alberti KG, Zimmet PZ, Del Prato S, Ji L, Sadikot SM, Herman WH, et al.; Delegates of the 2nd Diabetes Surgery Summit (2016) Metabolic surgery in the treatment algorithm for type 2 diabetes: a joint statement by International Diabetes Organizations. Diabetes Care 39: 861-877.

Rucker D, Padwal R, Li SK, Curioni C, and Lau DC (2007) Long term pharmacotherapy for obesity and overweight: updated meta-analysis. BMJ 335: 1194-1199.

Rushing PA, Hagan MM, Seeley RJ, Lutz TA, D'Alessio DA, Air EL, and Woods SC (2001) Inhibition of central amylin signaling increases food intake and body adiposity in rats. Endocrinology 142:5035.

Ryan KK, Tremaroli V, Clemmensen C, Kovatcheva-Datchary P, Myronovych A, Karns R, Wilson-Pérez HE, Sandoval DA, Kohli R, Bäckhed F, et al. (2014) FXR is a molecular target for the effects of vertical sleeve gastrectomy. Nature 509: 183-188.

Salera M, Giacomoni P, Pironi L, Cornia G, Capelli M, Marini A, Benfenati F, Miglioli M, and Barbara L (1982) Gastric inhibitory polypeptide release after oral glucose: relationship to glucose intolerance, diabetes mellitus, and obesity. J Clin Endocrinol Metab 55:329-336.

Salter JM (1960) Metabolic effects of glucagon in the Wistar rat. Am J Clin Nutr 8: $535-539$.

Salter JM, Ezrin C, Laidlaw JC, and Gornall AG (1960) Metabolic effects of glucagon in human subjects. Metabolism 9:753-768.

Sam AH, Salem V, and Ghatei MA (2011) Rimonabant: from RIO to ban. J Obes 2011: 432607.

Samanin R, Mennini T, and Garattini S (1980) Evidence that it is possible to cause anorexia by increasing release and/or directly stimulating postsynaptic serotonin receptors in the brain. Prog Neuropsychopharmacol 4:363-369.

Sandoval DA and D'Alessio DA (2015) Physiology of proglucagon peptides: role of glucagon and GLP-1 in health and disease. Physiol Rev 95:513-548.

Schepp W, Dehne K, Riedel T, Schmidtler J, Schaffer K, and Classen M (1996) Oxyntomodulin: a cAMP-dependent stimulus of rat parietal cell function via the receptor for glucagon-like peptide-1 (7-36)NH2. Digestion 57:398-405.

Schirra J, Nicolaus M, Roggel R, Katschinski M, Storr M, Woerle HJ, and Göke B (2006) Endogenous glucagon-like peptide 1 controls endocrine pancreatic secretion and antro-pyloro-duodenal motility in humans. Gut 55:243-251.

Schmidt JB, Pedersen SD, Gregersen NT, Vestergaard L, Nielsen MS, Ritz C, Madsbad S, Worm D, Hansen DL, Clausen TR, et al. (2016) Effects of RYGB on energy expenditure, appetite and glycaemic control: a randomized controlled clinical trial. Int $J$ Obes 40:281-290.

Schmitt C, Portron A, Jadidi S, Sarkar N, and DiMarchi R (2017) Pharmacodynamics, pharmacokinetics and safety of multiple ascending doses of the novel dual glucose-dependent insulinotropic polypeptide/glucagon-like peptide-1 agonist RG7697 in people with type 2 diabetes mellitus. Diabetes Obes Metab 19: 1436-1445.

Schuster CR and Thompson T (1969) Self administration of and behavioral dependence on drugs. Annu Rev Pharmacol 9:483-502.

Schwartz MW, Woods SC, Porte D Jr, Seeley RJ, and Baskin DG (2000) Central nervous system control of food intake. Nature 404:661-671.

Schwenk RW, Baumeier C, Finan B, Kluth O, Brauer C, Joost HG, DiMarchi RD, Tschöp MH, and Schürmann A (2015) GLP-1-oestrogen attenuates hyperphagia and protects from beta cell failure in diabetes-prone New Zealand obese (NZO) mice. Diabetologia 58:604-614.

Scruggs DM, Buffington C, and Cowan GS Jr (1994) Taste acuity of the morbidly obese before and after gastric bypass surgery. Obes Surg 4:24-28.

Seaton DA, Duncan LJ, Rose K, and Scott AM (1961) Diethyl-propion in the treatment of "refractory" obesity. BMJ 1:1009-1011.

Seino Y, Rasmussen MF, Zdravkovic M, and Kaku K (2008) Dose-dependent improvement in glycemia with once-daily liraglutide without hypoglycemia or weight gain: a double-blind, randomized, controlled trial in Japanese patients with type 2 diabetes. Diabetes Res Clin Pract 81:161-168.

Shah P, Vella A, Basu A, Basu R, Schwenk WF, and Rizza RA (2000) Lack of suppression of glucagon contributes to postprandial hyperglycemia in subjects with type 2 diabetes mellitus. J Clin Endocrinol Metab 85:4053-4059.

Shanahan WR, Rose JE, Glicklich A, Stubbe S, and Sanchez-Kam M (2017) Lorcaserin for smoking cessation and associated weight gain: a randomized 12-week clinical trial. Nicotine Tob Res 19:944-951.

Shank RP and Maryanoff BE (2008) Molecular pharmacodynamics, clinical therapeutics, and pharmacokinetics of topiramate. CNS Neurosci Ther 14:120-142.

Shibata C, Naito H, Jin XL, Ueno T, Funayama Y, Fukushima K, Hashimoto A Matsuno S, and Sasaki I (2001) Effect of glucagon, glicentin, glucagon-like peptide1 and -2 on interdigestive gastroduodenal motility in dogs with a vagally denervated gastric pouch. Scand J Gastroenterol 36:1049-1055.

Shimomura I, Hammer RE, Ikemoto S, Brown MS, and Goldstein JL (1999) Leptin reverses insulin resistance and diabetes mellitus in mice with congenital lipodystrophy. Nature 401:73-76. 
Shin AC and Berthoud HR (2011) Food reward functions as affected by obesity and bariatric surgery. Int J Obes 35 (Suppl 3):S40-S44.

Shulman GI, Ladenson PW, Wolfe MH, Ridgway EC, and Wolfe RR (1985) Substrate cycling between gluconeogenesis and glycolysis in euthyroid, hypothyroid, and hyperthyroid man. $J$ Clin Invest 76:757-764.

Silvestre RA, Peiró E, Dégano P, Miralles P, and Marco J (1990) Inhibitory effect of rat amylin on the insulin responses to glucose and arginine in the perfused rat pancreas. Regul Pept 31:23-31.

Simon V and Cota D (2017) Mechanisms in endocrinology: endocannabinoids and metabolism: past, present and future. Eur J Endocrinol 176:R309-R324.

Sisley S, Gutierrez-Aguilar R, Scott M, D'Alessio DA, Sandoval DA, and Seeley RJ (2014a) Neuronal GLP1R mediates liraglutide's anorectic but not glucose-lowering effect. J Clin Invest 124:2456-2463.

Sisley S, Smith K, Sandoval DA, and Seeley RJ (2014b) Differences in acute anorectic effects of long-acting GLP-1 receptor agonists in rats. Peptides 58:1-6.

Sivertsen J, Rosenmeier J, Holst JJ, and Vilsbøll T (2012) The effect of glucagon-like peptide 1 on cardiovascular risk. Nat Rev Cardiol 9:209-222.

Sjöström L, Lindroos AK, Peltonen M, Torgerson J, Bouchard C, Carlsson B, Dahlgren S, Larsson B, Narbro K, Sjöström CD, et al.; Swedish Obese Subjects Study Scientific Group (2004) Lifestyle, diabetes, and cardiovascular risk factors 10 years after bariatric surgery. $N$ Engl $J$ Med 351:2683-2693.

Sjöström L, Narbro K, Sjöström CD, Karason K, Larsson B, Wedel H, Lystig T, Sullivan M, Bouchard C, Carlsson B, et al.; Swedish Obese Subjects Study (2007) Effects of bariatric surgery on mortality in Swedish obese subjects. $N$ Engl J Med 357:741-752.

Sjouke B, Langslet G, Ceska R, Nicholls SJ, Nissen SE, Öhlander M, Ladenson PW, Olsson AG, Hovingh GK, and Kastelein JJ (2014) Eprotirome in patients with familial hypercholesterolaemia (the AKKA trial): a randomised, double-blind, placebo-controlled phase 3 study. Lancet Diabetes Endocrinol 2:455-463.

Smith IG and Goulder MA; Sibutramine Clinical Study 1047 Team (2001) Randomized placebo-controlled trial of long-term treatment with sibutramine in mild to moderate obesity. J Fam Pract 50:505-512.

Smith SR, Weissman NJ, Anderson CM, Sanchez M, Chuang E, Stubbe S, Bays H, and Shanahan WR; Behavioral Modification and Lorcaserin for Overweight and Obesity Management (BLOOM) Study Group (2010) Multicenter, placebocontrolled trial of lorcaserin for weight management. $N$ Engl J Med 363:245-256.

Sonne DP, Engstrøm T, and Treiman M (2008) Protective effects of GLP-1 analogues exendin-4 and GLP-1(9-36) amide against ischemia-reperfusion injury in rat heart. Regul Pept 146:243-249.

Sowden GL, Drucker DJ, Weinshenker D, and Swoap SJ (2007) Oxyntomodulin increases intrinsic heart rate in mice independent of the glucagon-like peptide-1 receptor. Am J Physiol Regul Integr Comp Physiol 292:R962-R970.

Stoffers DA, Kieffer TJ, Hussain MA, Drucker DJ, Bonner-Weir S, Habener JF, and Egan JM (2000) Insulinotropic glucagon-like peptide 1 agonists stimulate expression of homeodomain protein IDX-1 and increase islet size in mouse pancreas. Diabetes 49:741-748.

Storey JR, Calder CS, Hart DE, and Potter DL (2001) Topiramate in migraine prevention: a double-blind, placebo-controlled study. Headache 41:968-975.

Sun C, Trevaskis JL, Jodka CM, Neravetla S, Griffin P, Xu K, Wang Y, Parkes DG, Forood B, and Ghosh SS (2013) Bifunctional PEGylated exenatide-amylinomimetic hybrids to treat metabolic disorders: an example of long-acting dual hormonal therapeutics. J Med Chem 56:9328-9341.

Svane MS, Jørgensen NB, Bojsen-Møller KN, Dirksen C, Nielsen S, Kristiansen VB, Toräng S, Wewer Albrechtsen NJ, Rehfeld JF, Hartmann B, et al. (2016) Peptide $\mathrm{YY}$ and glucagon-like peptide-1 contribute to decreased food intake after Roux-en-Y gastric bypass surgery. Int J Obes (Lond) 40:1699-1706

Symons JD and Abel ED (2013) Lipotoxicity contributes to endothelial dysfunction: a focus on the contribution from ceramide. Rev Endocr Metab Disord 14:59-68.

Szenas P and Pattee CJ (1957) Phenmetrazine; a new anti-appetite drug. Can Serv Med $J$ 13:195-199.

Tainter ML (1935) Treatment of acute dinitrophenol poisoning. JAMA 104: 1071-1072.

Tainter ML, Cutting WC, and Hines E (1935) Effects of moderate doses of dinitrophenol on the energy exchange and nitrogen metabolism of patients under conditions of restricted dietary. J Pharmacol Exp Ther 55:326-353.

Tainter ML, Cutting WC, and Stockton AB (1934) Use of dinitrophenol in nutritional disorders: a critical survey of clinical results. Am J Public Health Nations Health 24:1045-1053.

Tainter ML, Stockton AB, and Cutting WC (1933) Use of dinitrophenol in obesity and related conditions. JAMA 101:1472-1475.

Takeda J, Seino Y, Tanaka K, Fukumoto H, Kayano T, Takahashi H, Mitani T, Kurono M, Suzuki T, Tobe T, et al. (1987) Sequence of an intestinal cDNA encoding human gastric inhibitory polypeptide precursor. Proc Natl Acad Sci USA $\mathbf{8 4}$ $7005-7008$

Taminato T, Seino Y, Goto Y, Inoue Y, and Kadowaki S (1977) Synthetic gastric inhibitory polypeptide: stimulatory effect on insulin and glucagon secretion in the rat. Diabetes 26:480-484

Tan TM, Field BC, McCullough KA, Troke RC, Chambers ES, Salem V, Gonzalez Maffe J, Baynes KC, De Silva A, Viardot A, et al. (2013) Coadministration of glucagon-like peptide-1 during glucagon infusion in humans results in increased energy expenditure and amelioration of hyperglycemia. Diabetes 62:1131-1138.

Thaler JP, Guyenet SJ, Dorfman MD, Wisse BE, and Schwartz MW (2013) Hypothalamic inflammation: marker or mechanism of obesity pathogenesis? Diabetes 62:2629-2634

Thaler JP, Yi CX, Schur EA, Guyenet SJ, Hwang BH, Dietrich MO, Zhao X, Sarruf DA, Izgur V, Maravilla KR, et al. (2012) Obesity is associated with hypothalamic injury in rodents and humans. $J$ Clin Invest 122:153-162.

Thompson RG, Gottlieb A, Organ K, Koda J, Kisicki J, and Kolterman OG (1997a) Pramlintide: a human amylin analogue reduced postprandial plasma glucose, insulin, and C-peptide concentrations in patients with type 2 diabetes. Diabet Med 14:547-555.

Thompson RG, Peterson J, Gottlieb A, and Mullane J (1997b) Effects of pramlintide, an analog of human amylin, on plasma glucose profiles in patients with IDDM: results of a multicenter trial. Diabetes 46:632-636.

Thorkildsen C, Neve S, Larsen BD, Meier E, and Petersen JS (2003) Glucagon-like peptide 1 receptor agonist ZP10A increases insulin mRNA expression and prevents diabetic progression in db/db mice. J Pharmacol Exp Ther 307:490-496.

Tiano JP, Tate CR, Yang BS, DiMarchi R, and Mauvais-Jarvis F (2015) Effect of targeted estrogen delivery using glucagon-like peptide-1 on insulin secretion, insulin sensitivity and glucose homeostasis. Sci Rep 5:10211.

Timmers L, Henriques JP, de Kleijn DP, Devries JH, Kemperman H, Steendijk P, Verlaan CW, Kerver M, Piek JJ, Doevendans PA, et al. (2009) Exenatide reduces infarct size and improves cardiac function in a porcine model of ischemia and reperfusion injury. J Am Coll Cardiol 53:501-510.

Trevaskis JL, Coffey T, Cole R, Lei C, Wittmer C, Walsh B, Weyer C, Koda J, Baron $\mathrm{AD}$, Parkes DG, et al. (2008) Amylin-mediated restoration of leptin responsiveness in diet-induced obesity: magnitude and mechanisms. Endocrinology 149: $5679-5687$

Trevaskis JL, Lei C, Koda JE, Weyer C, Parkes DG, and Roth JD (2010) Interaction of leptin and amylin in the long-term maintenance of weight loss in diet-induced obese rats. Obesity (Silver Spring) 18:21-26.

Trevaskis JL, Mack CM, Sun C, Soares CJ, D’Souza LJ, Levy OE, Lewis DY, Jodka CM, Tatarkiewicz K, Gedulin B, et al. (2013) Improved glucose control and reduced body weight in rodents with dual mechanism of action peptide hybrids. PLoS One 8:e78154.

Trevaskis JL, Sun C, Athanacio J, D’Souza L, Samant M, Tatarkiewicz K, Griffin PS, Wittmer C, Wang Y, Teng CH, et al. (2015) Synergistic metabolic benefits of an exenatide analogue and cholecystokinin in diet-induced obese and leptin-deficient rodents. Diabetes Obes Metab 17:61-73.

Trevaskis JL, Wittmer C, Athanacio J, Griffin PS, Parkes DG, and Roth JD (2016) Amylin/leptin synergy is absent in extreme obesity and not restored by calorie restriction-induced weight loss in rats. Obes Sci Pract 2:385-391.

Tschöp MH, Finan B, Clemmensen C, Gelfanov V, Perez-Tilve D, Müller TD, and DiMarchi RD (2016) Unimolecular polypharmacy for treatment of diabetes and obesity. Cell Metab 24:51-62.

Turek VF, Trevaskis JL, Levin BE, Dunn-Meynell AA, Irani B, Gu G, Wittmer C, Griffin PS, Vu C, Parkes DG, et al. (2010) Mechanisms of amylin/leptin synergy in rodent models. Endocrinology 151:143-152.

Umeda LM, Silva EA, Carneiro G, Arasaki CH, Geloneze B, and Zanella MT (2011) Early improvement in glycemic control after bariatric surgery and its relationships with insulin, GLP-1, and glucagon secretion in type 2 diabetic patients. Obes Surg 21:896-901.

Unger RH (2002) Lipotoxic diseases. Annu Rev Med 53:319-336.

Unger RH, Aguilar-Parada E, Müller WA, and Eisentraut AM (1970) Studies of pancreatic alpha cell function in normal and diabetic subjects. $J$ Clin Invest 49: 837-848.

Unger RH and Cherrington $\mathrm{AD}$ (2012) Glucagonocentric restructuring of diabetes: a pathophysiologic and therapeutic makeover. J Clin Invest 122:4-12.

Valverde I, Morales M, Clemente F, López-Delgado MI, Delgado E, Perea A and Villanueva-Peñacarrillo ML (1994) Glucagon-like peptide 1: a potent glycogenic hormone. FEBS Lett 349:313-316.

van Dongen MG, Geerts BF, Morgan ES, Brandt TA, de Kam ML, Romijn JA, Cohen AF, Bhanot S, and Burggraaf J (2015) First proof of pharmacology in humans of a novel glucagon receptor antisense drug. J Clin Pharmacol 55:298-306.

Van Gaal L, Pi-Sunyer X, Després JP, McCarthy C, and Scheen A (2008) Efficacy and safety of rimonabant for improvement of multiple cardiometabolic risk factors in overweight/obese patients: pooled 1-year data from the rimonabant in obesity (RIO) program. Diabetes Care 31 (Suppl 2):S229-S240.

Van Gaal LF, Rissanen AM, Scheen AJ, Ziegler O, and Rössner S; RIO-Europe Study Group (2005) Effects of the cannabinoid-1 receptor blocker rimonabant on weight reduction and cardiovascular risk factors in overweight patients: 1-year experience from the RIO-Europe study [published correction appears in Lancet (2005) 366: 370]. Lancet 365:1389-1397.

Vasselli JR (2008) Fructose-induced leptin resistance: discovery of an unsuspected form of the phenomenon and its significance: focus on "fructose-induced leptin resistance exacerbates weight gain in response to subsequent high-fat feeding," by Shapiro et al. Am J Physiol Regul Integr Comp Physiol 295:R1365-R1369.

Vasselli JR (2012) The role of dietary components in leptin resistance. Adv Nutr $\mathbf{3}$ : $736-738$

Vasselli JR, Scarpace PJ, Harris RB, and Banks WA (2013) Dietary components in the development of leptin resistance. Adv Nutr 4:164-175.

Vilsbøll T, Krarup T, Madsbad S, and Holst JJ (2002) Defective amplification of the late phase insulin response to glucose by GIP in obese type II diabetic patients. Diabetologia 45:1111-1119.

Vilsbøll T, Zdravkovic M, Le-Thi T, Krarup T, Schmitz O, Courrèges JP, Verhoeven R, Bugánová I, and Madsbad S (2007) Liraglutide, a long-acting human glucagonlike peptide-1 analog, given as monotherapy significantly improves glycemic control and lowers body weight without risk of hypoglycemia in patients with type 2 diabetes. Diabetes Care 30:1608-1610.

Virtue S and Vidal-Puig A (2008) It's not how fat you are, it's what you do with it that counts. PLoS Biol 6:e237.

Vogel H, Wolf S, Rabasa C, Rodriguez-Pacheco F, Babaei CS, Stöber F, Goldschmidt J, DiMarchi RD, Finan B, Tschöp MH, et al. (2016) GLP-1 and estrogen conjugate acts in the supramammillary nucleus to reduce food-reward and body weight. Neuropharmacology 110:396-406.

von Olshausen K, Bischoff S, Kahaly G, Mohr-Kahaly S, Erbel R, Beyer J, and Meyer $\mathrm{J}$ (1989) Cardiac arrhythmias and heart rate in hyperthyroidism. Am J Cardiol 63: 930-933. 
Wang J, Obici S, Morgan K, Barzilai N, Feng Z, and Rossetti L (2001) Overfeeding rapidly induces leptin and insulin resistance. Diabetes 50:2786-2791.

Wang X, Cahill CM, Piñeyro MA, Zhou J, Doyle ME, and Egan JM (1999) Glucagonlike peptide-1 regulates the beta cell transcription factor, PDX-1, in insulinoma cells. Endocrinology 140:4904-4907.

Wang Y, Du J, Zou H, Liu Y, Zhang Y, Gonzalez J, Chao E, Lu L, Yang P, Parker H, et al. (2016) Multifunctional antibody agonists targeting glucagon-like peptide-1, glucagon, and glucose-dependent insulinotropic polypeptide receptors. Angew Chem Int Ed Engl 55:12475-12478.

Wasada T, McCorkle K, Harris V, Kawai K, Howard B, and Unger RH (1981) Effect of gastric inhibitory polypeptide on plasma levels of chylomicron triglycerides in dogs. $J$ Clin Invest 68:1106-1107.

Watanabe O, Atobe Y, Akagi M, and Nishi K (1982) Effects of glucagon on myoelectrical activity of the stomach of conscious and anesthetized dogs. Eur J Pharmacol 79:31-41.

Weiner J, Kranz M, Klöting N, Kunath A, Steinhoff K, Rijntjes E, Köhrle J, Zeisig V, Hankir M, Gebhardt C, et al. (2016) Thyroid hormone status defines brown adipose tissue activity and browning of white adipose tissues in mice. Sci Rep 6:38124.

Weintraub M, Hasday JD, Mushlin AI, and Lockwood DH (1984) A double-blind clinical trial in weight control: use of fenfluramine and phentermine alone and in combination. Arch Intern Med 144:1143-1148.

Weintraub M, Sundaresan PR, Madan M, Schuster B, Balder A, Lasagna L, and Cox C (1992a) Long-term weight control study. I (weeks 0 to 34 ). The enhancement of behavior modification, caloric restriction, and exercise by fenfluramine plus phentermine versus placebo. Clin Pharmacol Ther 51:586-594.

Weintraub M, Sundaresan PR, Schuster B, Averbuch M, Stein EC, and Byrne L (1992b) Long-term weight control study. V (weeks 190 to 210). Follow-up of participants after cessation of medication. Clin Pharmacol Ther 51:615-618.

Weintraub M, Sundaresan PR, Schuster B, Averbuch M, Stein EC, Cox C, and Byrne L (1992c) Long-term weight control study. IV (weeks 156 to 190). The second double-blind phase. Clin Pharmacol Ther 51:608-614.

Weintraub M, Sundaresan PR, Schuster B, Moscucci M, and Stein EC (1992d) Longterm weight control study. III (weeks 104 to 156). An open-label study of dose adjustment of fenfluramine and phentermine. Clin Pharmacol Ther 51:602-607.

Weinzimer SA, Sherr JL, Cengiz E, Kim G, Ruiz JL, Carria L, Voskanyan G, Roy A and Tamborlane WV (2012) Effect of pramlintide on prandial glycemic excursions during closed-loop control in adolescents and young adults with type 1 diabetes. Diabetes Care 35:1994-1999.

Weissman NJ, Tighe JF Jr, Gottdiener JS, and Gwynne JT Sustained-Release Dexfenfluramine Study Group (1998) An assessment of heart-valve abnormalities in obese patients taking dexfenfluramine, sustained-release dexfenfluramine, or placebo. N Engl J Med 339:725-732.

Weissman NJ, Tighe JF Jr, Gottdiener JS, and Gwynne JT (1999) Prevalence of valvular-regurgitation associated with dexfenfluramine three to five months after discontinuation of treatment. J Am Coll Cardiol 34:2088-2095.

Werling M, Fändriks L, Olbers T, Bueter M, Sjöström L, Lönroth H, Wallenius V, Stenlöf K, and le Roux CW (2015) Roux-en-Y gastric bypass surgery increases respiratory quotient and energy expenditure during food intake. PLoS One 10 e0129784.

Werling M, Olbers T, Fändriks L, Bueter M, Lönroth H, Stenlöf K, and le Roux CW (2013) Increased postprandial energy expenditure may explain superior long term weight loss after Roux-en-Y gastric bypass compared to vertical banded gastroplasty. PLoS One 8:e60280.

Westermark P, Wernstedt C, O’Brien TD, Hayden DW, and Johnson KH (1987) Islet amyloid in type 2 human diabetes mellitus and adult diabetic cats contains a novel putative polypeptide hormone. Am J Pathol 127:414-417.

Westerterp-Plantenga MS, Saris WH, Hukshorn CJ, and Campfield LA (2001) Effects of weekly administration of pegylated recombinant human OB protein on appetite profile and energy metabolism in obese men. Am J Clin Nutr 74:426-434.

Whaley RA, Hart TM, and Klitgaard HM (1959) Metabolic effects of L-thyroxine and L-triiodothyronine on the intact rat and selected excised tissues. Am J Physiol 196 1258-1261.

White HS, Brown SD, Woodhead JH, Skeen GA, and Wolf HH (2000) Topiramate modulates GABA-evoked currents in murine cortical neurons by a nonbenzodiazepine mechanism. Epilepsia 41 (Suppl 1):S17-S20.

Whitehouse FW and James TN (1966) Chronotropic action of glucagon on the sinus node. Proc Soc Exp Biol Med 122:823-826.
WHO (2016) Global Report on Diabetes, WHO, Geneva, Switzerland.

Willms B, Werner J, Holst JJ, Orskov C, Creutzfeldt W, and Nauck MA (1996) Gastric emptying, glucose responses, and insulin secretion after a liquid test meal: effects of exogenous glucagon-like peptide-1 (GLP-1)-(7-36) amide in type 2 (noninsulin-dependent) diabetic patients. J Clin Endocrinol Metab 81:327-332.

Wilsey J, Zolotukhin S, Prima V, and Scarpace PJ (2003) Central leptin gene therapy fails to overcome leptin resistance associated with diet-induced obesity. $\mathrm{Am} J$ Physiol Regul Integr Comp Physiol 285:R1011-R1020.

Wilson MC, Hitomi M, and Schuster CR (1971) Psychomotor stimulant self administration as a function of dosage per injection in the rhesus monkey. Psychopharmacology (Berl) 22:271-281.

Wilson R and Long C (1960) A clinical evaluation of tenuate-a new anti-appetite compound. J Ir Med Assoc 46:86-88.

Wilson-Pérez HE, Chambers AP, Ryan KK, Li B, Sandoval DA, Stoffers D, Drucker DJ, Pérez-Tilve D, and Seeley RJ (2013) Vertical sleeve gastrectomy is effective in two genetic mouse models of glucagon-like peptide 1 receptor deficiency. Diabetes 62:2380-2385

Wing RR, Lang W, Wadden TA, Safford M, Knowler WC, Bertoni AG, Hill JO, Brancati FL, Peters A, and Wagenknecht L; Look AHEAD Research Group (2011) Benefits of modest weight loss in improving cardiovascular risk factors in overweight and obese individuals with type 2 diabetes. Diabetes Care 34: 1481-1486.

Winslow DH, Bowden CH, DiDonato KP, and McCullough PA (2012) A randomized, double-blind, placebo-controlled study of an oral, extended-release formulation of phentermine/topiramate for the treatment of obstructive sleep apnea in obese adults. Sleep (Basel) 35:1529-1539.

Woeber KA (1992) Thyrotoxicosis and the heart. N Engl J Med 327:94-98.

Woods SC, Lutz TA, Geary N, and Langhans W (2006) Pancreatic signals controlling food intake; insulin, glucagon and amylin. Philos Trans $R$ Soc Lond B Biol Sci 361: $1219-1235$

Wooltorton E (2002) Obesity drug sibutramine (meridia): hypertension and cardiac arrhythmias. CMAJ 166:1307-1308.

Wynne K, Park AJ, Small CJ, Meeran K, Ghatei MA, Frost GS, and Bloom SR (2006) Oxyntomodulin increases energy expenditure in addition to decreasing energy intake in overweight and obese humans: a randomised controlled trial. Int $J$ Obes 30:1729-1736.

Wynne K, Park AJ, Small CJ, Patterson M, Ellis SM, Murphy KG, Wren AM, Frost GS, Meeran K, Ghatei MA, et al. (2005) Subcutaneous oxyntomodulin reduces body weight in overweight and obese subjects: a double-blind, randomized, controlled trial. Diabetes 54:2390-2395

Xiong Y, Guo J, Candelore MR, Liang R, Miller C, Dallas-Yang Q, Jiang G, McCann PE, Qureshi SA, Tong X, et al. (2012) Discovery of a novel glucagon receptor antagonist N-[(4-(1S)-1-[3-(3, 5-dichlorophenyl)-5-(6-methoxynaphthalen-2-yl)$1 \mathrm{H}$-pyrazol-1-yl]ethylphenyl)carbonyl]- $\beta$-alanine (MK-0893) for the treatment of type II diabetes. J Med Chem 55:6137-6148.

Xu Y, Jones JE, Kohno D, Williams KW, Lee CE, Choi MJ, Anderson JG, Heisler LK, Zigman JM, Lowell BB, et al. (2008) 5-HT2CRs expressed by pro-opiomelanocortin neurons regulate energy homeostasis. Neuron 60:582-589.

Yanovski SZ and Yanovski JA (2002) Obesity. N Engl J Med 346:591-602.

Yokel RA and Pickens R (1973) Self-administration of optical isomers of amphetamine and methylamphetamine by rats. J Pharmacol Exp Ther 187:27-33.

Young A (2005) Tissue expression and secretion of amylin. Adv Pharmacol 52:19-45.

Zelber-Sagi S, Kessler A, Brazowsky E, Webb M, Lurie Y, Santo M, Leshno M, Blendis L, Halpern Z, and Oren R (2006) A double-blind randomized placebocontrolled trial of orlistat for the treatment of nonalcoholic fatty liver disease. Clin Gastroenterol Hepatol 4:639-644.

Zhang J and Wang N (2014) Leptin in chronic kidney disease: a link between hematopoiesis, bone metabolism, and nutrition. Int Urol Nephrol 46:1169-1174.

Zhang Y, Proenca R, Maffei M, Barone M, Leopold L, and Friedman JM (1994) Positional cloning of the mouse obese gene and its human homologue. Nature 372 : 425-432.

Zhang Z, Foppen E, Su Y, Bisschop PH, Kalsbeek A, Fliers E, and Boelen A (2016) Metabolic effects of chronic T3 administration in the hypothalamic paraventricular and ventromedial nucleus in male rats. Endocrinology 157:4076-4085.

Zhao XH, Jiang JK, and Lu YQ (2015) Evaluation of efficacy of resin hemoperfusion in patients with acute 2,4-dinitrophenol poisoning by dynamic monitoring of plasma toxin concentration. J Zhejiang Univ Sci B 16:720-726. 